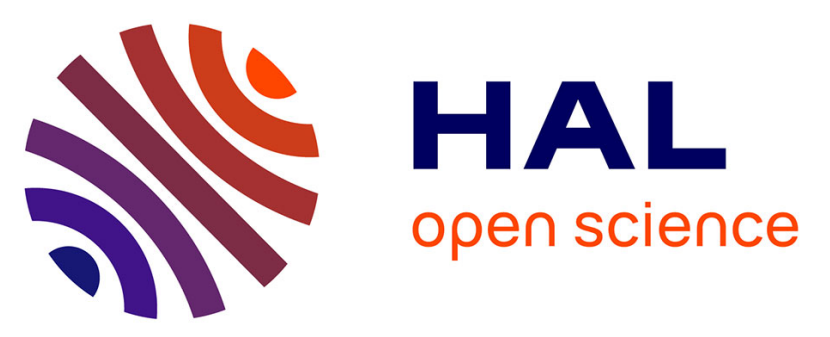

\title{
Latest Early-early Middle Eocene deposits of Algeria (Glib Zegdou, HGL50), yield the richest and most diverse fauna of amphibians and squamate reptiles from the Palaeogene of Africa
}

\author{
Jean-Claude Rage, Mohammed Adaci, Mustapha Bensalah, Mahammed \\ Mahboubi, Laurent Marivaux, Fateh Mebrouk, Rodolphe Tabuce
}

\section{To cite this version:}

Jean-Claude Rage, Mohammed Adaci, Mustapha Bensalah, Mahammed Mahboubi, Laurent Marivaux, et al.. Latest Early-early Middle Eocene deposits of Algeria (Glib Zegdou, HGL50), yield the richest and most diverse fauna of amphibians and squamate reptiles from the Palaeogene of Africa. Palaeovertebrata, 2021, 44 (1- e1), pp.1-32. 10.18563/pv.44.1.e1 . hal-03136008

\section{HAL Id: hal-03136008 \\ https://hal.umontpellier.fr/hal-03136008}

Submitted on 9 Feb 2021

HAL is a multi-disciplinary open access archive for the deposit and dissemination of scientific research documents, whether they are published or not. The documents may come from teaching and research institutions in France or abroad, or from public or private research centers.
L'archive ouverte pluridisciplinaire HAL, est destinée au dépôt et à la diffusion de documents scientifiques de niveau recherche, publiés ou non, émanant des établissements d'enseignement et de recherche français ou étrangers, des laboratoires publics ou privés. 


\title{
Latest Early-early Middle Eocene deposits of Algeria (Glib Zegdou, HGL50), yield the richest and most diverse fauna of amphibians and squamate reptiles from the Palaeogene of Africa
}

\author{
Jean-Claude RAGE ${ }^{a}$, Mohammed ADACI ${ }^{\mathrm{b}}$, Mustapha BenSAlah ${ }^{\mathrm{b}}$, Mahammed MAHBOUbic ${ }^{\mathrm{c}}$, \\ LAURENT MARIVAUX ${ }^{\mathrm{d}}$, FATEH MEBROUK $^{\mathrm{c}, e} \&$ Rodolphe TABUCE $^{\mathrm{d} *}$
}

${ }^{a}$ CR2P, Sorbonne Universités, UMR 7207, CNRS, Muséum National d'Histoire Naturelle, Université Paris 6, CP 38, 57 rue

Cuvier, 75231 Paris cedex 05, France

${ }^{b}$ Laboratoire de Recherche $n^{\circ} 25$, Université de Tlemcen, BP. 119, Tlemcen 13000, Algeria

'Laboratoire de Paléontologie, Stratigraphie et Paléoenvironnement, Université d'Oran 2, BP. 1524, El M'naouer, Oran 31000,

Algeria

'Institut des Sciences de l'Evolution de Montpellier (ISE-M), UMR 5554 CNRS/UM/IRD/EPHE, Université de Montpellier, Place Eugène Bataillon, 34095 Montpellier cedex 5, France

eDépartement des Sciences de la Terre et de l'Univers, Faculté des Sciences de la Nature et de la Vie, Université Mohamed Seddik Ben Yahia - Jijel, BP. 98 Cité Ouled Aïssa, 18000 Jijel, Algeria

* Corresponding author: rodolphe.tabuce@umontpellier.fr

\begin{abstract}
HGL50 is a latest Early-early Middle Eocene vertebrate-bearing locality located in Western Algeria. It has produced the richest and most diverse fauna of amphibians and squamate reptiles reported from the Palaeogene of Africa. Moreover, it is one of the rare faunas including amphibians and squamates known from the period of isolation of Africa. The assemblage comprises 17 to 20 taxa (one gymnophionan, one probable caudate, three to six anurans, seven 'lizards', and five snakes). Two new taxa were recovered: the anuran Rocekophryne ornata gen. et sp. nov. and the snake Afrotortrix draaensis gen. et sp. nov. The locality has also yielded the first confirmed anilioid snake, the first Palaeogene gymnophionan, and probably the first caudate from the Palaeogene (and possibly from the Tertiary) of Africa. The presence of a caudate at that time in Africa would be of particular interest; unfortunately, the available material does not permit a definitive identification. The fauna comprises Gondwanan and more specifically West Gondwanan vicariants, probably autochthonous groups and a Eurasian immigrant (assuming that the identification of the caudate is accurate). The fauna from HGL50 is clearly distinguished from the few other Eocene assemblages of Africa. However, if this results largely from differences in geological ages, geographic positions of the localities and mainly differences in environments took a part in the composition of the faunas.
\end{abstract}

Keywords: amphibians, squamates, Eocene, Africa, Algeria

Submitted 14 February 2018, Accepted 02 December 2020

Published Online 9 February 2021, doi: 10.18563/pv.44.1.e1

(C) Copyright Rodolphe Tabuce February 2021

\section{INTRODUCTION}

Africa underwent a long time of geographic isolation from the late Early Cretaceous to the Early Miocene, that is over 90 million years. This time of endemism likely acted strongly on the faunas present then in Africa (Gheerbrant \& Rage, 2006). More specifically, it was suggested that some amphibian and squamate clades might have originated or were subject to marked radiations in the continent at that time (Rage et al., 2013; McCartney \& Seiffert, 2016).

Unfortunately, the faunas that lived in Africa during this period of isolation remain largely unknown. Fossiliferous sites from this time interval are comparatively scarce. This dearth in knowledge particularly affects amphibians and squamate reptiles, more specifically those from the Palaeocene-Oligocene interval.

The recovery of a rich assemblage of amphibians and squamates from the latest Early-early Middle Eocene of HGL50, in Algeria, fills a gap between the known faunas of the
Late Palaeocene (in Morocco; Augé \& Rage, 2006) and of the ?late Middle Eocene (in Namibia; Rage et al., 2013).

Eocene localities that produced amphibians and squamates are so few in Africa that the list may be provided here (Fig. 1). Before the present study of HGL50, only two diverse faunas of Eocene age were reported from Africa: Silica North (?Bartonian, but see below) in Namibia, from which amphibians and squamates are known (Rage et al., 2013), and Birket Qarun locality 2 (BQ-2, Priabonian) in Egypt, which produced an unbalanced fauna lacking amphibians (Holmes et al., 2010a; McCartney \& Seiffert 2016). It should be noted, however, that another diverse fauna is known but still unpublished; it comes from Chambi, Tunisia, that is coeval with HGL50; a provisional list of the amphibians from Chambi was included in Gardner \& Rage (2016). Some Eocene localities yielded small faunas (at most four taxa): N'Tagourt 2, Morocco, Ypresian (Augé \& Rage, 2006); El Kohol, Algeria, Ypresian (Mahboubi et al., 1986; Mebrouk et al., 1997); Dur At Talah, Libya, ?Bartonian (Hoffstetter 1961, who reported the locality as Gebel Coquin);

\footnotetext{
${ }^{\dagger}$ Deceased after submission on March 30, 2018
} 
and Silica South, Namibia, ?Bartonian (but see below) (Rage et al., 2013). In addition, a few other fossiliferous sites produced one taxon each, either an amphibian or a squamate: Ouled Abdoun Basin (in fact, several loci), Morocco, Ypresian (Houssaye et al., 2013); Lândana, Sassa Zau and Ambrizete, Angola, Middle Eocene (Antunes 1964); Tamaguilelt, Mali, Lutetian (Rage 1983); Mahenge, Tanzania, Lutetian (Báez \& Harrison 2005); Black Crow, Namibia, Lutetian (Rage et al., 2013); and Bir el Ater, Algeria, Bartonian-Priabonian (Coiffait et al., 1984).

Amphibians and squamates are ectotherm tetrapods of generally small size. Because of their size, they may be relatively numerous in vertebrate-bearing localities and, as ectotherms, they provide informations additional to those afforded by mammals.

The present study, which deals with the fauna from HGL50, is the first report of an assemblage of amphibians and squamates from the late Early Eocene-early Middle Eocene in Africa.

\section{GEOLOGICAL SETTING}

In the western region of the Algerian Sahara, the Complex of the Gour Lazib area is comprised of an assemblage of outliers made of Caenozoic sediments. Among them, Glib Zegdou is an outlier that includes several fossiliferous levels (Mahboubi
1995; Adaci et al., 2007, 2016). Mahboubi (1995) defined there the Glib Zegdou Formation, which comprises three members: the Lower, Intermediate and Upper members, which are all Eocene in age (Lower-Middle Eocene, age given essentially by charophytes; Adaci et al., 2007; Mebrouk 2011). Vertebratebearing loci were recovered from the Lower and Intermediate Members, whereas the Upper member produced only remains of a terrestrial gastropod.

HGL50 is a fossiliferous site in the Intermediate Member. It yielded hundreds of vertebrate remains. Sediments of the Intermediate Member are of fluviatile origin. Their geological age is close to the Ypresian-Lutetian boundary, either latest Ypresian or early Lutetian (Mebrouk \& Feist 1999; Adaci et al., 2007, 2016; Mebrouk 2011; Coster et al., 2012). The fossiliferous level is a lenticular bed of carbonate cemented sandstone. The fossils were therefore obtained using acidpreparation, followed by screen-washing. Parts of the vertebrate fauna were studied and published: primates (Tabuce et al., 2009; Marivaux et al., 2011a), chiropterans (Ravel et al., 2015, 2016), rodents (Marivaux et al., 2011b), hyracoids (Tabuce et al., 2007), creodonts (Solé et al., 2014) and birds (Mourer et al., 2011). In addition, Gardner \& Rage (2016) published a brief preliminary list of the amphibians (note that HGL50 is named 'Glib Zegdou' in their article).

Amphibians and squamates from HGL50 are represented by slightly more than a thousand disarticulated bones and

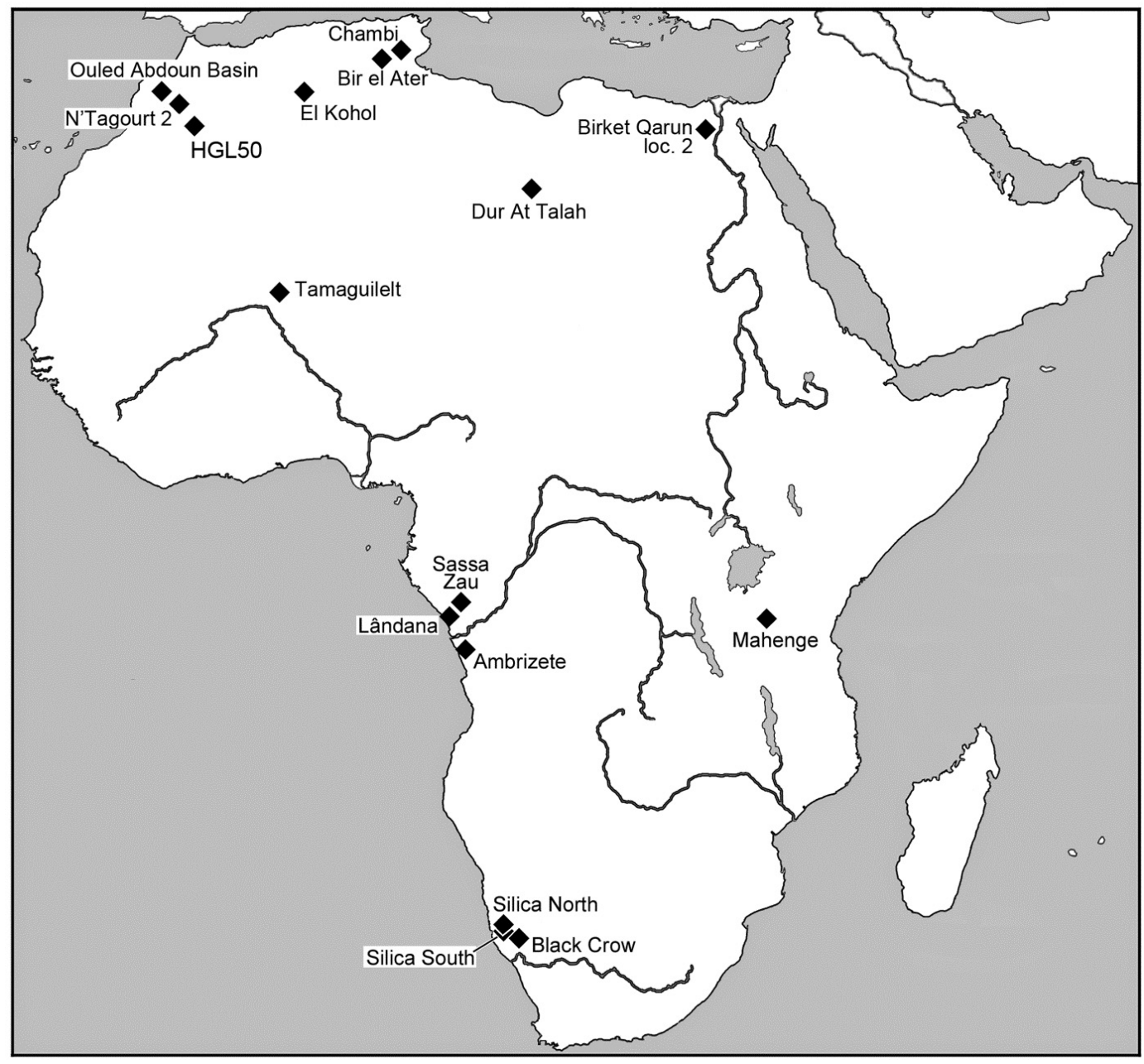

Figure 1. Map of Africa showing localities Eocene in age, which yielded amphibians and/or squamates (however, see Discussion regarding the ages of Silica North and Silica South). 
fragments. It must be noted that, because of acid processing, specimens are brittle; handling and observation of these small bones may be difficult. The material is curated in the palaeontological collections (ISE-M) of the Université de Montpellier (UM), France.

\section{SYSTEMATIC PALAEONTOLOGY}

\section{LISSAMPHIBIA Haeckel, 1866 \\ GYMNOPHIONA Rafinesque-Schmaltz, 1814 \\ APODA Oppel, 1811 \\ FAMILY INDETERMINATE GENUS AND SPECIES INDETERMINATE}

Figure 2A-E

Material. 33 vertebrae (UM/HGL50-481 to 485).

\section{Description}

All vertebrae are elongate, which suggests that they come from the mid- and posterior dorsal regions. The neural arch is moderately vaulted. Most vertebrae lack a neural spine; however, on a few specimens, a low and faint neural spine may be discerned in the mid part or mid plus posterior parts of the neural arch. A prominent ridge connects pre- and postzygapophyses. An oblong thickening of this ridge, just posterior to the prezygapophysis, forms the diapophysis. The interzygapophyseal constriction is shallow. The centrum is amphicoelous, with deep cotyles, and it is clearly narrower than the neural arch; a marked slope change separates the centrum from the lateral walls. Ventrally, the centrum bears a rather deep sagittal ridge. Two elongate basapophyseal processes (parapophyses; Estes \& Wake 1972) originate on the ventral face of the centrum, posterior to the cotylar rim. They diverge, extend below the coltylar rim and markedly project anteriorly, beyond the cotyle, on either side of the vertebra. A slight bulging on the lateroventral face of each basapophyseal process corresponds to the ventral (parapophyseal) articulation for the rib, but there is no delimited facet. All available vertebrae lack spinal foramina.

\section{Remarks}

The presence of elongate basapophyseal processes shows that this fossil belongs to the crown-group of the Gymnophiona, i.e. Apoda (Evans \& Sigogneau-Russell 2001). No attempt is made at a more precise assignment. The vertebral morphology of apodans remains poorly known and such a referral would require the examination of the vertebrae of all, or at least many, apodan taxa, which is beyond the scope of the present study.

Gymnophionans are primarily Gondwanan, although their most basal and earliest taxon (Eocaecilia micropodia Jenkins \& Walsh 1993) was recovered from the Early Jurassic of North America (Jenkins \& Walsh 1993). Fossils are exceedingly rare and, aside from the present report, only three gymnophionans were previously recorded in Africa (Gardner \& Rage 2016). These include a non-apodan gymnophionan and two indeterminate apodans. The non-apodan taxon is Rubricacaecilia monbaroni Evans \& Sigogneau-Russell, 2001; it comes from Anoual, Morocco, that is earliest Cretaceous (Berriasian) or Late Jurassic in age (Haddoumi et al., 2016). The two apodans were recovered from the Late Cretaceous of
Wadi Abu Hashim, Sudan (Evans et al., 1996), a locality that appears to be Cenomanian in age (Cavin et al., 2010) although a Campanian-Maastrichtian age was suggested recently (Eisawi 2015; Klein et al., 2016), and from the Early Miocene of Napak XV, Uganda (Rage \& Pickford 2011). The material from HGL50 provides the first record of gymnophionans from the Palaeogene of Africa.

\section{? CAUDATA Scopoli, 1777 \\ FAMILY INDETERMINATE GENUS AND SPECIES INDETERMINATE}

Figure $2 \mathrm{~F}-\mathrm{H}$

Material. One incomplete dorsal vertebra (UM/HGL50-486).

\section{Description}

The vertebra is damaged and brittle. It is tall, narrow and moderately elongate. The centrum is amphicoelous and cylindrical; the anterior and posterior cotyles are deep. The neural arch is fused to the centrum, high, narrow and it surrounds the broad neural canal. Only the posterior part of the roof of the neural arch is preserved; it bears a well-developed neural spine. Posteriorly, small postzygapophyses are present. Anteriorly, the areas that bore the prezygapophyses are broken away. On the left side, a transverse process is preserved. It is directed lateroventrally and appears to consist of a dorsal and a ventral processes that are closely appressed. Therefore, it is similar to rib-bearers of Caudata. Unfortunately, it is not possible to state whether articular facets are present on the extremities of the rib-bearrers. Two strong anterior basapophyses are present. The basapophyses originate from the lateroventral areas of the cotylar rim, which distinguishes them from the basapophyseal processes of gymnophionans. On each side, in the posterior half of the neural arch and approximately at the level of the postzygapophyses, a flange projects from the neural arch. It is well preserved on the right side, where it is directed posterolaterally. Aside from the basapophyses, the ventral face of the centrum lacks projecting structures. There is no detectable foramen on this vertebra.

\section{Remarks}

The fusion of the neural arch with the centrum and the presence of zygapophyses show that this vertebra belongs to a tetrapod. The referral to Caudata is somewhat a default identification because, based on the overall morphology, this vertebra cannot be referred to another group. However, some features more specifically suggest caudatan relationships. The anterior, short basapophyses seem typical. In addition, if the transverse process is really a rib-bearer, then the assignment to caudates is confirmed. The flanges that are on the neural arch appear to be unique and they afford no information about the relationships of this taxon.

If this specimen is actually a representative of Caudata, then it is one of the very rare extinct salamanders reported from a Gondwanan territory and more specifically from Africa. In Africa, aside from extant taxa found in the Pleistocene of the northernmost part of the continent (Bailon et al., 2011), Caudata were previously reported only from the CenomanianSantonian interval (Late Cretaceous) and, with doubts, from the Bathonian (Middle Jurassic) and the Middle Miocene (Gardner \& Rage 2016). The taxa from the Late Cretaceous are regarded 
either as members of a Gondwanan family (Noterpetontidae) that would have resulted from vicariance (Rage et al., 1993) or members of an extant Laurasian family (Sirenidae) that would have entered Gondwanan territories through dispersal (Evans et al., 1996). From the Bathonian, only a fragment of dentary recovered in Morocco is regarded as a possible caudate (Haddoumi et al., 2016). The latter is reminiscent of basal salamanders from the Middle Jurassic of Asia (Skutchas \& Krasnolutskii 2011; Skutchas 2016). As for the report from the Miocene, it corresponds only to the citation of the name 'salamander', without any comment or figure, in an article on the Middle Miocene of Maboko Island, Kenya (Andrews et al., 1981). This report is highly questionable (Gardner \& Rage 2016).

The search for the affinities of a taxon represented only by such an incomplete specimen is illusory. However, it may be stated that the vertebra from HGL50 markedly differs from those of the African Cretaceous in lacking the system of crests that characterizes them and in being amphicoelous instead of procoelous. It cannot be compared to the specimen from the Bathonian of Morocco, which is a cranial bone, but it clearly differs from all the vertebrae recovered from the Middle Jurassic of Laurasian continents (Evans et al., 1988; Evans \& Milner 1994; Averianov et al., 2008; Skutchas 2013). The specimen from Glib Zegdou differs from the latter in having a centrum that is markedly smaller with regard to the neural arch and neural canal, and in having non-divergent rib-bearers.

The probable salamander from HGL50 does not appear to be related to other known African Caudata. It likely entered Africa from a northern continent, where caudates were frequent. Interchanges indeed took place between Africa and Eurasia, via the Mediterranean Sill, during the Early Cainozoic (Gheerbrant \& Rage 2006); although this filter route was not favourable to amphibians, it was presumed that at least ranoid frogs crossed the Tethys owing to this stepping stone way (Laloy et al., 2013).
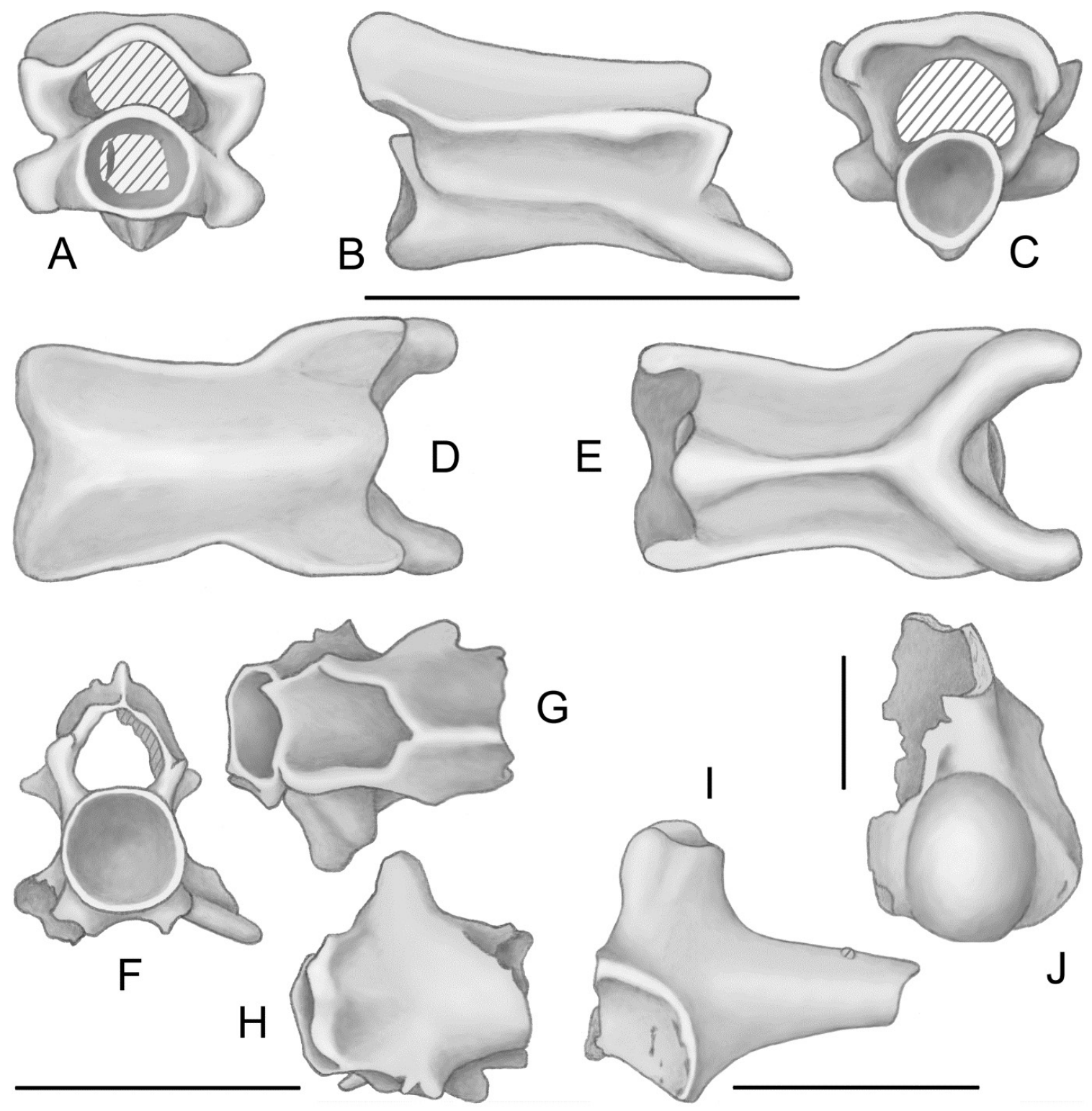

Figure 2. A-E, Gymnophiona indeterminate, dorsal vertebra (UM/HGL50-481) in anterior (A), right lateral (B), posterior (C), dorsal (D), and ventral (E) views. F-H, ? Caudata indeterminate, dorsal vertebra (UM/HGL50-486) in anterior (F), dorsal (G) and ventral (H) views. I, J, Anura: Pipidae indeterminate, right ilium (UM/ HGL50-487) in lateral view (I) and right humerus (UM/HGL50-488) in ventral view (J). Scale bars $=2 \mathrm{~mm}$. 
ANURA Fischer von Waldheim, 1813

Frogs are relatively numerous. The largest taxon is represented by hyperossified, ornamented skull bones, to which are associated size-compatible postcranial bones; this taxon is regarded as a ranoid. Smaller frogs comprise several taxa, including a Pipidae.

\section{PIPIDAE Gray, 1825}

\section{GENUS AND SPECIES INDETERMINATE}

Figure 2I, J

Material. One ilium (UM/HGL50-487) and one humerus (UM/ HGL50-488).

\section{Description and remarks}

Two incomplete bones, an ilium and a humerus, are assigned to the Pipidae. Only the posterior part of the ilium is preserved (Fig. 2I). It is characterized by the absence of a dorsal crest on the preserved part of the shaft and by the well-defined, large and tall tuber superius. Such a tuber superius points to Pipidae. However, the size and height of this tuber may be approached, or even matched, in some North American Bufonidae (Tihen 1962). The absence of a dorsal crest in the preserved portion of the shaft is not significant because, in most pipids, the crest does not extend posteriorly on the part of the shaft that is close to the acetabular region. On the other hand, all bufonids lack a dorsal crest. The preserved part of the pars descendens is very narrow, which is consistent with pipids but differs from bufonids.

The humerus is represented by a distal portion of the bone (Fig. 2J). The lateral epicondyle is large, although somewhat less developed than the medial epicondyle. The relatively large size of the lateral epicondyle gives an almost symmetrical appearance to the distal extremity of the bone, whereas in almost all anurans this extremity is markedly asymmetrical. However, almost symmetrical extremities are known in Pipidae, in the extant basal genus Leiopelma (Worthy 1987), and to a lesser degree in the extinct Palaeobatrachidae. More precisely, the relative sizes of the epicondyles of HGL50-488 correspond to those in various pipids and Leiopelma species. The caput humeri is somewhat compressed mediolaterally, a feature that occurs irregularly in pipids. The combined evidence provided by the ilium and humerus clearly suggests referral to the Pipidae.

Pipidae are West Gondwanan anurans, first known in the Cenomanian from which they were reported either as stempipids (Báez et al., 2007) or Pipidae (Rage \& Dutheil 2008). They are strictly aquatic anurans, still living in Africa and South America. Pipids are frequent in fossiliferous localities of Africa (Gardner \& Rage 2016) and their presence in the Eocene of the northern part of the continent is not surprising.

\section{NEOBATRACHIA Reig, 1958 RANOIDEA Rafinesque-Schmaltz, 1814}

Here, Ranoidea is regarded as equivalent to Ranoides Frost $e t$ $a l$. (2006). We retain the term Ranoidea in its broad acceptation, which has been more frequently used, for ease of comparison with the palaeontological literature (Gardner \& Rage 2016).
A large ranoid anuran is present and described as a new taxon. As all taxa from the locality, it is represented by isolated bones; the reasons for assigning these bones to a single species are given below (see 'Remarks').

\section{Genus ROCEKOPHRYNE nov.}

LSID. urn:1sid:zoobank.org:act:6FE37E49-8CB8-4A4D84BA-6B231EC619EE

Type and only known species. Rocekophryne ornata sp. nov.

Derivation of name. Named for Zbyněk Roček, in honour of

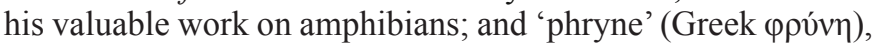
toad, a suffix often used in anuran genus names.

Diagnosis. As for the type species and only known species.

\section{Rocekophryne ornata sp. nov.}

Figures 3, 4

LSID. urn:lsid:zoobank.org:act:0C781F80-C139-4FDB-8856EDF2B9CBA8D2

Holotype. The posterior half of a frontoparietal (UM/HGL50489).

Referred material. Twenty-seven incomplete or fragmentary frontoparietals (UM/HGL50-490 to 493); 89 incomplete or fragmentary maxillae (UM/HGL50-494 to 503); three incomplete premaxillae (UM/HGL50-504, 505); seven fragmentary squamosals (UM/HGL50-506, 507); more than 260 fragments of ornamented cranial bones (UM/HGL50-508 to 512); five pre- $8^{\text {th }}$ presacral vertebrae (UM/HGL50-513, $514)$; five $8^{\text {th }}$ presacral vertebrae (UM/HGL50-515, 516); one sacral vertebra (UM/HGL50-517); three humeri (UM/HGL50518 to 520$)$; ten ilia (UM/HGL50-521 to 523).

Type locality. HGL50, Glib Zegdou outlier, Gour Lazib area, Western Algeria.

Horizon. Latest Early Eocene-earliest Middle Eocene.

Derivation of name. From Latin, ornatus, in reference to the ornamented pattern of the skull.

Diagnosis. A diplasiocoelous anuran distinguished from all other anurans by the following, unique combination of characters: presence of a strong exostotic ornamentation on skull dermal bones, of lateral and occipital flanges on the frontoparietal, of non-pedicellate and unicuspid teeth, and of a system locking teeth in the tooth slots; absence of incrassatio frontoparietalis and of occipital foramina on the frontoparietal.

\section{Description}

Where possible, the anatomical nomenclature follows Roček (1981, 1994). 
Holotype. The holotype is the posterior part (approximately the posterior half) of an azygous frontoparietal (Fig. 3A, B), which corresponds to the two frontoparietals fused into a single bone. There is no trace of a sagittal suture line. The bone is strong, hyperossified. It comprises a thick table and thinner lateral and posterior flanges. The table is markedly prominent dorsally. It is flat and covered by an exostotic ornamentation made of more or less circular and deep pits; the pits are clearly separated from each other by well-defined ridges. There is no parietal foramen on this preserved part. Laterally and posteriorly, the table is sharply limited. The parasagittal ridges, that limit the table laterally, are straight to scarcely concave laterally, and they slightly converge anteriorly. On the lateral margins, there is neither trace of a bony contact for the squamosal nor a tectum supraorbitale on which a frontoparietal-squamosal ligament would have been attached. Therefore, the orbit was not limited posteriorly by a parieto-squamosal arch (postorbital arch; Wild 1997). The posterior limit, i.e. the transverse ridge (Roček et al., 2015), of the table forms two concavities separated by a triangular projection that points posteriorly. An incomplete paraoccipital process is preserved on the right side. It is narrow and directed more posteriorly than laterally. The exostotic ornamentation affects its dorsal surface where it forms low and broad tubercles, but pits are lacking there. On either side of the table, a flange spreads laterally and slightly ventrally. Both flanges are largely broken away and their original extent is unknown. Their dorsal surface is smooth. Another smooth flange, the occipital flange, markedly extends posterior to the table; it spreads slightly ventrally. The occipital flange bears a sagittal ridge, the posterior median process, which is a prolongation of the posterior triangular projection of the table. The occipital flange was apparently continuous with the lateral ones. Such a large occipital flange rarely occurs in anurans; it is known only in some Palaeobatrachidae. The limit between the table and the occipital flange corresponds to a marked step that forms the vertical facies posterior (Roček 1981). In $R$. ornata, the facies posterior is formed only by the thickness of the exostotic table and it is not pierced by occipital foramina or canals. The ventral face of the holotype is entirely smooth. It lacks ridges, depressions and any trace of incrassation (incrassatio frontoparietalis sensu Roček 1980, 1994).

Other frontoparietal fragments. The holotype is the only preserved broad posterior part of a frontoparietal. A fragment (Fig. 3C, D) shows that in the anterior part of the frontoparietal,

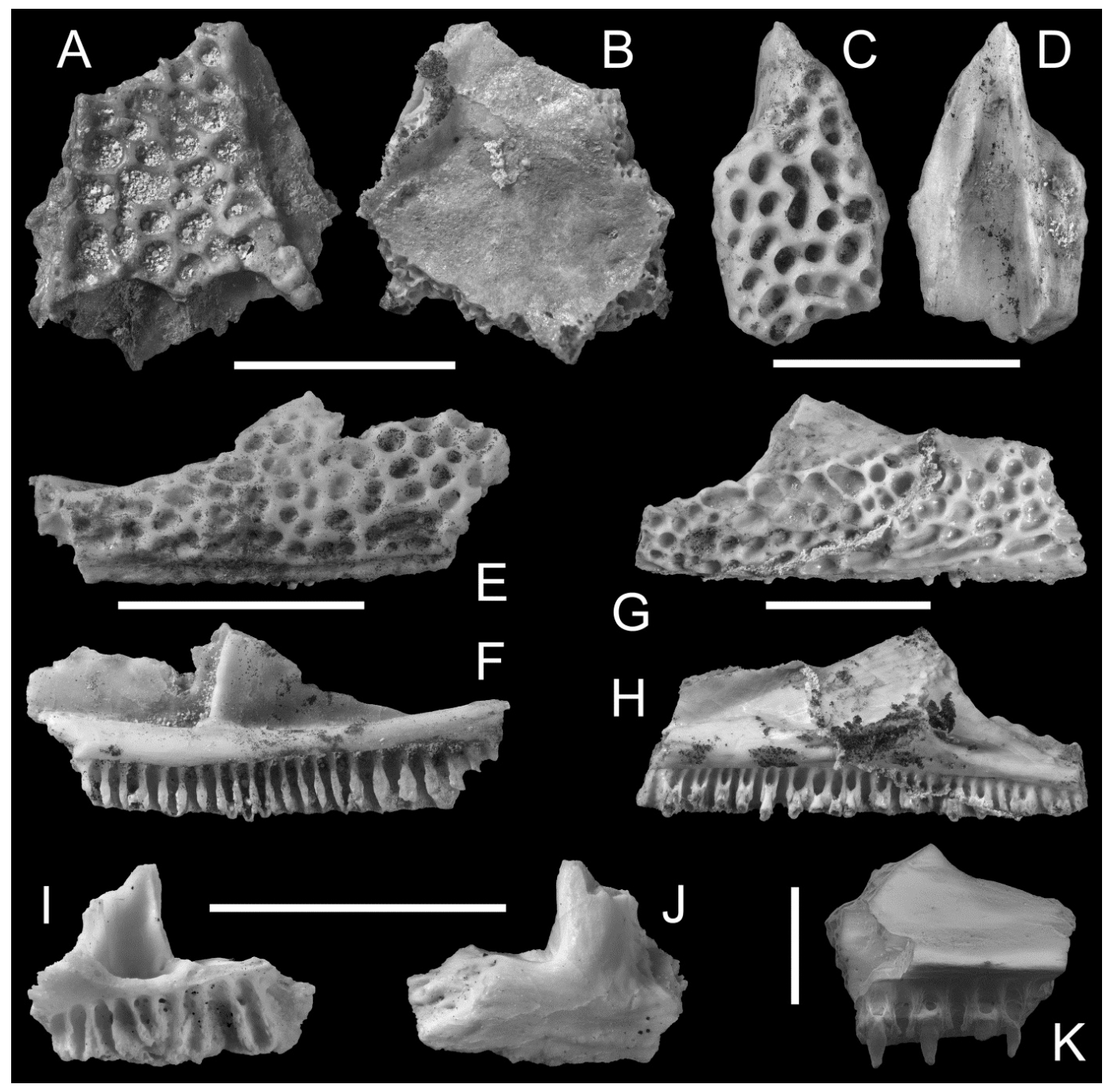

Figure 3. Rocekophryne ornata gen. et sp. nov., cranial bones. A, B, posterior portion of frontoparietal (UM/HGL50-489), Holotype, in dorsal (A) and ventral (B) views. C, D, left anterior part of frontoparietal (UM/HGL50-490) in dorsal (C) and ventral (D) views. E, F, anterior portion of right maxilla (UM/HGL50-495) in lateral (E) and medial (F) views. G, H, mid- and posterior portions of maxilla (UM/HGL50-494) in lateral (G) and medial (H) views. I, J, right premaxilla (UM/ HGL50-504) in medial (I) and lateral (J) views. K, close up of a fragment bearing teeth (UM/HGL50-503). A-J, scale bars $=5$ mm; K, scale bar = 1 mm. 
a vertical and shallow descending ridge (pars contacta) was present on either side of the bone; each pars contacta is likely the anterior, vertical prolongation of the lateral, subhorizontal flange that occurs in the posterior part of the bone. The pars contacta slightly converge anteriorly; they attached the frontoparietal to the underlying neurocranium. Incrassations are lacking, as in the posterior part of the frontoparietal. The table projects laterally beyond the pars contacta, except in the most anterior part where the lateral border of the frontoparietal is formed by the pars contacta itself. On the anterior portion of the frontoparietal, the pits are narrower than those of the posterior part of the bone. None of the fragments of posterior parts of frontoparietals shows a parietal foramen.

Maxilla. The most complete specimen (UM/HGL50-494) includes the mid- and posterior (but not posteriormost) portions of a right maxilla that preserves the processus zygomatico-maxillaris and the processus pterygoideus (Fig. $3 \mathrm{G}, \mathrm{H})$. The preserved part is tall anterior to the processus zygomatico-maxillaris, but it is markedly shallow posterior to the process. The external face, except the broad processus zygomatico-maxillaris, bears an ornamentation similar to that of the frontoparietal. The ornamentation appears clearly to be a secondary exostosis: on the posterior shallow part of the maxilla, it extends beyond the dorsal limit of the bone itself (Fig. $3 \mathrm{H})$. Ventrally, in the anterior area, several pits located against the crista dentalis merge and form elongate grooves. Such a change in the ornamentation, close to the crista dentalis, is frequent in anurans. It should be noted that, in UM/HGL50494, the ornamentation covers entirely the pars dentalis (sensu Evans et al., 2014) and reaches the crista dentalis. The shape of the margo orbitalis suggests that the orbit was large. Unfortunately, the margo is slightly damaged; therefore it is impossible to determine whether the lamella alaris of the squamosal extended anteriorly along the dorsal margin of the maxilla. However, at least one fragment suggests that there was no anterior extent of the squamosal. The processus zygomaticomaxillaris is tall.

On the medial face, at the level of the processus zygomaticomaxillaris, the processus pterygoideus rises from the lamina horizontalis (= palatine shelf; Agnolin 2012; pars palatina, Evans et al., 2014). The tip of the processus is broken off. From the base of the processus, a ridge extends vertically on the medial face of the processus zygomatico-maxillaris. This ridge and the processus pterygoideus form the anterior limit of the posterior depression (Roček 1994). The lamina horizontalis projects moderately medially; its medial margin is rounded. In the anterior part of UM/HGL50-494, anterior to the processus pterygoideus, the lamina horizontalis is markedly extended dorso-ventrally, but its height decreases both anteriorly and posteriorly. In the posterior part, the lamina is clearly shallow (about half the vertical extent of the tallest portion). Along the taller part of the lamina horizontalis, a groove runs in its dorsal border; it accommodated the cartilaginous suborbital bar of the palatoquadrate. The pars dentalis is moderately tall. In $\mathrm{UM} / \mathrm{HGL} 50-494$, all teeth were vertical; however, as shown by UM/HGL50-496, teeth were inclined posteriorly in the posteriormost part of the maxilla.

A fragment (UM/HGL50-495) represents the anterior portion of a maxilla. In this region of the maxilla, the lamina horizontalis becomes shallow, thin and it broadens horizontally, and is slightly upturned. In specimens smaller than UM/ HGL50-494, an unornamented strip covers the ventral part of the pars dentalis. The presence of a smooth strip along the ventral part of the maxilla occurs frequently in frogs that have ornamented skull bones (e.g. Roček 1994; Evans et al., 2014; Gardner \& Brinkman 2015). It is worth noting that in one fragment (UM/HGL50-497), the damaged ventral margin displays a space between the ornamented layer and the bone itself. This confirms that the ornamentation is a secondary exostosis.

Premaxilla. Two incomplete premaxillae, whose size is consistent only with that of the above described frontoparietals and maxillae, are referred to $R$. ornata. A third, smaller specimen is also assigned to the taxon. None of the three specimens is complete. The extremities of the pars facialis (alary process) and of the medial and posterolateral branches of the pars dentalis are broken away. The external face of the bone is smooth. The absence of ornamentation on the premaxillae of frogs whose skull is ornamented is frequent; this is perhaps even the general condition. The pars facialis appears as a vertical, wide gutter, whose concave side faces medially. Ventrally, the concavity reaches the level of the lamina horizontalis. In UM/ HGL50-504, the posterolateral branch of the pars dentalis is comparatively well preserved, although lacking its tip. The distal portion of this branch bears a marked depression pierced by two foramina (Fig. 3J). This shows that the premaxilla was overlapped by the pars dentalis of the maxilla. On the medial face, the pars dentalis is relatively tall. Teeth are not preserved. The lamina horizontalis is thin and it is broken off on all specimens. However, on one of the specimens, a part of the lamina clearly projects posterodorsally; this area perhaps formed the base of a thin dorsal maxillary process (sensu Evans et al., 2014, fig. 12).

Dentition. Teeth are clearly pleurodont and are inserted in deep, tall and well-limited slots. However, almost all slots are empty. Teeth are non-pedicellate and they appear to be unicuspid, more or less fang-like (Fig. 3K). The interdental septa lack the terminal (i.e. ventral) knobs that strengthen the implantation of teeth in Palaeobatrachidae (Venczel 2004; Roček 2005), but they show a similar device that locks the tooth bases in the slots. The medial border of each interdental septum is thickened and it produces an anterior and a posterior small lappets that partly obstruct the medial openings of the adjacent slots (Fig. 3F, K). In some cases, two lappets produced by two successive septa join and form a bony bridge across the lingual opening of the slot. Although this system locks the tooth bases, teeth are often lacking in fossilized bones and lappets are indeed more easily seen where teeth are lacking in the slots.

Squamosal. The squamosal is represented by some fragments that display the same ornamentation as the frontoparietal and maxilla. Their inner face bears the base of a process that is likely the processus posterolateralis. Therefore, the fragments would be parts of the lamella alaris (otic plate; sensu Evans et al., 2014). They are too damaged to afford taxonomic information.

Vertebrae. Available vertebrae are all incomplete but they represent all portions of the vertebral column, except the atlas. The most characteristic specimen is a sacral vertebra (Fig. 4A, B). The centrum forms an anterior broad and depressed condyle and it bears two posterior, smaller condyles for articulation with the urostyle. The two posterior condyles are clearly separated from each other. Only the right sacral apophysis is preserved, but it lacks its distal part. It is not expanded and its section is 
approximately circular. The combination of these characters is typical of ranoid frogs.

Five vertebrae, whose centra are amphicoelous, are assigned to this taxon. They represent the last presacral, i.e. the $8^{\text {th }}$ vertebra. Unfortunately, a large part of the neural arch is broken away in all of them (Fig. 4C, D). The anterior and posterior cotyles are depressed and the outline of the posterior cotyle fits that of the anterior condyle of the sacral vertebra. The transverse processes are directed laterally. The prezygapophyseal facet is broad. In three of these vertebrae, the bottoms of the cotyles are pierced by an irregular hole but there is no canal joining the anterior and posterior holes. These openings likely do not represent a notochordal canal.

Presacral vertebrae anterior to the $8^{\text {th }}$ one are all procoelous. As in the sacral and $8^{\text {th }}$ vertebrae, the cotyle-condyle system is depressed. One of these vertebrae (UM/HGL50-512) is almost complete, lacking only one transverse process and part of the condyle (Fig. 4E, F). The transverse process is comparatively short and directed transversely, which suggests that the specimen occupied the $6^{\text {th }}$ or $7^{\text {th }}$ position. Despite this posterior position in the column, the neural arch is short, of the nonimbricate type. The prezygapophyseal facet is narrower than that in the $8^{\text {th }}$ vertebrae and its axis is directed almost anteriorly. Such differences in the shape and orientation of the facet range within the usual intracolumnar variation. The neural spine comprises an anterior low ridge and a posterior tubercular part that is damaged.

Ilia. All ilia are very incomplete; they are represented by only a part of the acetabular area and the posteriormost portion of the shaft. However, observable characters are consistent with assignment to ranoids. The shaft bears a relatively high dorsal crest and the posterior border of the crest is thickened, thus forming the tuber superius (Fig. 4I). The latter tuber does not clearly project above the dorsal limit of the crest. Although the acetabular part is poorly preserved, it may be inferred that neither an interiliac tubercle nor an interiliac groove were present. This referral is consistent with the composition of the fauna and with the relative abundance of taxa recognized in the locality. In addition, the size of these ilia is consistent with that of other bones belonging to R. ornata.

Humerus. Humeri are represented by distal portions, or even often only by the distalmost parts comprised of the caput humeri and epicondyles. The caput humeri is well spherical and not shifted laterally. In the most complete specimens, it is clearly in line with the axis of the diaphysis. A fossa cubitalis is present; it is limited on both sides. The epicondyles are strongly asymmetrical. The medial epicondyle is comparatively strong but it does not project beyond the distal limit of the caput humeri. The lateral epicondyle is markedly reduced and applied against the caput humeri, where it may even appear as a shallow depression (Fig. 4G, H).

\section{Remarks}

The available skull bones secure distinction of Rocekophryne ornata as a new taxon. They show a combination of characters that is unique: despite the presence of a thick exostotic component, the frontoparietal lacks occipital foramina (either as openings of grooves or canals); the frontoparietal bears lateral and occipital flanges; the frontoparietal also lacks any trace of incrassatio frontoparietalis; teeth are non-pedicellate

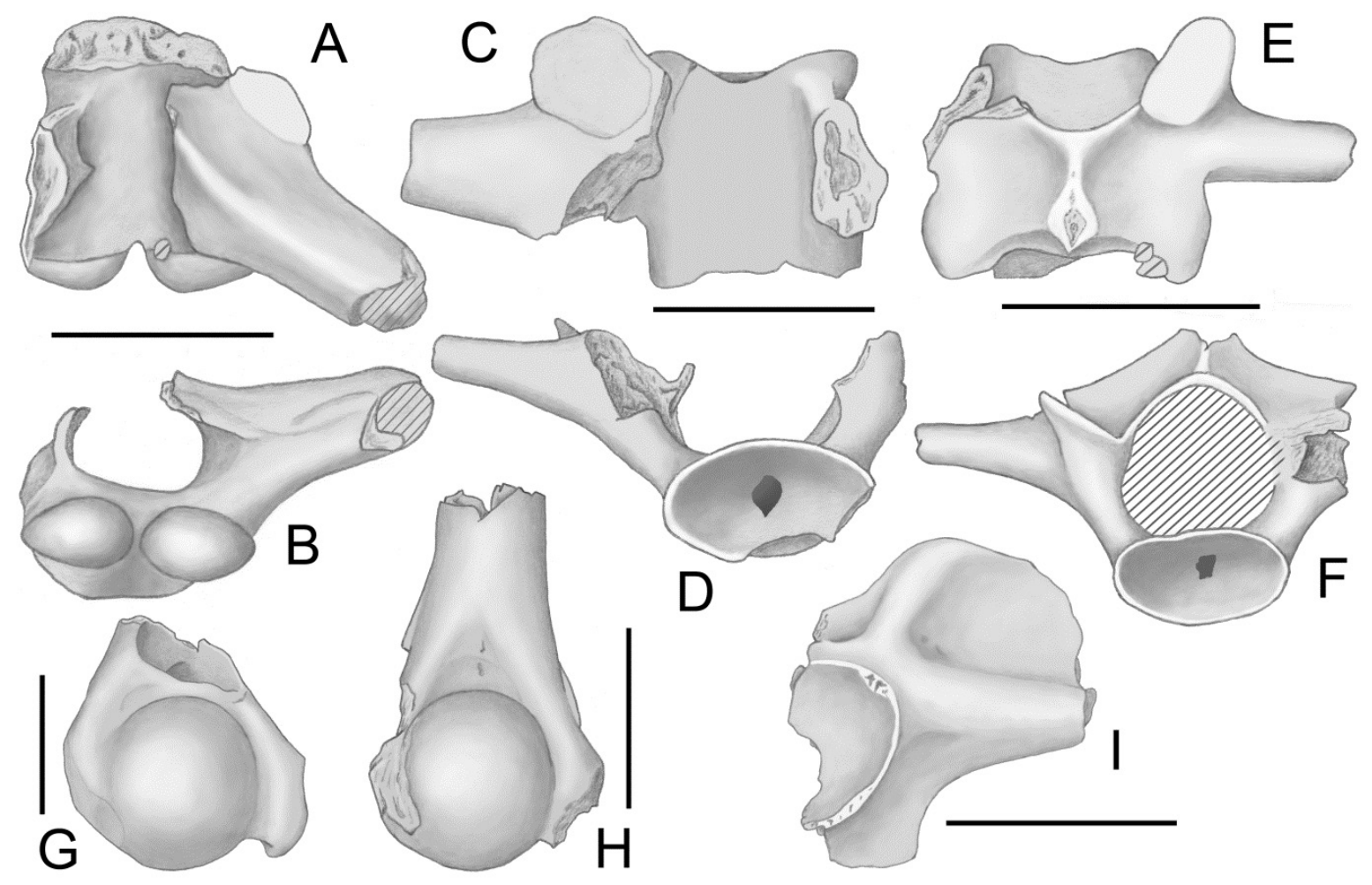

Figure 4. Rocekophryne ornata gen. et sp. nov., postcranial bones. A, B, sacral vertebra (UM/HGL50-517) in dorsal (A) and posterior (B) views. C, D, $8^{\text {th }}$ presacral vertebra (UM/HGL50-515) in dorsal (C) and posterior (D) views. E, F, presacral vertebra (UM/HGL50-513) in dorsal (E) and anterior (F) views. G, distal portion of humerus (UM/HGL50-519) in ventral view. H, incomplete humerus (UM/HGL50-518) in ventral view. I, posterior portion of right ilium (UM/HGL50-521) in lateral view. Scale bars $=3 \mathrm{~mm}$. 
and unicuspid; the bases of teeth are locked in the tooth slots by lappets of the interdental septa.

Whereas it is easy to demonstrate that this anuran from HGL50 is a new taxon, the search for its relationships is complicated because the referred bones are isolated and they display a mosaic of characters. The core problem is the association of isolated bones, more specifically the association of postcranial elements with cranial bones. Postcranial bones are associated with each other on the basis of their ranoid morphology and size consistency. On the other hand, the association of cranial bones with each other is secured by their common, characteristic ornamentation (except on the premaxilla) and similarity in size. However, contrary to postcranial bones, skull bones do not show typical ranoid features. Cranial and postcranial bones are associated on the basis of size consistency; they also represent the largest and most abundant anuran in the locality.

The ratio between the number of cranial bones and the number of postcranial elements is high (cranial bones being by far more numerous), which may appear surprising. However, in anurans, mainly in well-ossified taxa, preserved cranial bones are often clearly more numerous than those from the postcranial skeleton. For example, this is the case for the hyperossified Beelzebufo (Maastrichtian of Madagascar); cranial bones of this anuran are five times more numerous than postcranial ones (Evans et al., 2014). Another example is the strongly ossified Pelobates fahlbuschi (Miocene of Germany); in its type locality, it is represented by 1059 disartculated bones, of which only 32 are postcranial elements (Böhme 2010). Therefore, the ratio between cranial elements and poscranial ones in Rocekophryne is consistent with the ratio known for other well-ossified anurans. It should be added that more than half of the cranial bones assigned to Rocekophryne are only fragments (identifiable thanks to ornamentation), whereas fragments of postcranial bones cannot be identified; thus the number of cranial bones is tilted to the side of over-representation.

Only postcranial bones provide clear information on the relationships of Rocekophryne ornata. Among neobatrachians, disarticulated cranial bones provide few useful characters and those assigned to Rocekophryne show only ten cranial characters that are included in the available matrices (Fabrezi 2006; Evans et al., 2008; Báez et al., 2009; Agnolin 2012; Laloy et al., 2013; Evans et al., 2014). Among these ten characters, three are linked to hyperossification and, therefore, can be convergent among non-related groups (Báez \& Gómez 2014; Evans et al., 2014), four correspond to artificial states within continuous variation and cannot be coded confidently, and one is doubtful in Rocekophryne. Therefore, only two characters encountered in both Rocekophryne and available matrices might be used (the fusion between the frontoparietals and the absence of a parieto-squamosal arch), but among anurans they show variations that depend largely on the degree of ossification.

As is frequent in anurans, significant characters are more numerous in the postcranial skeleton than in the skull. Eight of the observable postcranial characters are in the matrices, of which five may be theoretically coded easily, whereas three represent continuous variations that cannot be coded confidently (Simões et al., 2017). However, among the five characters that may be easily coded, at least two are liable to convergence and intraspecific variation. Consequently, only three postcranial characters noted in Rocekophryne and that are in the matrices are really significant, which cannot permit an analysis. In addition, matrices still lack characters that would be likely significant (e.g. pedicellate/non-pedicellate teeth, presence/absence of lateral and occipital flanges on the frontoparietal, depth of the lamina horizontalis on maxilla...), but complementing matrices is, by far, beyond the scope of this study.

As far as the search for relationships is concerned, the most significant feature is the composition of the vertebral column: sacral vertebra biconvex (i.e., with an anterior condyle), last presacral amphicoelous, and other presacrals procoelous. Such a vertebral column is diplasiocoelous, a condition known only in ranoids, although all of them are not diplasiocoelous (Frost et al., 2006). On this basis, Rocekophryne ornata is assigned to the ranoids. Such a referral is supported by the morphology of ilia, humeri, and more specifically by the overall morphology of the sacral vertebra.

As stated above, ranoid characters cannot be detected on isolated skull bones, and so it is on those of $R$. ornata. However, surprisingly, skull bones assigned to Rocekophryne display features reminiscent of Alytidae (= Discoglossidae), Calyptocephalellidae and mainly Palaeobatrachidae.

Characters of palaeobatrachids occurring in Rocekophryne are the presence of lateral and occipital flanges, and characters of the dentition. Lateral flanges occur in palaeobatrachids whose frontoparietal has a delimited table (Roček et al., 2015). Such palaeobatrachids have also an occipital flange that may strongly resemble that of Rocekophryne. More specifically, the marked posterior extent of the occipital flange of Rocekophryne is similar to that of various palaeobatrachids: Albionbatrachus oligocenicus Venczel, Codrea \& Fărcaş, 2013, from the Early Oligocene of Romania, Palaeobatrachus sp. from the late Oligocene of Germany (Roček et al., 2015) and P. robustus Hossini \& Rage, 2000, from the Early Miocene of France. Teeth appear to be similar in Rocekophryne and palaeobatrachids in being non-pedicellate and unicuspid (Z. Roček and M. Venczel, pers. comm., 2016; pers. obs.). However, palaeobatrachid teeth remain poorly known and their characteristics should be checked. An interesting feature common to Rocekophryne and palaeobatrachids is the system that locks the tooth bases in the slots. Aside from these similarities, skull bones of Rocekophryne differ from those of palaeobatrachids in lacking incrassatio frontoparietalis on the inner side of the frontoparietal and in having a markedly broader frontoparietal table.

Cranial characters common to Rocekophryne and Calyptocephalellidae are the presence of a strong exostotic ornamentation, of a well-developed lamina horizontalis, of a high laminar processus zygomatico-maxillaris, and of fanglike (although pedicellate and bicuspid in calyptocephalellids) teeth. However, the first two characters are dependent on hyperossification (and are therefore liable to convergence) and calyptocephalellids clearly differ from $R$. ornata in having pedicellate and bicuspid teeth, and in lacking lateral and occipital flanges on the frontoparietal (Muzzopappa \& Báez 2009; Agnolin 2012).

One of the peculiar features of $R$. ornata, i.e. the presence of lateral and occipital flanges on the frontoparietal, occurs also in Latonia gigantea (Lartet, 1851), a hyperossified alytid from the Miocene of Western Europe. However, this morphological trait is present only in juvenile individuals of L. gigantea (Roček 1994; Rage \& Hossini 2000). In adults, the frontoparietal does not show any traces of the flanges and its table is extended.

In summary, despite cranial characters common to $R$. ornata on the one hand and to Palaeobatrachidae, Calyptocephalellidae, and at least one Alytidae on the other hand, it does not appear possible to refer the species to one of these three families. 
However, we must acknowledge that cranial characters suggesting affinities with Palaeobatrachidae are somewhat disconcerting. If the search for relationships were based only on skull bones, then Rocekophryne would have been likely regarded as close to the Palaeobatrachidae. This family is unknown from Africa. Records of confirmed palaeobatrachids are all from Europe, where they range from the Cretaceous to the Pleistocene (Wuttke et al., 2012; Villa et al., 2016). In addition, some possible palaeobatrachids are present in the Late Cretaceous, and perhaps the Early Palaeocene, of North America (Gardner 2008). Although no palaeobatrachid was reported from Africa, coracoids showing a typical feature of that family were recovered in Africa from rich localities dating from the Late Cretaceous, the Middle Eocene (if Silica North is really Middle Eocene in age; see below) and the Early Miocene. However, there is no other bones reminiscent of palaeobatrachids in these three localities, and the coracoids were interpreted as belonging to pipids, a Gondwanan taxon closely related to the Palaeobatrachidae (Rage et al., 2013). If $R$. ornata were a palaeobatrachid, it would be then astonishing that the cranial bones of this species, which are the largest and most frequent anuran ones, have no matching postcranial elements in the locality. Conversely, it would be no less surprising that the postcranial bones have no corresponding cranial bones. Such an association (ranoid postcranial bones associated with hyperossified cranial bones) is supported by the ranoid Thaumastosaurus gezei Rage \& Roček, 2007, from the Eocene of Europe, for which the association of bones cannot be questioned since the skeleton is articulated in a "mummified' specimen (Laloy et al., 2013). Some characters of the skull of T. gezei recall those of Rocekophryne: presence of an exostotic ornamentation consisting of pits and ridges, frontoparietal table broad and well-delimited (Rage \& Roček 2007), and perhaps presence of the system locking tooth bases. This character cannot be observed in Thaumastosaurus bottii de Stefano, 1903, and T. gezei, two well-known species from the Eocene of France (Roček \& Lamaud 1995; Rage \& Roček 2007), but paradoxically it may be seen in the poorly known T. wardi Holman \& Harrison, 2002, and T. sulcatus Holman \& Harrison, 2003, from the Eocene of England. In the latter two species, the interdental septa appear to form a locking system similar to that of Rocekophryne and Palaeobatrachidae. Despite these similarities, Thaumastosaurus clearly differs from Rocekophryne in lacking frontoparietal flanges, and in having incrassatio frontoparietalis and a less tall processus zygomatico-maxillaris.

In conclusion, assignment of Rocekophryne to ranoids cannot be definitively confirmed. However, assuming that the association of skull bones and vertebrae is not erroneous, this anuran had a diplasiocoelous vertebral column. This structure occurs only in ranoids.

\section{RANOIDEA INDETERMINATE}

Material. Six pre-8th vertebrae (UM/HGL50-524); eight 8th vertebrae (UM/HGL50-525); seven sacral vertebrae (UM/ HGL50-526); 21 humeri (UM/HGL50-527, 528); 14 ilia (UM/ HGL50-529).

\section{Descriptions and remarks}

Several skeletal elements (vertebrae, humeri, ilia) show a morphology typical of ranoids, but they are smaller than those assigned to Rocekophryne ornata. Aside from the smaller size, they do not show noticeable morphological differences but they are generally poorly preserved. They may belong either to juvenile representatives of $R$. ornata or to a distinct taxon. Only humeri clearly suggest the presence of a second ranoid.

In most humeri, the caput humeri is well preserved, not worn, which suggests that they belong to adults, at least to postmetamorphic individuals. Therefore, the size difference may be significant and a small ranoid, taxonomically distinct from $R$. ornata, is likely present in the locality. It is, nevertheless, possible that bones of juvenile $R$. ornata are also amongst these skeletal elements referred to small ranoids.

No skull bone may be confidently assigned the small ranoid. Numerous fragments of non-hyperossified, non-ornamented skull bones are present in the locality, but they do not show feature(s) that would permit unquestionable assignment to ranoids. In view of the number of such skull bone fragments and of the composition of the anuran fauna, at least a part of the fragments certainly belong to a small ranoid, but it is not possible to state which ones. Consequently, all fragments are referred to as Anura indeterminate (see below).

\section{ANURA INDETERMINATE}

Figure 5A-F

Material. Twenty-three fragments (UM/HGL50-530) and more than 200 tiny fragments (UM/HGL50-531) of nonornamented maxillae; one incomplete atlas (UM/HGL50-532); one procoelous complex atlas $+\mathrm{V} 2$ represented by fused centra (UM/HGL50-533); one almost complete presacral vertebra (UM/HGL50-534); 27 incomplete or fragmentary presacral vertebrae (UM/HGL50-535); one almost complete humerus (UM/HGL50-536); 56 distal extremities of humeri (UM/ HGL50-537); 69 radioulna (UM/HGL50-538); one relatively complete ilium (UM/HGL50-539); 10 incomplete ilia (UM/ HGL50-540, 541); 25 tibiofibulae (UM/HGL50-542).

\section{Descriptions and remarks}

Numerous bones belonging to anurans cannot be referred precisely within the group. Most of them cannot be identified because they are too poorly preserved, which is the case for fragmentary skull bones, an incomplete atlas, an incomplete atlantal complex, ilia and most presacral vertebrae and humeri. As for radioulnae and tibiofibulae, they generally do not permit identification because they lack significant features. However, among these bones three specimens (one vertebra, one humerus and three ilia) demonstrate the presence of taxa distinct from the Pipidae and Ranoidea reported above.

Vertebra $U M / H G L 50-534$. This tiny specimen is a relatively complete presacral vertebra (Fig. 5A-C). It is procoelous and depressed. It belongs to a non-adult individual as shown by the ventral part of the centrum that is not completely ossified; more specifically, the ventral part of the cotyle is not completed. The morphology of the zygapophyses, which are narrow and projecting, may also reflect the non-fully grown stage. However, the neural arch is long, of the imbricate type, a state that cannot result from the non-adult condition. Conversely, in earlier stages the neural arch is shorter than in adults. Therefore, this vertebra is both procoelous and of the imbricate type. In other words, it cannot be assigned to the Pipidae or to the Ranoidea. The broad and long neural arch is reminiscent of various Microhylidae (de Sá \& Trueb 1991; Lehr \& Trueb 
2007) and the overall morphology of the vertebra is consistent with that of this family. Unfortunately, on the basis of this single specimen, this identication cannot be confirmed. The fossil record of microhylids is very limited. Rare microhylids were reported from the Miocene (or latest Oligocene?) of Australia and from the Pleistocene of North America, Japan and perhaps Madagascar (Sanchiz 1998; Gardner \& Rage 2016). Today, Microhylidae are present in Africa, south of the Sahara; they also occur in southern North America, South America and in south and southeastern Asia up to northernmost Australia.

Humerus UM/HGL50-536. The specimen is small, but almost complete (Fig. 5D, E). The proximal extremity is broken away but, despite this, the diaphysis is clearly elongate; in addition, it is straight and slender. The diameter of the narrowest portion of the diaphysis is smaller than the diameter of the caput humeri. A prominent ventral crest is present on the proximal part of the diaphysis. The caput humeri is in line with the diaphysis and it is relatively small. The fossa cubitalis is triangular and elongate. The two epicondyles are small and the medial one is larger than the lateral epicondyle, thereby giving a narrow and asymmetrical shape to the distal extremity. The epicondyles do not approach the distal limit of the caput humeri. The combination of an asymmetrical distal extremity, small epicondyles and slenderness suggests neobatrachian affinities. However, a precise assignment is not possible. Various neobatrachians can be discarded because their humerus is curved, and/or not slender, or has a laterally shifted caput humeri. However, HGL50-536 is consistent with the condition found in several neobatrachian taxa. It might be even referred to ranoids, but to a taxon distinct from those described above, because it is more gracile and displays a clearly reduced medial epicondyle.
Ilia UM/HGL50-539, 540. Three ilia belonging to the same taxon cannot be referred to the Pipidae or Ranoidea (Fig. 5F). They lack a dorsal crest and they bear a triangular, relatively small tuber superius located above the anterior half of the acetabulum. In addition, the pars ascendens is narrow and very short. The combination of these three characters points to Bufonidae and Brevicipitidae. However, the basis of the broken off pars descendens extends markedly anterior to the acetabulum. Such an extent is mainly known in Hylidae, and it may also occur in some Bufonidae (e.g. the South American Nannophryne), but it permits Brevicipitidae to be discounted (Van Dijk 2001). On the other hand, none of the features of these ilia definitively argues against assignment to Hylidae, although the morphology of the tuber superius and pars ascendens is clearly more consistent with that of Bufonidae. Both Hylidae and Bufonidae are diverse and numerous (Frost et al., 2006) and the osteology of most of their species remains unknown. Therefore, a precise assignment does not appear possible for the three ilia.

Today, Bufonidae are almost cosmopolitan, they are absent only from Australia and Antarctica. Hylidae occur in the Americas, Australia, Europe and part of Asia. In Africa, they inhabit only the northernmost part of the continent, where they appear to be immigrants from Europe.

\section{? ANURA}

Figure 5G-H

Material. Twenty-four presumed distal carpals 3-4-5 (UM/ HGL50-543-545).

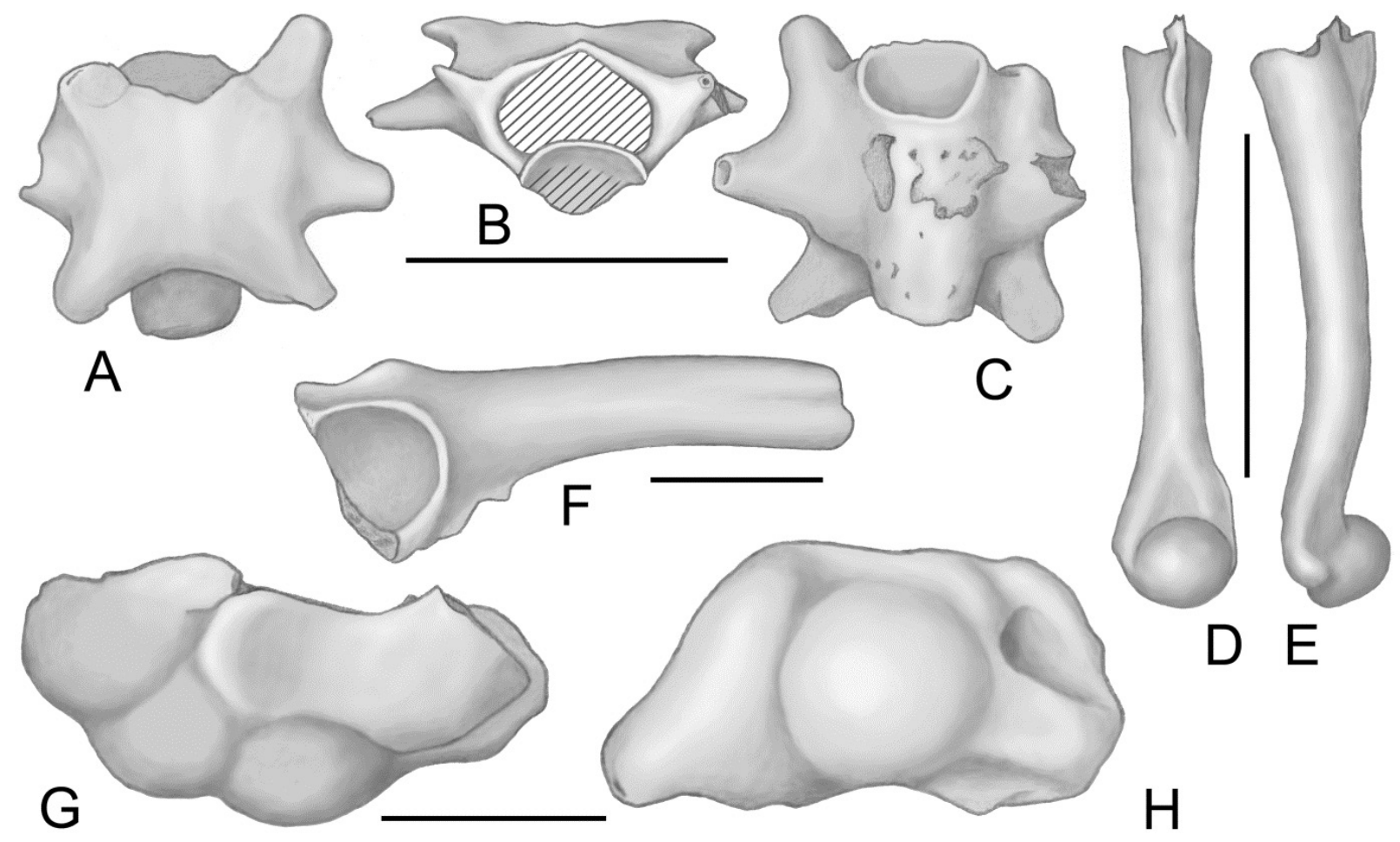

Figure 5. A-F, Anura indeterminate. A-C, presacral vertebra (UM/HGL50-534) in dorsal (A), anterior (B), and ventral (C) views. D, E, left humerus (UM/HGL50536) in ventral (D) and medial (E) views. F, right ilium (UM/HGL50-539) in lateral view. G, H, ? Anura, presumed composite distal carpals 3-4-5 (UM/HGL50-543) in dorsal $(\mathbf{G})$ and distal $(\mathbf{H})$ views. Scale bars $=2 \mathrm{~mm}$. 


\section{Description and remarks}

A comparatively small element (Fig. 5G, H), represented by several specimens, appears to be a composite distal carpals 3-4-5 (or 2-3-4 in another nomenclature; Rage \& VergnaudGrazzini 1995). However, the morphology of this element was never described, and this bone was never reported in extinct faunas. Its identification as a carpal element, and therefore as an anuran bone, cannot be definitively confirmed. Anteriorly, i.e. distally, the bone forms two rounded protuberances, flanked medially by a shallower flat surface. The lateral protuberance is prolonged lateroventrally by a short process. The posterior face of the bone is shallowly concave.

A composite carpal 3-4-5 occurs in numerous neobatrachians (Fabrezi \& Barg 2001). If really a carpal 3-4-5, the larger specimens (UM/HGL50-543, 544) should belong to Rocekophryne ornata, which would be consistent with both the size of the larger humeri of Rocekophryne and the relative abundance of taxa.

\section{SQUAMATA Oppel, 1811 \\ IGUANIA Cuvier, 1817 ACRODONTA Cope, 1864}

Acrodonta is a clade whose members have only acrodont teeth or acrodont plus some anterior pleurodont teeth. Within Acrodonta, the clade Chamaeleonidae is characterized, among other features, by the presence of only acrodont teeth. Nonchamaeleonid acrodontans were traditionally assigned to the family Agamidae. However, the monophyly of this assemblage cannot be demonstrated and it appears to be the paraphyletic (e.g. Gauthier et al., 2012). Hereafter, this assemblage is referred to as 'agamids'.

\section{'AGAMIDS' \\ GENUS AND SPECIES INDETERMINATE}

Figure 6A

Material. One anterior portion of a left dentary (UM/HGL50546).

\section{Description}

The specimen bore five teeth (the last one broken away after the photograph was taken). The bone is deep and, anteriorly it forms a broad, approximately ovoid symphyseal surface. There is no protruding subdental shelf, but a marked dental groove (sensu Čern̆anský 2010) extends ventral to the tooth row; it reaches the anterior tip of the bone, dorsal to the symphyseal facet. The Meckelian groove opens ventrally and is scarcely exposed in medial aspect; anteriorly, it reaches the symphysis. Between the Meckelian groove and the dental groove, the supra-alveolar ridge (sensu Čerňanský 2010) is very deep.

The limit between bone and teeth does not clearly appear. The last three teeth (i.e. teeth 3, 4, and 5) are acrodont. Their bases apparently extend more ventrally on the lingual side, where they perhaps reach the dental groove, than on the labial side; if the limit of the teeth is really so ventral on the lingual face, the implantation may be described more precisely as subpleurodont (Averianov \& Danilov 1996), pleuroacrodont (Evans et al., 2002) or apicolingual (Apesteguía et al., 2016) rather than really acrodont. The acrodont teeth are triangular and compressed labio-lingually. They lack anterior and posterior flanges, they have sharp edges, and their tip is rounded. Neither striae nor wear facets are discernible. Their elongate bases are aligned with the axis of the dentary. These teeth are clearly separated by small spaces. The first tooth is damaged; apparently its distal part is broken away, but the tooth was likely short. The remaining portion is cylindrical and inclined anteriorly. The basis of the tooth is truncated by the dental groove, and the mode of implantation cannot be observed confidently. However, the orientation of the tooth and its cylindrical section are similar to those of the anteriormost teeth of 'agamids', which are pleurodont. The second tooth is more or less intermediate morphologically between the posterior acrodont teeth and the presumed pleurodont anterior tooth. Its orientation is similar to that of the first tooth. Its mode of implantation cannot be determined.

\section{Remarks}

The presence of acrodont (apicolingual), triangular and labiolingually compressed teeth, the alignment of the bases of acrodont teeth with the axis of the bone, the presence of at least one anterior pleurodont tooth, and the presence of a dental groove represent a combination of characters that points to the agamid assemblage.

Today, 'agamids' inhabit Africa (but not Madagascar), southern Eurasia and Australia. The earliest record of possible acrodontan lizards is from the Early or Middle Jurassic of India (Evans et al., 2002); however, Jones et al., (2013) questioned the referral of the Indian fossils to Acrodonta. The earliest confirmed Acrodonta was recovered from the Late Cretaceous: Jeddaherdan aleadonta Apesteguía et al., 2016, from the Cenomanian of Africa; although it represents the earliest member of Acrodonta, Jeddaherdan may be referred to the extant uromastycines (Apesteguía et al., 2016), a group that is still present in Africa. In addition, Simões et al. (2015) reported Gueragama sulamerica, from the Turonian-Campanian of South America, as an acrodont. The Cretaceous fossils suggest that African uromastycines, or even African agamids, are West Gondwanan vicariants. By contrast, on a molecular basis, Macey et al. (2000) regarded African agamids as possible African autochthtons and/or trans-Tethyan immigrants of Asian origin; however, at that time the Cretaceous fossils were not recovered yet.

Aside from Jeddaherdan, the oldest confirmed acrodontan from Africa is the 'agamid' from HGL50. However, between them, an acrodontan tooth whose assignment is questionable was recovered from the Late Palaeocene of Morocco (Augé \& Rage 2006); this fossil may belong to a rhynchocephalian or to an acrodontan lizard. In Africa, 'agamids' were also reported from the Early Oligocene of the Arabian Peninsula (Thomas et al., 1991), which is part of the African Plate, and of Egypt (Holmes et al., 2010b). Comparison of the HGL50 specimen with 'agamids' from the African Oligocene are not possible because the dentaries from the Oligocene are poorly preserved.

In Asia, priscagamine agamids were reported from the Late Cretaceous by Gao \& Hou (1995), but priscagamines are now excluded from the agamid assemblage and are regarded as the sister taxon to Acrodonta (Smith 2009; Gauthier et al., 2012). Therefore, the earliest Acrodonta from Asia are taxa from the Early-Middle Palaeocene of China (Dong et al., 2016). In Europe and North America, 'agamids' are first known in the Early Eocene (Augé 2005; Smith 2011). In Australia, they do not occur before the Late Oligocene and/or Early Miocene (Archer et al., 2006). 
GEKKOTA Camp, 1923

GEKKONIDAE s.l. Gray, 1825

Modern gekkotans have long been all included in the Gekkonidae. However, several families were recently erected, including a restricted family Gekkonidae (Daza et al., 2014). Geckos are small lizards whose bones are delicate. Their fossilized remains are often disarticulated and poorly preserved; generally, they do not permit assignment within the assemblage of modern gekkotans.

\section{GENUS AND SPECIES INDETERMINATE}

Figure 6B

Material. Seven incomplete dentaries (UM/HGL50-547, 548) and four fragments bearing teeth (UM/HGL50-549).

\section{Description}

The dentaries are elongate and slender. On the lingual face, the Meckelian groove is closed. The subdental shelf is discernible in the posterior part of the bone; it is relatively deep and it clearly projects lingually. On the anterior portion of the dentary, where the Meckelian groove is closed, the shelf becomes indistinguishable from the more ventral part of the bone; in this portion, the dentary appears to be tubular, ventral to the tooth row. A shallow sulcus dentalis runs along the bases of the teeth. On the labial face, several mental foramina are present, but their number cannot be determined. Teeth are deeply pleurodont, conical, tall and pointed. They lack accessory cusps. Tooth bases are closely spaced and teeth were numerous. Replacement pits are present lingually.

\section{Remarks}

The number of teeth, absence of accessory cusps on teeth, interstices between teeth very small, slenderness of the dentary, closure of the Meckelian groove, and tubular aspect show that these specimens belong to Gekkonidae s.l. Unfortunately, the morphology of the dentary is very homogenous within Gekkonidae s.l. and it does not permit easy identification within the group. Therefore, the use of Gekkonidae in its former acceptation (here, Gekkonidae s.1.) is a convenient way to report most gekkotan fossils.

The earliest known Gekkota was recovered from the Early Cretaceous (Albian?) of Asia (Arnold \& Poinar 2008), but fossils referable to Gekkonidae s.l. did not occur before the Cainozoic. In Africa, a gekkonid s.l. was reported from the Late Palaeocene of Morocco (Augé \& Rage 2006), and therefore the presence of the taxon in the Eocene could not be unexpected.

\section{SCINCOMORPHAN LIZARDS}

Figure 6C-E

Scincomorphans make up a very large and cosmopolitan assemblage that occurs on all continents except Antarctica. The monophyly of the group has been questioned. Molecular phylogenies do not support monophyly of this assemblage (e.g., Pyron et al., 2013; Zheng and Wiens 2016). However, Gauthier et al. (2012), on the basis of the most integrative morphological analysis, regarded scincomorphans as a clade. Irrespective to the phylogentic structure of the assemblage, scincomorphan is used here only as morphological concept. Scincomorphans are first known in the Bathonian (Middle Jurassic) of Eurasia (Evans 2003; Skutchas 2006) and Africa (Haddoumi et al., 2016). At HGL50, scincomorphans are represented only by fragments of bones bearing a few teeth. It is worth noting that none of the preserved teeth of lizards shows striation at HGL50. The absence of striae may result from acid processing (the surface shows irregular, tiny alveoli), although this appears to be unlikely. The striation pattern may be useful for identification in scincomorphans (Kosma 2004), unfortunately it cannot be used on the specimens from the locality. Despite poor preservation and scarcity, the material suggests that three distinct taxa are present at HGL50.

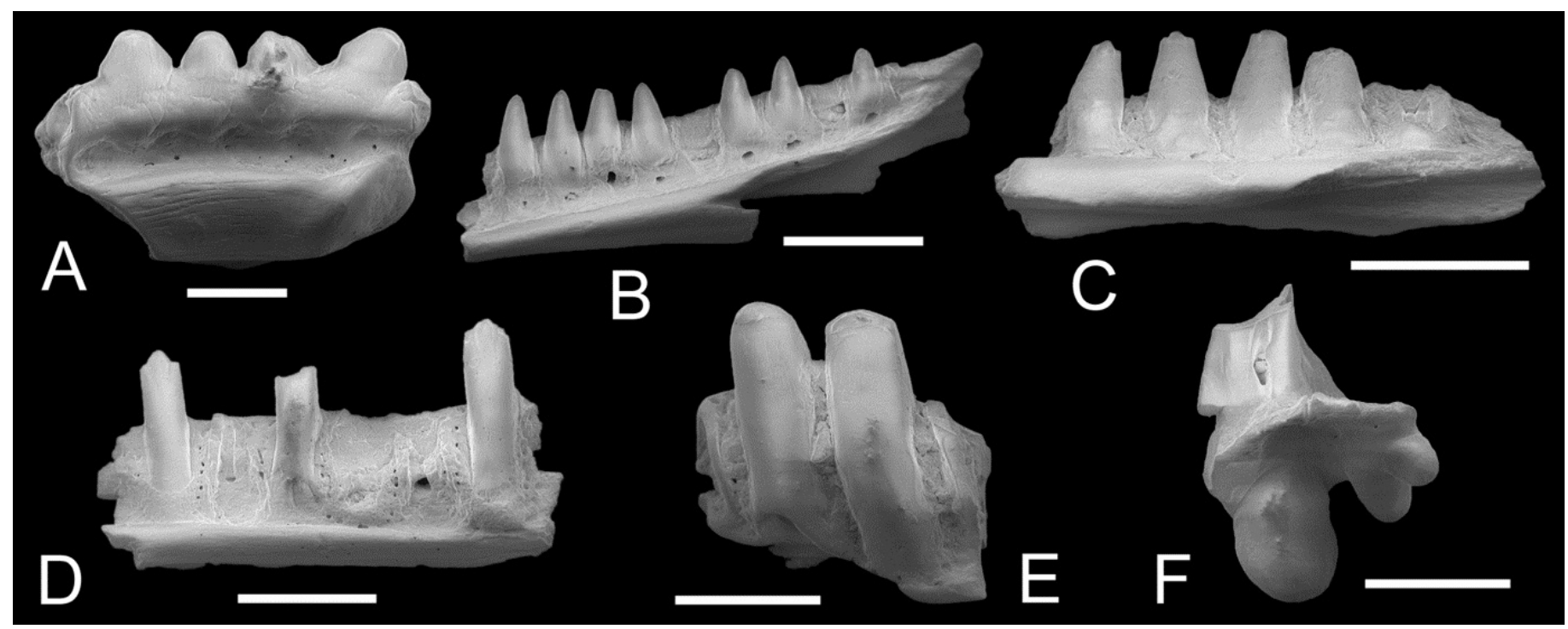

Figure 6. Non-varanoid lacertilians. A, 'agamid' acrodontan, incomplete left dentary (UM/HGL50-546) in lingual view. B, Gekkonidae s.1., incomplete right dentary (UM/HGL50-547) in lingual view. C, scincomorphan, genus and species indeterminate A, fragment of dentary (UM/HGL50-550) in lingual view. D, scincomorphan, genus and species indeterminate B, fragment of bone bearing teeth (UM/HGL50-552) in lingual view. E, scincomorphan, genus and species indeterminate, fragment of bone bearing teeth (UM/HGL50-554) in lingual view. F, Amphisbaenia, incomplete premaxilla (UM/HGL50-557) in lingual view. Scale bars =1 mm. 


\section{FAMILIES INDETERMINATE}

\section{GENUS AND SPECIES INDETERMINATE A}

Figure 6C

Material. One fragment of dentary bearing four teeth (UM/ HGL50-550) and perhaps a fragment of maxilla bearing three teeth (UM/HGL50-551).

\section{Description}

HGL50-550 is a fragment of dentary that probably corresponds to the posterior portion of the tooth row, as suggested by the moderate depth of the parapet. The Meckelian groove was open but its width cannot be evaluated. The subdental shelf is relatively deep and it projects only weakly lingually. There is no sulcus dentalis. Teeth are shallowly pleurodont (subpleurodont; Nydam \& Voci 2007) and not tall. They are tricuspid (the tips of the two posterior teeth are damaged). The main, pointed central cusp is flanked by an anterior and a posterior non pointed cusps. The lower part of the tooth shafts is bulbous. The preserved teeth do not have replacement pits. Teeth are clearly separated from each other. Cementum appears to be present in moderate amount.

HGL50-551 has teeth somewhat similar to those of HGL50550 , but they lack accessory cusps. However, this absence may result from erosion.

\section{Remarks}

The morphology of the teeth of HGL50-550, which are both tricuspid and bulbous, rarely occurs in lizards. However, a similar morphology is found in the posterior portion of the tooth row in Chamops (Gao \& Fox 1996; Nydam \& Voci 2007) and Gallotia (Kosma 2004). Chamops is a borioteiioid from the Late Cretaceous of North America whereas Gallotia is an extant lacertid from the Canary Islands; in other words they both belong to the scincomorphan assemblage. The little deposit of cementum and non markedly projecting subdental shelf in the fossils from HGL50 are consistent with the morphology in the scincomorphan assemblage. Based on these poorly preserved fragments, it is not possible to suggest an identification beyond scincomorphans.

It is worth noting that this lizard from HGL50 is reminiscent of 'indeterminate lacertilian A' from the Late Palaeocene of Adar Mgorn 1, Morocco (Augé \& Rage 2006). In the latter, the central cusp is larger but this may be a variation within the tooth series. The specimens from both localities being very incomplete, a definitive conclusion is not possible.

\section{GENUS AND SPECIES INDETERMINATE B}

Figure 6D

Material. One fragment of bone bearing teeth (UM/HGL50552) and perhaps three other fragments bearing teeth (UM/ HGL50-553).

\section{Description}

The description is based only on HGL50-552, the teeth of which are better preserved than in the other specimens. This is a fragment of an indeterminate bone (maxilla or dentary) that bears two preserved teeth and an incomplete one. The sub- or supradental shelf is moderately deep and not markedly prominent lingually. The sulcus dentalis is lacking. Teeth are tall, deeply pleurodont, relatively slender and tricuspid; their shaft is straight and cylindrical. The crown comprises a central cusp and smaller anterior and posterior cusps. Weak grooves separate the main cusp from the smaller ones. The sizes and shapes of the two accessory cusps being similar, the crown appears symmetrical in lingual or labial views. Striae are apparently absent. A replacement pit of moderate size opens posterolingually in the base of one tooth. The parapet is deep and about half of the tooth height projects beyond it. Cementum is present but it is not thick. Judged from remains of tooth bases, teeth were separated by small interstices.

\section{Remarks}

One of the main characteristics of these remains is the tricuspid condition of the tooth crowns. Pleurodont, tricuspid teeth occur in non-acrodont iguanian (i.e. in 'iguanids s.l.') and in scincomorphans. The symmetrical accessory cuspids and the absence of sulcus dentalis are more frequently encountered in iguanids s.l. than in scincomorphans (Augé 2005; Smith 2009). Conversely, the presence of only weak grooves between the cusps is generally found in scincomorphans (Smith 2009). The most significant feature appears to be the posterolingual opening of the replacement pit, a position that does not occur in iguanids s.1. (Estes et al., 1988; Nydam \& Fitzpatrick 2009). The absence of striation is frequent in iguanids s.l. (Smith 2009), whereas striation is common in scincomorphans (Kosma 2004). However, as stated above, none of the lizards from the locality shows striae on tooth crowns, which is surprising, and this character cannot be taken into consideration. Finally, on the basis of the moderate size and posterolingual position of the replacement pit, this lizard is regarded as a scincomorphan.

\section{GENUS AND SPECIES INDETERMINATE C}

Figure 6E

Material. One fragment of bone bearing two teeth (UM/ HGL50-554), three fragments of maxillae bearing teeth (UM/ HGL50-555), and two larger fragments bearing one tooth each (UM/HGL50-556).

\section{Description}

No part of the subdental shelf is preserved but a portion of supradental shelf remains on a fragment of maxilla. It is comparatively thin and it projects mderately lingually. A narrow and shallow sulcus dentalis appears to be present but this cannot be definitively confirmed. A large replacement pit opens lingually at the base of several teeth. Teeth are comparatively tall and deeply pleurodont, with about three quarters of their height attached to the vertical alveolar surface of the parapet (sensu Rage \& Augé 2010). The shaft is straight, cylindrical and thick. The crown lacks accessory cuspids and it forms a blunt apex. A more or less distinct, elongate and narrow area stretches anteroposteriorly on the apex. It is not clear whether these areas represent wear facets. Teeth are not widely spaced and there is no extended areas of cementum.

\section{Remarks}

These fragmentary remains do not offer a good basis for the search of affinities. However, the moderately developed 
supradental shelf and the lingual opening of the replacement pits point to scincomorphans (Nydam \& Cifelli 2002). Such a referral is consistent with the overall tooth morphology.

\section{AMPHISBAENIA Gray, 1844 FAMILY INDETERMINATE GENUS AND SPECIES INDETERMINATE}

Figure 6F

Material. One incomplete premaxilla (UM/HGL50-557) and five trunk vertebrae (UM/HGL50-558 and 559).

\section{Description}

The premaxilla preserves the lower portion of the nasal process and the right maxillary process. The bone bears three teeth: one large median tooth and, on the maxillary process, two smaller teeth. It cannot be determined whether an important part of the maxillary process is broken away, i.e. if more than two teeth were present on the process. All teeth are short, rounded and shallowly pleurodont. Although the nasal process is incomplete, it may be inferred that the premaxilla lacked a rostral process. The preserved part of the nasal process is not wide and it narrows dorsally. A pair of small foramina opens at the base of the nasal process.

The vertebrae are depressed and lack a zygosphenezygantrum system. The neural spine is underdeveloped and the ventral face of the centrum is narrow, flat to weakly convex, and limited by subparallel subcentral ridges. In addition, vertebrae lack projecting prezygapophyseal processes, their paradiapophyses are globulous, forming a single articular facet, and the posterior border of the neural arch is almost straight or slightly concave. The cotyle and condyle are markedly flattened dorsoventrally. The zygapophyses are inclined on the horizontal. Two foramina open on the ventral face of the centrum; generally, at least one of them is large.

Anterior trunk vertebrae are relatively short whereas more posterior ones are elongate. On two vertebrae from the anterior portion of the vertebral column, the neural spine is represented by a posterior, low and poorly defined tubercle. Anteriorly, the tubercle is prolonged by a faint ridge. There is no neural spine on the other vertebrae. On the posterior, elongate vertebrae, the neural arch projects anteriorly between the prezygapophyses, but there is no zygosphene. Aside from the neural spine, where present, the neural arch lacks ridges. The posterior border of all vertebrae is smooth, without denticles.

\section{Remarks}

Because of size consistency and composition of the sample, it is presumed, but not demonstrated, that the premaxilla and vertebrae belong to the same taxon.

The presence of a large median tooth on the premaxilla is typical of amphisbaenians. This bone displays various other characters that are, however, not clearly significant at family level (Kearney 2003). As far as vertebrae are concerned, the depressed overall build, absence of a zygosphene-zygantrum system, neural spine underdeveloped, ventral face of centrum narrow and limited by parallel subcentral ridges, absence of prezygapophyseal processes, paradiapophyses globulous forming a single articular facet, and absence of a median notch in the posterior border of the neural arch are characters whose combination secures referral to amphisbaenians. Unfortunately, the vertebral morphology of amphisbaenians is homogenous and offers few characters taxonomically significant within the group. At family level, only the absence of denticles on the posterior border of the neural arch provides information. Denticles occur in Rhineuridae and several related genera lumped as Rhineuroidea by Kearney (2003). Therefore, the fossil from HGL50 cannot be assigned to this taxon, but it is not possible to suggest a more precise referral.

Amphisbaenians are worm-like lizards, extant representatives of which occur mainly in Africa and South America. They are also scattered in southern North America, Caribbean islands, southwestern Europe and the Middle East. The presence of the earliest amphisbaenians in the Late Cretaceous is debated. A possible amphisbaenian was reported from the Campanian of Spain (Rage 1999) but Blain et al. (2010) stated that it more likely belongs to anguids. On the other hand, Tałanda (2016) recently interpreted Slavoia from the Campanian of Mongolia as a stem amphisbaenian. The Palaeocene produced the earliest unquestionable amphisbaenians in Africa (Augé \& Rage 2006), Europe (Folie et al., 2013) and North America (Sullivan \& Lucas 1986; Longrich et al., 2015). Subsequently, amphisbaenians largely diversified during the Eocene (Augé 2012). Indeterminate amphisbaenians were already reported from the Eocene of Africa (Rage et al., 2013).

\section{? VARANOIDEA Gray, 1827 FAMILY INDETERMINATE GENUS AND SPECIES INDETERMINATE}

Figure 7

Material. One incomplete dorsal (UM/HGL50-560), one incomplete caudal (UM/HGL50-561) and perhaps another caudal vertebrae (UM/HGL50-562).

\section{Description}

The dorsal vertebra is represented by the left half of a centrum. Although very incomplete, this specimen is reminiscent of varanids. A precondylar constriction is present, but it is not strongly marked; the condyle is wider than the posterior part of the centrum, the anterior part of the condyle forming a flange that faces anteriorly. In addition, although the dorsal limit of the cotyle is damaged, it clearly appears that it was located markedly more anteriorly than the ventral limit. Therefore, the axis of the condyle is oblique and the condyle faces posterodorsally. The condyle was approximately circular, not depressed. As in Varanus, the subcentral ridge that limit the ventral face of the centrum laterally is marked, although rounded. The ridge follows a curve that is concave laterally; it shows that a constriction of the centrum, narrower than the precondylar constriction, is located anterior to the latter, as may occur in Varanus.

UM/HGL50-561 is an incomplete caudal vertebra that preserves the centrum, lateral walls and left prezygapophysis. It is characterized by the presence of two posteroventral peduncles located against the condyle. The peduncles articulated with a chevron. Unfortunately, it is not possible to estimate the lengths of the peduncles because their extremities are damaged; however, based on the remaining parts, it may be inferred that they clearly projected from the centrum. The peduncles are prolonged anteriorly by thick ridges that converge and join in the sagittal plane. The orientation of the condyle is difficult 
to observe because of the presence of peduncles against its ventral limit. However, the cotyle is largely exposed in ventral aspect, which corresponds to an oblique condyle. There is no marked precondylar constriction. The bases of the tranverse processes show that two processes were present on either side. The two processes were separated by a narrow space. The cross section of the anterior process is circular, whereas that of the posterior process is dorsoventrally flattened and somewhat extended anteroposteriorly. Apparently, the two processes were convergent, leaving a space between their bases. There is no autotomy septum.

$\mathrm{UM} / \mathrm{HGL} 50-562$ is larger but its peduncles are weak. Its referral to the same taxon as UM/HGL50-561 cannot be confirmed.

\section{Remarks}

Both UM/HGL50-560 and 561 display characteristics known in varanoids. The marked precondylar constriction that occurs in the dorsal vertebra is a derived feature of Varanus and of the extinct Saniwa (Pregill et al., 1986; Augé 2005; Smith et al., 2008). Saniwa is a varanid, which was reported only from the Laurasian continents, where its presence is confirmed only in the Eocene. Among lizards, the obliquity of the cotyle-condyle system characterizes some anguimorphan lizards: varanoids (i.e. among extant lizards, Varanidae and Lanthanotidae) and Helodermatidae. In addition, the overall morphology of the centrum of the dorsal vertebra is quite Varanus-like. Obviously, the use of overall morphology may appear subjective, but it cannot be ignored. In the present case, the curve followed by the subcentral ridge and rounded aspect of the ridge appear to be typical. However, in varanids the condyle is strongly depressed, whereas it is circular in the fossil from HGL50.

The caudal vertebra lacks a clear precondylar constriction; this is not consistent with varanids, but this character is known in varanoids. In addition, even in Varanus, the constriction is, by far, less marked in the caudal region than in the dorsal portion of the column. The presence of projecting peduncles for articulation with a chevron points to varanoids (Estes et al., 1988). The caudal vertebra lacks an autotomy septum; this absence is encountered in varanoids but also in Acrodonta. A feature does not appear to be consistent with varanoids: the presence of two transverse processes on each side of the caudal vertebra. The two processes likely converged and merged; Conrad (2006) regarded such fused processes as a single process whose basis is pierced by a foramen. In varanoids, transverse processes are really single, their bases are not formed by two roots separated by a space. However, transverse processes originating from two roots, as in UM/HGL50-561, are present in Shinisaurus, a lizard whose debated relationships may be close to varanoids (Conrad 2008; Conrad et al., 2011; Gauthier et al., 2012).

In summary, as stated above, both UM/HGL50-560 and 561 display features that suggest assignment to varanoids. Some characters even suggest varanid affinities. However, the nondepressed condyle in the dorsal vertebra and the presence of two roots for the transverse process, or of two transverse processes, in the caudal vertebra do not appear to be consistent with Varanidae. In addition, it cannot be determined whether the two vertebrae belong to a single species or if two species were present in the locality.

In Africa all varanoids, whether extant or extinct, are Varanidae. As far as the Palaeogene is concerned, they were reported from the Late Eocene and the Early Oligocene of Egypt. The varanid from the Late Eocene (Birket Qarun Formation) was referred to as Varanus by Holmes et al. (2010a). However, there is no evidence of a typical precondylar constriction on the

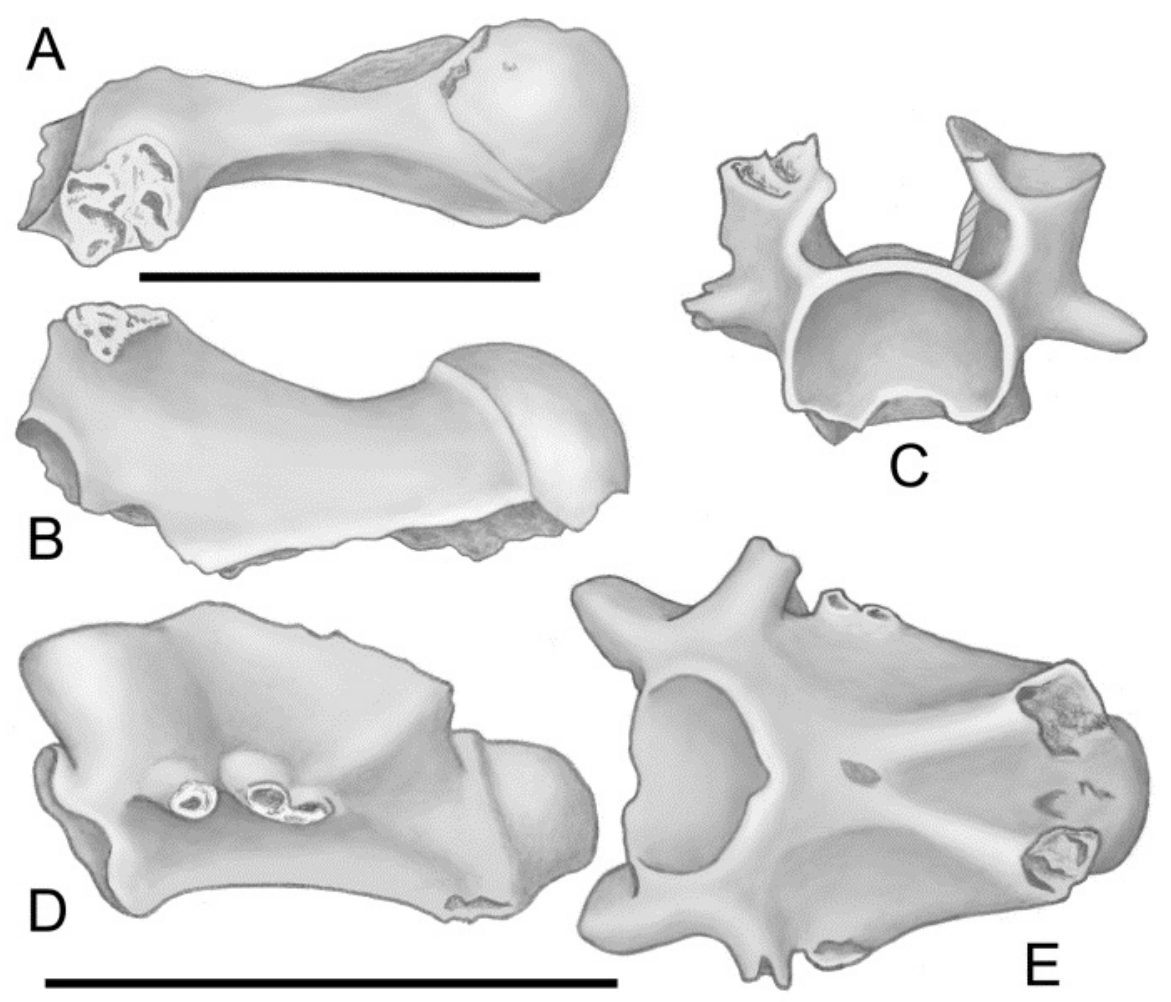

Figure 7. ? Varanoidea. A, B, incomplete dorsal vertebra (UM/HGL50-560) in left lateral (A) and ventral (B) views. C-E, caudal vertebra (UM/HGL50-561) in anterior $(\mathbf{C})$, left lateral (D) and ventral (E) views. Scale bars $=3 \mathrm{~mm}$. 
referred dorsal vertebrae, although the condyle itself is wider than the posterior part of the centrum (Holmes et al., 2010a, text-fig. 1F). If a precondylar constriction is really absent, these vertebrae cannot be assigned to Varanus. This feature also distinguishes the Eocene varanid of Egypt from the trunk vertebra of HGL50. However, interestingly, it should be noted that, as UM/HGL50-561, a caudal vertebra from the Eocene of Egypt is provided with two roots for the transverse process, or had two transverse processes (Holmes et al., 2010a, text-fig. $1 \mathrm{G})$

Fossils from the Early Oligocene of Egypt were reported as stem-Varanus by Smith et al. (2008) and as Varanus by Holmes et al. (2010b). Although found in the same locality, they may represent two distinct taxa (Holmes et al., 2010a).

Unfortunately, no definitive conclusion may be drawn from the material from the Eocene. It may be only stated that UM/ HGL50-560 from the latest Early-early Middle Eocene of HGL is likely the earliest terrestrial varanoid from Africa. What remains to be assessed is whether the caudal UM/HGL50-561 belongs to the same taxon or represents another varanid or varanoid.

\section{NON-OPHIDIAN SQUAMATES INDETERMINATE}

Some specimens belonging to 'lizards' could not be determined. Identifications is not possible either because the specimens are not significant, which is the case of vertebrae (identification of vertebrae is difficult in "lizards"), or because the specimens are too fragmentary.

Material. Three dorsal vertebrae belonging to nonamphisbaenian and non-varanoid 'lizards' (UM/HGL50-563), five comparatively elongated dorsal vertebrae (UM/HGL50564) and 14 fragments of bones bearing incomplete teeth (UM/ HGL50-565).

OPHIDIA Brongniart, 1800 sensu Caldwell \& Lee, 1997 SERPENTES Linnaeus, 1758

SCOLECOPHIDIA Duméril \& Bibron, 1844 FAMILY INDETERMINATE GENUS AND SPECIES INDETERMINATE

Material. Five trunk vertebrae (UM/HGL50-566, 567).

\section{Description}

The vertebrae are small, depressed but relatively elongated. They lack a neural spine and the neural arch is markedly depressed. In dorsal view, the interzygapophyseal constriction is well expressed and the posterior border of the neural arch forms a shallow concavity, but there is no median notch. The axis of the prezygapophyseal facets is almost parallel to the vertebral axis. Prezygapophyseal processes are all broken away; their remaining bases show that they were large and directed almost laterally. In anterior view the cotyle is depressed, the zygosphene is thin, and the paracotylar foramina are absent. In lateral aspect, the paradiapophyses are globulous, not extended dorsoventrally; they lack any distinction between the dia- and parapophyseal areas. In ventral view, the centrum is narrow and devoid of a distinct haemal keel. The lateral borders of the centrum are subparallel. The subcentral foramina appear as large, irregular foramina.

\section{Remarks}

Identification of scolecophidian vertebrae is easy. The combination of the characters described above unquestionably points to Scolecophidia. Among these characters, the fact that the orientation of the axis of the prezygapophyseal facet is quite different from that of the prezygapophyseal process appears to be significant. However, the vertebrae are simple in morphology and they lack variation; consequently, identification within scolecophidians is difficult, or even impossible on the basis of vertebrae. Unfortunately, extinct scolecophidians are represented only by vertebrae.

Likely due to their small size and brittleness of their skeleton, extinct scolecophidians are rare (Mead 2013). The earliest scolecophidian was recovered from the Palaeocene of Hainin, Belgium (Folie 2006; Mead 2013), a locality that was generally dated as Middle or Late Palaeocene, but that appears to be Early Palaeocene in age (De Bast \& Smith 2013, 2017). In Africa, the earliest scolecophidian comes from the Late Palaeocene of Adrar Mgorn 1, Morocco (Augé \& Rage 2006). It should be noted that Mead (2013, fig. 3) erroneously reported the Moroccan fossil from the Early Eocene. Today, scolecophidians are present on all continents, where areas are sufficiently warm.

\section{ALETHINOPHIDIA Nopesa, 1923 ANILIOID-GRADE SNAKES}

Anilioids make up an assemblage of basal alethinophidians; this assemblage was variously regarded monophyletic (e.g. Palci et al., 2013), paraphyletic forming the stem of Macrostomata (e.g. Cundall et al., 1993; Gauthier et al., 2012), or even polyphyletic (e.g. Vidal \& Hedges 2004; Pyron et al., 2013). This group comprises 11 extant genera. Aside from the specialized Uropeltidae that are restricted to southern India and Sri Lanka, there are three generalized genera: Anilius from South America, and Cylindrophis and Anomochilus from southeastern Asia. In addition, several extinct taxa were assigned to anilioids: Coniophis dabiebus Rage \& Werner, 1999, from the Late Cretaceous of Africa; Coniophis cosgriffi Armstrong-Ziegler, 1978, from the Campanian of North America, although regarded as a nomen dubium (Sullivan \& Lucas 2015); Australophis anilioides Gómez, Báez \& Rougier, 2008, from the Campanian-Maastrichtian of South America; Coniophis precedens Marsh, 1892, from the Maastrichtian of North America (Longrich et al., 2012); Hoffstetterella brasiliensis Rage, 1998, from the Palaeocene or Eocene of Brasil; Coniophis carinatus Hecht, 1959, and C. platycarinatus Hecht, 1959, from the Early Eocene of North America; Eoanilius europae Rage, 1974, and E. oligocenicus Szyndlar, 1994, from the Eocene and Oligocene-Early Miocene respectively of Europe (Rage 2006); Colombophis portai Hoffstetter \& Rage, 1977, and C. spinosus Hsiou, Albino \& Ferigolo, 2010, from the Middle and Late Miocene respectively of South America; and Michauxophis occitanus Bailon, 1988, from the Pliocene of Europe. Aside from these named species, undescribed anilioids were reported from all continents except Australia and Antarctica (Gómez et al., 2008); they were often referred to as Coniophis sp., which is the case in Africa. Although the referral of Eoanilius to anilioids was questioned by Smith (2013), this genus is retained in this assemblage for comparisons with the new taxon from HGL50.

Coniophis deserves special comments. Coniophis was 
originally described on the basis of vertebrae from the Maastrichtian of North America. Subsequently, other species were named and indeterminate species were also reported. However, the vertebrae assigned to Coniophis display mainly plesiomorphic features, and as such it may be suspected that this 'genus' is a wastebasket in which are placed various primitive snakes. In addition, the vertebral morphology is not homogenous, two main morphologies may be distinguished within the material assigned to Coniophis (Rage \& Werner 1999). Among named species, only C. dabiebus and perhaps C. cosgriffi appear to be closely related to the type species C. precedens. Rage et al. (2004) even advocated that part of snakes assigned to Coniophis antedate the ScolecophidiaAlethinophidia dichotomy and are not anilioids as a result, an assumption which was subsequently suggested for C. precedens (Longrich et al., 2012). However, the later opinion (based on skull bones assigned to this species) was questioned by Nydam et al. (2014). In any case, Coniophis is likely an artificial grouping of species; this assemblage may include stem-snakes (the Cretaceous species) and anilioids (most Eocene species).

Among snake vertebrae from HGL50, are several specimens that show a typical anilioid morphology. They may be easily distinguished from anilioid snakes described formerly.

\section{FAMILY INDETERMINATE}

\section{Genus AFROTORTRIX nov.}

LSID. urn:1sid:zoobank.org:act:75E07E4C-3662-4051-98C1FBA7E26CB62B

Type and only known species. Afrotortrix draaensis sp. nov.

Derivation of name: 'Afro' refers to the geographic origin. 'Tortrix' was formerly used as genus name for the living anilioids Anilius and Cylindrophis.

Diagnosis: As for the type species and only known species.

\section{Afrotortrix draaensis sp. nov.}

Figures 8, 9

LSID. urn:lsid:zoobank.org:act:C2B3EA54-D64A-4110-83448A609D6DC316

Holotype. One mid-trunk vertebra (UM/HGL50-568).

Referred material. Twenty trunk vertebrae (HGL50-569 to 573) and perhaps four poorly preserved trunk vertebrae (HGL50574).

Type locality. HGL50, Glib Zegdou outlier, Gour Lazib area, Western Algeria.

Horizon. Latest Early Eocene-earliest Middle Eocene.

Derivation of name. From Oued Draa, a relatively close river.

Diagnosis. An anilioid-grade snake that differs from all other snakes of this assemblage, except Colombophis, in having frequent paracotylar foramina. Distinguished from Anilius, Cylindrophis, 'Coniophis', Australophis, Hoffstetterella and Colombophis in having zygapophyses clearly less inclined on the horizontal. Differs from Australophis and Colombophis in having less massively built vertebrae. Further distinguished from Hoffstetterella and Eoanilius in lacking a marked median notch in the posterior border of the neural arch, and from Anilius and Hoffstetterella in having a tubercular, non bladelike neural spine.

\section{Description}

Holotype. The specimen is a mid-trunk vertebra that lacks only a part of the left prezygapophysis (Fig. 8). Its measurements are as follows (in $\mathrm{mm}$ ): width across postzygapophyses: 2.8 ; length of centrum from cotylar rim to tip of condyle: 1.7; length from prezygapophysis to postzygapophysis: 2.2 ; width of zygosphene: 1.3; width of cotyle on external edge: 1.1; width of interzygapophyseal constriction: 1.6.

In anterior view, the vertebra is wide, depressed and not massive, with a broad neural canal. The zygosphene is thin and scarcely wider than the cotyle; its roof weakly arches dorsally. The cotyle is comparatively small and depressed. The preserved prezygapophysis clearly projects laterally; its articular facet barely slants from the horizontal and it lies at about half the height of the neural canal. An incipient prezygapophyseal process is present; it weakly protrudes ventrally but it does not project laterally. The paradiapophyses do not project strongly laterally; their ventral limit is approximately level with the ventral margin of the cotyle. One paracotylar foramen opens on each side of the cotyle.

In dorsal view, the vertebra appears somewhat wider than long. The articular facet of the prezygapophysis is approximately oval and its major axis is oblique. The interzygapophyseal constriction is rather deep. The anterior border of the zygosphene is almost straight and it forms two small lateral lobes. The posterior border of the neural arch forms a regular concavity that lacks a median notch. The neural spine is a low, anteroposteriorly short tubercle restricted to the posteriormost part of the neural arch; anteriorly, it is prolonged by a weak ridge that vanishes approximately at mid-length of the neural arch.

In lateral view, the vertebra is slightly longer than high. The posterior part of the neural arch does not rise posteriorly. The neural spine is low and it clearly projects dorsally only in the posterior portion of the neural arch. The paradiapophyses are relatively tall and narrow. A faint subdivision appears between the bulging diapophysis and the almost flat paradiapophysis. The interzygapophyseal and subcentral ridges are poorly marked. The haemal keel does not project ventrally. Lateral foramina are present.

In ventral view, the centrum is poorly limited laterally by faint subcentral ridges; it moderately widens anteriorly. The haemal keel is relatively wide and its ventral margin is blunt. It is constricted in the anterior half of the centrum; more posteriorly, it becomes poorly defined. In the anterior half, the ventral face of the centrum is weakly depressed on either side of the haemal keel. Subcentral foramina open there, against the keel.

In posterior view, the neural arch is markedly depressed. It does not bulge above the zygantrum. The lateral walls of the 
neural canal are thin. The neural spine appears as a very low mound.

Intracolumnar variation. Anterior, mid- and posterior trunk vertebrae are available. Unfortunately, none of the rare (i.e. four) caudal vertebrae found in the locality may be assigned confidently to this snake. General proportions of the vertebrae do not change significantly along the vertebral column. Otherwise, the main usual variations occur: a hypapophysis is present in the anterior trunk region, the neural arch becomes gradually more depressed as one proceeds anteroposteriorly along the vertebral column, the neural spine is higher in anterior trunks, and subcentral grooves appear on posterior trunk vertebrae.

In the anterior portion of the trunk (Fig. 9A-E), vertebrae mainly differ from those of the mid- and posterior trunk regions in having hypapophyses. In the available specimens, the hypapophyses are strong and directed posteroventrally. The neural spine is slightly taller and anteroposteriorly longer than in mid-trunks. The ridge that prolongs the neural spine anteriorly is longer than in mid-trunks; it reaches the posterior part of the zygosphene. The neural arch is moderately vaulted.

The morphology of mid-trunk vertebrae is illustrated by the holotype. Vertebral morphology of this region is homogenous. The lateral lobes of the zygosphene appears to be smaller than those of vertebrae from other regions, but it cannot be determined whether this is really a characteristic of the species or only a variation in the available specimens.

In the posterior portion of the trunk (Fig. 9F-J), the neural spine appears as a small tubercle located against the posterior border of the neural arch; it is anteroposteriorly short and it is not prolonged anteriorly by a ridge. The prezygapophyseal process is more protruding than in more anterior vertebrae. The cotylar rim is somewhat angled lateroventrally, but it does not form protruding ventrolateral cotylar processes (sensu LaDuke 1991). However, paracotylar notches are comparatively well expressed between the cotyle and each paradiapophysis. The neural arch is depressed, even more strongly than in the mid- trunk region. On the ventral face, well-defined and narrow subcentral grooves (subcentral paramedian lymphatic fossae; LaDuke 1991) are present. Their anterior outlets form the paracotylar notches. Medially, the subcentral grooves limit the haemal keel, which is clearly wider than in the mid-trunk portion.

\section{Remarks}

The material includes only vertebrae that mainly display plesiomorphic features, which prevents any phylogenetic approach. However, it is possible to suggest referral to the anilioid assemblage. The presence of a prezygapophyseal process, even if only incipient, places Afrotortrix with the crown-group, i.e. Serpentes. The presence of a neural spine, the non-globular paradiapophysis, and the overall morphology clearly show that Afrotortrix is not a scolecophidian. Within Alethinophidia, the absence of a median notch in the posterior border of the neural arch is a feature found only among snakes of the anilioid grade. Obviously, this character is plesiomorphic and as such cannot lead to definitively exclude Afrotortrix from the Macrostomata. However, the referral of Afrotortrix to the anilioid assemblage is consistent with several other characters whose polarity is unknown: vertebrae depressed, more specifically neural arch markedly depressed; neural spine low and restricted to the posterior part of the neural arch; prezygapophyseal processes incipient. It being understood that the vertebrae of the extant Anomochilus are still unknown, Afrotortrix may be clearly distinguished from the other taxa assigned to the anilioid assemblage. Coniophis is included in the following comparison because, whatever the relationships of all species referred to it, its vertebrae display an overall anilioid morphology.

Afrotortrix differs from all anilioids, except Colombophis, in having paracotylar foramina. As in Colombophis, their occurrence is irregular, but they are frequent. In the available specimens referred to Afrotortrix, 32 paracotylar areas are preserved. Twenty-two of them have a paracotylar foramen and eight lack it; in two cases, the presence or absence cannot

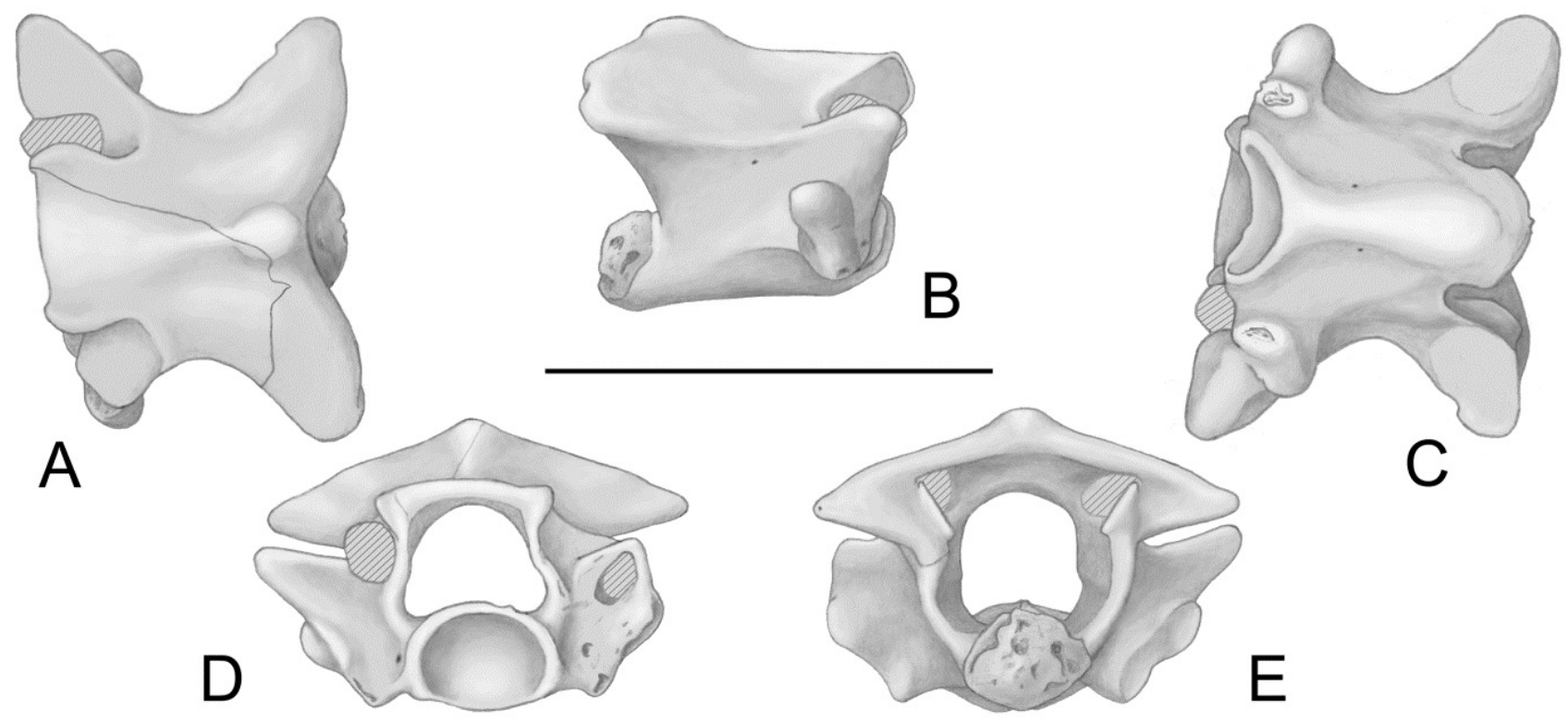

Figure 8. Afrotortrix draaensis gen. et sp. nov., mid-trunk vertebra (UM/HGL50-568), Holotype, in dorsal (A), right lateral (B), ventral (C), anterior (D), and posterior $(\mathbf{E})$ views. Scale bar $=3 \mathrm{~mm}$. 
be determined. The significance of these foramina is puzzling. They characterize both advanced snakes (colubroids, in the classical acceptance) and various stem-snakes. They are absent generally, but may be rarely and irregularly present in some other snakes. Several other features allow for a better distinction of Afrotortrix. The weak inclination of the zygapophyses is similar in Afrotortrix, Eoanilius and Michauxophis, which distinguishes them from other anilioids whose zygapophyses are more slanting. The absence of a median notch in the posterior border of the neural arch is a characteristic common to Afrotortrix and most anilioids; the notch occurs only in Hoffstetterella and Eoanilius. Afrotortrix, as almost all anilioids, except Anilius and Hoffstetterella, has a largely tubercular neural spine that is restricted to the posterior part of the neural arch. In Anilius and Hoffstetterella, there is a blade-like neural spine, although low, developed on most of the length of the neural arch. The vertebrae of Afrotortrix are markedly less massively built than those of Australophis and Colombophis. Afrotortrix further differs from Coniophis species, except $C$. carinatus and $C$. platycarinatus, in having prezygapophyseal processes. In addition, the prezygapophyses of Afrotortrix are clearly less elongated laterally than those of Anilius, Cylindrophis, Colombophis, Australophis and Coniophis platycarinatus. Conversely, they are markedly more elongated laterally than in the Cretaceous species of Coniophis (i.e. C. precedens, C. cosgriffi, and C. dabiebus).

Only two anilioids were previously reported from Africa, and their relationships may be now questioned. Coniophis dabiebus, from the Late Cretaceous of Sudan (Rage \& Werner 1999), may be closely related to C. precedens; both species lack prezygapophyseal processes and their prezygapophyses are not elongated laterally. As C. precedens (Longrich et al., 2012), the Sudanese species may be a stem-snake, not an anilioid. The few specimens from the Palaeocene and Eocene of Morocco, referred to as Coniophis sp. (Augé \& Rage 2006), are poorly preserved and their relationships within the 'Coniophis' assemblage cannot be determined; they may be anilioids or not. Consequently, Afrotortrix is the only confirmed anilioid from Africa.

\section{BOOID-GRADE SNAKES}

Booids are generally regarded as basal macrostomatans, forming the paraphyletic stem group of caenophidians (e.g. Cundall et al., 1993 (part); Lee \& Scanlon 2002; Gauthier et al., 2012). However, in molecular trees they are recovered polyphyletic (e.g. Vidal \& Hedges 2009; Pyron et al.,

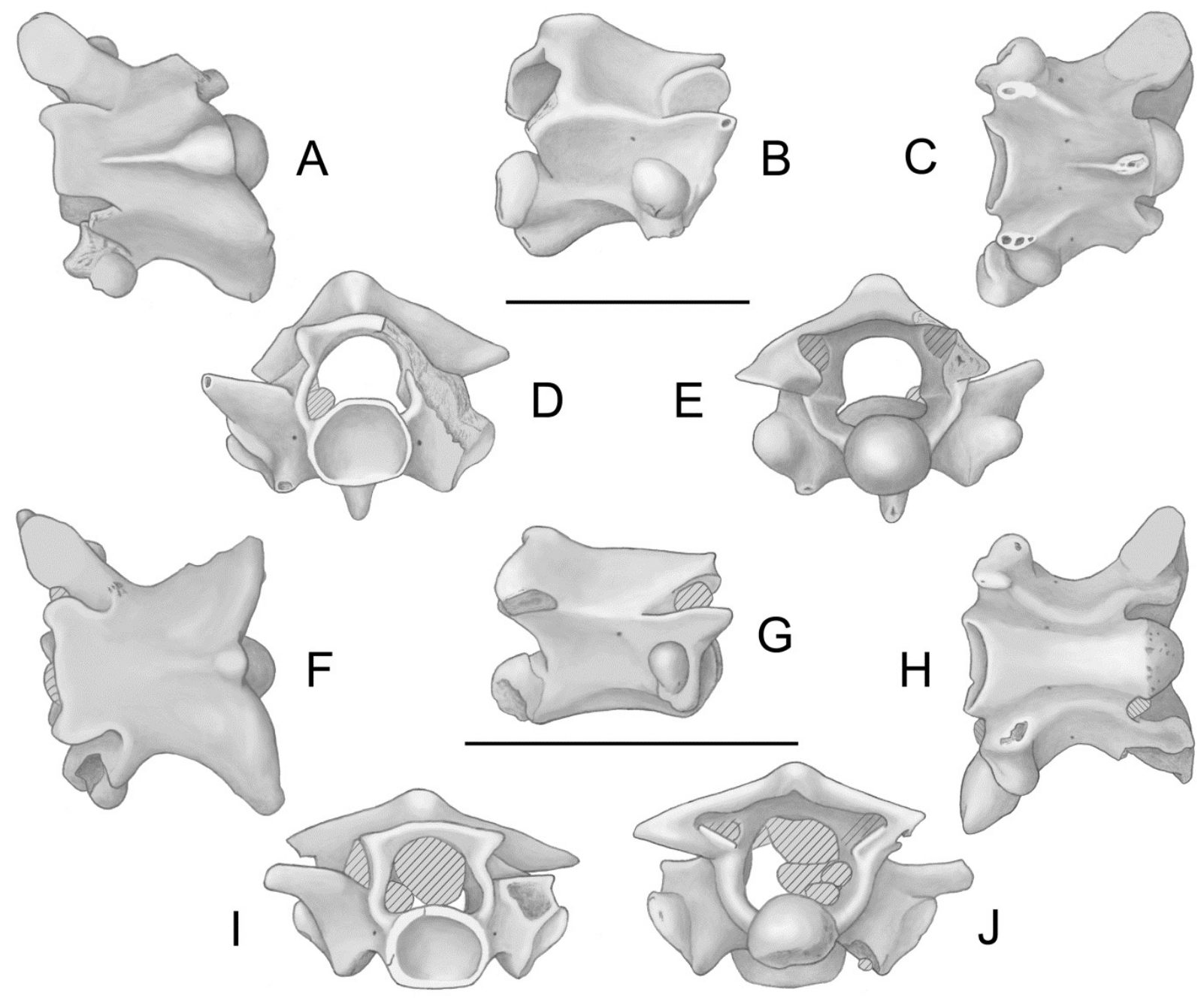

Figure 9. Afrotortrix draaensis gen. et sp. nov., A-E, anterior trunk vertebra (UM/HGL50-569) in dorsal (A), right lateral (B), ventral (C), anterior (D) and posterior (E) views. F-J, posterior trunk vertebra (UM/HGL50-570) in dorsal (F), right lateral (G), ventral (H), anterior (I), and posterior, slightly inclined anteroventrallty (J) views. Scale bar $=3 \mathrm{~mm}$. 
2013; Reeder et al., 2015). Obviously the content of booids varies according to the adopted phylogeny; here, we follow morphologically based phylogenies and we regard booids as including xenopeltids, loxocemids, boids (boines and erycines), pythonids, bolyerids, tropidophiids and ungaliophiids. Today, booids occupy a large part of the World, lacking generally from cold and temperate territories of the northern continents and from Antarctica. The group was even more widely widespread during the Palaeogene; at that time, booids largely dominated snake faunas in North America and Europe (Rage 1987, 2013) and these fossils cannot be all assigned to extant families. In Africa, booids are represented today only by pythons, erycines and the still enigmatic Calabaria. Extinct booids are rare in Africa before the Neogene. Only an indeterminate boid and a tropidophiid s.l. from the Late Palaeocene (Augé \& Rage 2006), indeterminate booids and a tropidophiid from the Late Eocene (McCartney \& Seiffert 2016), and a boid (but see below) and two indeterminate booids from the Late Oligocene (McCartney et al., 2014) were so far reported. The vertebral morphology is comparatively homogenous in booids (Szyndlar \& Rage 2003); consequently, a precise assignment within the group may be difficult.

Some vertebrae document the presence of booids at HGL50. Two taxa are likely present but they cannot be identified precisely.

\section{FAMILY INDETERMINATE BOOID TAXON A}

Figure 10A-C

Material. One mid- or posterior trunk vertebra (UM/HGL50575).

\section{Description}

The single specimen is a small trunk vertebra (centrum length $=2.4 \mathrm{~mm}$ ) whose anterior part is damaged. The two prezygapophyses are broken away and the anterior face cannot be observed. The vertebra was likely wider than long. The interzygapophyseal constriction is well expressed although not deep. The neural spine is blade-like, but it comprises a thick posterior part and a thinner anterior portion; the thick part is anteroposteriorly short. The neural spine extends on most of the length of the preserved part of the neural arch; it probably did not reach the zygosphene. The neural spine is relatively high and its anterior border is inclined. A marked median notch indents the posterior border of the neural arch. The neural canal is comparatively broad and high. In posterior view, the neural arch is markedly depressed ('extremely depressed' sensu Ikeda 2007), which represents the main characteristic of this vertebra. The postzygapophyses are inclined on the horizontal. The condyle is depressed and relatively wide. On the ventral face, the haemal keel is wide and shallow; it appears poorly marked off from the centrum.

\section{Remarks}

The overall proportions of this specimen do not differ significantly from those of anilioid vertebrae. However, a median notch is present in the posterior border of the neural arch and the blade-like neural spine is relatively high. The combination of these two features prevents assignment to the anilioid assemblage and leads to refer the specimen to the booids. No precise assignment is possible within booids. The combination of a depressed neural arch, a developed non-tubercular neural spine and absence of a deep haemal keel points to ungaliophiids, loxocemids, erycines and Calabaria. The vertebra differs from those of ungaliophiines in being clearly less elongate, but no available feature permits clear distinction from loxocemids, erycines and Calabaria. Moreover, the specimen is reminiscent of various extinct taxa whose assignment within booids is indeterminated or questionable. Among the latter taxa is Rukwanyoka holmani McCartney, Stevens \& O'Connor, 2014, from the Late Oligocene of Tanzania. $R$. holmani is the only named booid from the Palaeogene of Africa, and its taxonomic assignment deserves comments. Referral within booids is often difficult and McCartney et al. (2014) proceeded by successive eliminations. They assigned Rukwanyoka to the Boinae, which would be highly significant from a palaeobiogeographical point of view, inasmuch as boines were previously not reported from Africa. However, the strongly depressed, almost flattened neural arch of this snake is not consistent with boines. Among the taxa considered by McCartney et al. (2014), tropidophiids were discarded because Rukwanyoka would display characters that do not occur in the group: relatively wide centrum, anteroposteriorly short centrum and absence of a hypapophysis in the mid-trunk region. Yet, judged from the figures in McCartney et al. (2014), the centrum width and elongation are similar to those in tropidophiids. As for the absence of hypapophyses, there is a frequent confusion. Underwood (1967) reported the presence of hypapophyses throughout the trunk region in tropidophiids. This opinion was subsequently often endorsed (e.g. Holman 2000; Gauthier et al., 2012). However, tropidophiids lack a true hypapophysis in the mid- and posterior portions of the trunk region, where it is replaced by a more or less deep, blade-like haemal keel (Bogert 1968; Szyndlar et al., 2008). These deep haemal keels were likely confused with hypapophyses by Underwood (1967) during dissection, but not observed on fully prepared vertebrae. Rukwanyoka has a deep haemal keel, which is reminiscent of that in tropidophiids, although it is less deep than that of most known species of this taxon. Consequently, Rukwanyoka is clearly more consistent with tropidophiids than with boines, and an assignment to the former of these groups appears to be possible. Conversely, despite overall similarity with Rukwanyoka, booid taxon A from HGL50 cannot be referred to tropidophiids because it lacks any structure projecting ventrally on the centrum.

It should be noted also that Palaeogene booids were probably not all represented by members of extant groups. The precise taxonomic referral of many booids from the Early Cainozoic remains doubtful or unknown and the presence of extinct booid groups at that time may be suspected. Booid taxon A, and perhaps Rukwanyoka, could belong to such extinct group(s).

\section{BOOID TAXON B}

Figure 10D-F

Material. One anterior trunk vertebra (UM/HGL50-576) and perhaps two caudal vertebrae (UM/HGL50-577).

\section{Description}

The size of the anterior trunk vertebra is similar to that of booid A (centrum length $=2.3 \mathrm{~mm}$ ). As in the latter, the anterior face is damaged, but the left prezygapophysis is preserved. The vertebra is clearly wider than long, with a marked but not deep 
interzygapophyseal constriction. The neural spine is blade-like and short anteroposteriorly; its upper part is broken away and its height remains unknown. It was not comprised of two parts; it is relatively thick and there is no thinner anterior portion. The median notch in the posterior border of the neural arch is deeper than in booid A. The neural canal is wider and less tall than that of booid A. The neural arch is clearly vaulted ('arched' sensu Ikeda 2007). The zygapophyses are horizontal. The condyle is depressed. The basis of a broken off hypapophysis remains ventrally. Two caudal vertebrae are assigned to this taxon with reservation.

\section{Remarks}

Comparisons between booids taxon A and taxon B are not easy because they are represented by an anterior trunk (booid taxon B) and a mid- or posterior trunk (booid taxon A) vertebrae. The presence in booid taxon B of a hypapophysis, an anteroposteriorly shorter neural spine, a deeper median notch and of a more vaulted neural arch represents usual intracolumnar variation. However, the neural arch of the anterior vertebra (booid taxon B) is markedly vaulted, whereas that of the mid- or posterior vertebra (booid taxon A) is almost flat. This difference appears to exceed the variation occurring in a vertebral column; it likely reflects the presence of two distinct taxa. The horizontal extension of the zygapophyseal facets of booid taxon B, whereas those of booid taxon A are inclined, supports assignment to two distinct taxa.

In snakes, anterior trunk vertebrae rarely afford significant information from a taxonomic point of view. The vertebra assigned to booid taxon B shows booid features (see above), but no more precise referral may be suggested.

\section{BOOIDS INDETERMINATE}

Material. Four poorly preserved vertebrae (UM/HGL50-578).

\section{COLUBROIDEA Oppel, 1811}

As traditionally conceived, the Colubroidea have been the dominant group among snakes since the Early Miocene. Unfortunately, this long-standing taxonomic term was also recently applied to less inclusive clades and even to small groups (review in Zaher et al., 2009). Because of this state of confusion, Zaher et al. (2009) erected the name Colubroides to replace Colubroidea in its traditional meaning. However, Burbrink \& Crother (2011) conservatively retained the name Colubroidea in its classic meaning. As such, the taxon Colubroidea represents the sister group to the Acrochordoidea, both making up the Caenophidia, and it includes 'colubrids', elapids, viperids and various extinct taxa.
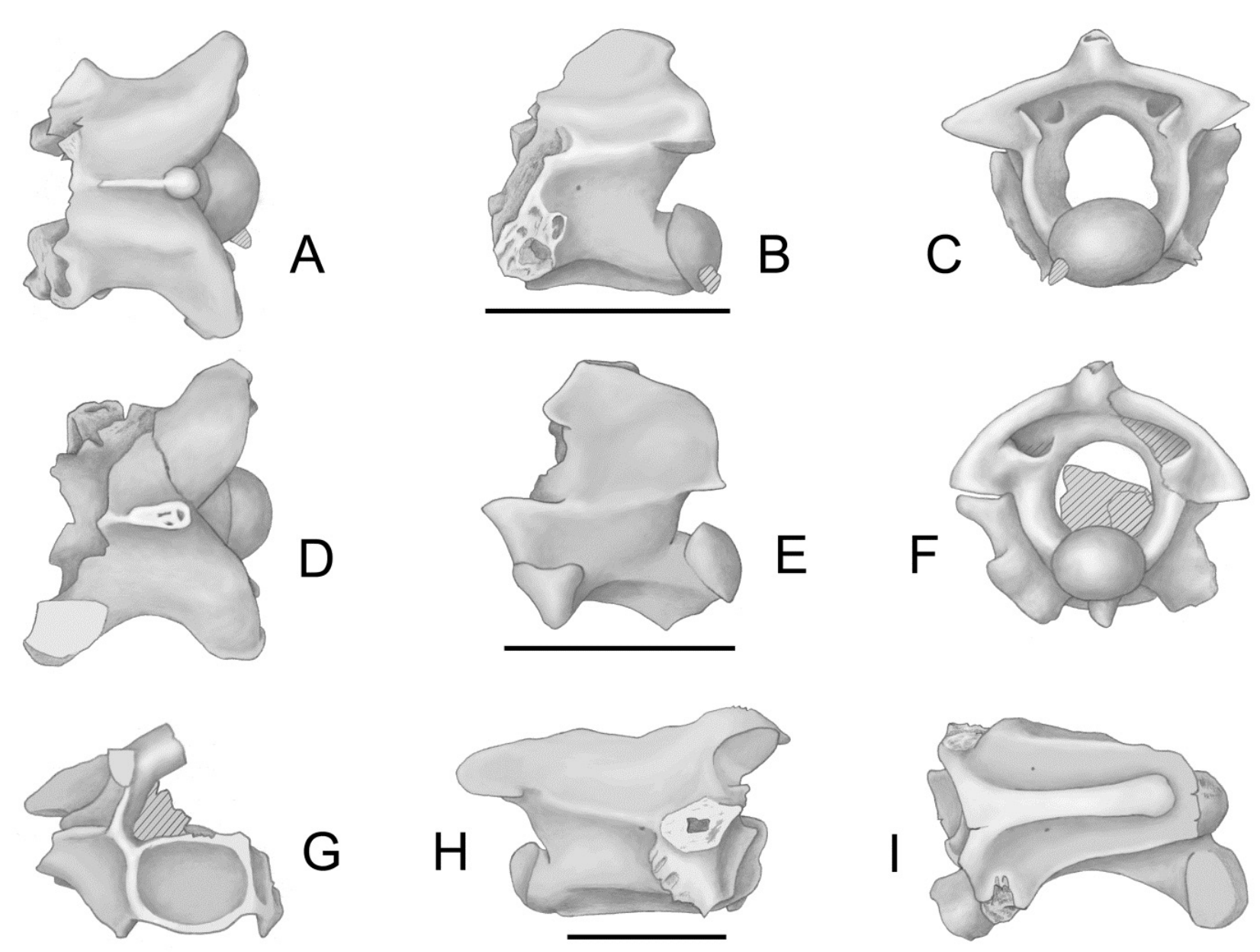

Figure 10. Booid-grade snakes. A-C, Booid taxon A, mid- or posterior trunk vertebra (UM/HGL50-575) in dorsal (A), left lateral (B), and posterior (C) views. D-F, Booid taxon B, anterior trunk vertebra (UM/HGL50-576) in dorsal (D), left lateral (E), and posterior (F) views. G-I, Colubroidea indeterminate, mid-trunk vertebra $(\mathrm{UM} / \mathrm{HGL50-579)}$ in anterior $(\mathbf{G})$, right lateral $(\mathbf{H})$, and ventral (I) views. Scale bars $=3 \mathrm{~mm}$. 


\section{FAMILY INDETERMINATE}

\section{GENUS AND SPECIES INDETERMINATE}

Figure 10G-I

Material. One incomplete mid-trunk vertebra (UM/HGL50579).

\section{Description}

The specimen is very incomplete, however it shows significant features. It comprises the centrum, the right lateral wall and postzygapophysis, parts of the neural arch, zygosphene, right prezygapophysis and paradiapophysis.

The centrum is $5 \mathrm{~mm}$ long. The vertebra is elongate and lightly built as shown by the moderate thickness of the lateral wall, neural arch and centrum. The centrum is elongate and narrow, well limited by marked subcentral ridges; the latter ridges are almost straight in both lateral and ventral aspects. The oblong/oblanceolate (sensu Auffenberg 1963) haemal keel is sharply marked off from the centrum. The ventral face of the centrum, on either side of the haemal keel, as well as the ventral surface of the keel are flat. The neural canal is comparatively broad; its width is similar to that of the cotyle. The zygapophyseal facet extends horizontally. The anterior face of the prezygapophysis does not form a marked paracotylar fossa. Unfortunately, the presence or absence of a paracotylar foramen cannot be determined. A small dot occurs on the area of the paracotylar foramen. This dot is not an orifice, but it may be a paracotylar foramen covered by a thin film of matrix. The zygosphene is slightly wider than the neural canal and it markedly projects anteriorly. Its roof was arched dorsally; in lateral view, it appears to be dome-shaped. The paradiapophysis is damaged but it is obvious that it clearly extended posteriorly, which appears to be a peculiar feature. The specimen preserves the ventral tips of both paradiapophyses; they project ventrally below the cotylar rim but there are no well-defined paracotylar notches.

\section{Remarks}

The light build and the elongation of the vertebra are characteristics of the Colubroidea. Unfortunately, the state of preservation of the specimen prevents reliable comparisons.

The earliest colubroids were reported from the Late Cretaceous of Wadi Abu Hashim (Rage \& Werner 1999), a Sudanese locality whose geological age is debated within the Late Cretaceous (see above). Such a geological age is consistent with the molecular estimate of Burbrink \& Pyron (2008). Colubroids diversified and geographically spread during the Eocene. Although not numerous, Eocene colubroids were recovered in Europe (Rage 1987), India (Rage et al., 2003, 2008), Southeastern Asia (Rage et al., 1992; Head et al., 2005), North America (Parmley \& Holman 2003; Smith 2013) and Africa (see below). They were also present in the Early Cainozoic of South America but their geological age, Palaeocene or Eocene, is uncertain (Rage 2008). Apart from the fossils from North America, which are Colubridae, these early colubroids likely do not belong to the crown-group; they were either referred to extinct families (Anomalophiidae, Russellophiidae; Rage 1984) or reported without family reference.

In Africa, Eocene colubroids were reported from only two localities in addition to HGL50: Silica North (if really Eocene) in Namibia (Rage et al., 2013) and Birket Qarun Locality 2 in Egypt (McCartney \& Seiffert 2016). Silica North was first considered as Lutetian in age (Pickford et al., 2008), but Pickford et al., (2014) subsequently assigned it to the Bartonian (but see Discussion below). The indeterminate colubroid from Silica North is represented by a single, incomplete vertebra that differs from the colubroid of HGL50 in having ventrolateral cotylar processes, a vaulted neural arch, and paradiapophyses without a posterior expansion (Rage et al., 2013). Birket Qarun loc. 2 is a younger locality; it is assigned to the earliest Priabonian, i.e. to the early Late Eocene (McCartney $\&$ Seiffert 2016). The locality produced two colubroids: an indeterminate russellophiid and a colubroid without family reference, Renenutet enmerwer McCartney \& Seiffert, 2016. McCartney \& Seiffert (2016) did not regard russellophiids as members of colubroids and they referred them as a taxon of uncertain relationships within caenophidians. However, we retain russellophiids in the colubroids because the only marked difference with the crown-group (i.e. the absence of prezygapophyseal processes) is plesiomorphic; russellophiids may be stem colubroids. The russellophiid from Egypt is known by a single vertebra that is distinguished from the colubroid of HGL50 by its markedly vaulted neural arch, its arched subcentral ridges, its shallower interzygapophyseal constriction, and by its posteriorly non-extending paradiapophyses. Renenutet bears some resemblance to the colubroid from HGL50. The two snakes have similar ventral faces of the centrum and their zygosphenes are both dorsally convex and anteriorly projecting (McCartney \& Seiffert 2016, fig. 7C). However, in Renenutet, this morphology of the zygosphene occurs only in posterior trunk vertebrae. Nevertheless, despite similarities, the vertebra from HGL50 clearly differs from Renenutet in lacking parazygosphenal foramina and in having posteriorly extended paradiapophyses. The association of the peculiar morphology of the zygosphene and posteriorly extended paradiapophysis in the colubroid from HGL50 appears to be unique, but no further comparison is possible.

\section{OPHIDIA INDETERMINATE}

Material. Five fragmentary trunk vertebrae (UM/HGL50-580) and four caudal vertebrae (UM/HGL50-581).

\section{DISCUSSION}

\section{Composition of the fauna and palaeobiogeographic aspects}

HGL50, Early-Middle Eocene of Algeria, is the richest amphibian and squamate-bearing locality from the period of geographic isolation of Africa, i.e. the period that extended from the early Late Cretaceous to the Early Miocene. It produced 17 to 20 taxa (Fig. 11). Amphibians include a possible salamander (caudate), a caecilian (gymnophionan) and three to six frogs (anurans), of which one is a new genus and species (Rocekophryne ornata). 'Lizards', i.e. non-ophidian squamates, comprise seven taxa, and snakes (ophidians) are represented by five taxa, one being a new genus and species (Afrotortrix draaensis).

The presence of a caudate, assuming the identification is accurate, was unexpected. In Africa, it is the only caudate 
recorded from the Campanian-Early Pleistocene (or PalaeoceneEarly Pleistocene if Wadi Abu Hashim is Maastrichtian in age). Both extinct and extant caudates occur mostly in Laurasian continents, which suggests that the representative from HGL50 is an immigrant from Eurasia. Trans-Tethyan interchanges took place between Eurasia and Africa during the Early Caenozoic (Gheerbrant \& Rage 2006; Chaimanee et al., 2012; Marivaux et al., 2013, 2014a, b, 2017), which is consistent with such a dispersal hypothesis. However, the possibility that this fossil evolved from caudates that were present earlier in Africa cannot be definitively rejected (Gardner \& Rage 2016).

The gymnophionan is one of the very rare fossils belonging to this group. Although it is the first gymnophionan reported from the Palaeogene of Africa, its presence in the Eocene of the continent does not raise problems.

The assemblage of anurans appears somewhat odd with regard to other African localities because pipids are scarce whereas ranoids are largely dominant. Pipids are obligate freshwater dwellers and, because of their ecological requirements, they are not present in all fossiliferous localities. However, where present, they are generally dominant (Roček \& Rage 2000). At HGL50, only two bones belong to pipids whereas more than 550 specimens are assigned to ranoids. Even if a large part of the specimens allocated to ranoids are only fragments of skull bones, this difference is highly significant but it cannot be explained. In Africa, pipids are West Gondwanan holdovers (Rage et al., 2013). By contrast, although already reported from the Eocene and even from the Late Cretaceous in Africa, ranoids are not West Gondwanan vicariants; they are perhaps autochthonous in Africa (Savage 1973; Feller \& Hedges 1998; Rage et al., 2013).

As far as lizards are concerned, the 'agamid' from HGL50 represents a landmark between the Cenomanian Jeddaherdan

\begin{tabular}{l}
\hline Lissamphibia \\
Gymnophiona indeterminate \\
? Caudata indeterminate \\
Anura \\
Pipidae indeterminate \\
Ranoidea \\
Rocekophryne ornata gen. et sp. nov. \\
Ranoidea indeterminate \\
Anura indeterminate \\
Squamata \\
Iguania \\
Acrodonta \\
'agamid' indeterminate \\
Gekkota \\
Gekkonidae s.l. indeterminate \\
Scincomorpha \\
Genus and species indeterminate A \\
Genus and species indeterminate B \\
Genus and species indeterminate C \\
Amphisbaenia indeterminate \\
? Varanoidea indeterminate \\
Serpentes \\
Scolecophidia indeterminate \\
Anilioid-grade snake \\
Afrotortrix draaensis gen. et sp. nov. \\
Booid-grade snake \\
Booid taxon A \\
Booid taxon B \\
Colubroidea indeterminate \\
\hline
\end{tabular}

Figure 11. List of taxa from HGL50. from Morocco (Apesteguía et al., 2016) and the diverse modern fauna of Africa. As pipids, this ante-Miocene 'agamid' appears to be a West Gondwanan vicariant. The varanoid is the earliest terrestrial representative of the group in Africa. Holmes et al. (2010a) and Smith et al. (2008) commented on possible exchanges of varanids between Asia and Africa during the Palaeogene. Unfortunately, the identification of the material from HGL50 is not sufficiently precise for contributing to this discussion. The gekkonid, scincomorphans and amphisbaenian rank among the oldest ones to be recorded in Africa, but are not the earliest. More precise indentifications cannot be reached and these three groups do not afford significant information.

All snakes from HGL50 belong to the crown-group, i.e. Serpentes. The locality lacks basal ophidians such as madtsoiids, which nevertheless occur elsewhere in the Eocene of Africa. Afrotortrix is the only confirmed snake of anilioid grade in Africa. It cannot be determined whether it is a West Gondwanan vicariant, an African autochthon, or if it entered Africa through a dispersal of unknown geographic origin. The colubroid is one of the rare representatives of this group in the Eocene worldwide. McCartney \& Seiffert (2016) noted that colubroids underwent a significant radiation in Gondwana, including Africa, before subsequent dominance in northern continents. Stressing the fact that colubroids were present in Africa during isolation of the continent, Rage et al. (2013) even suggested that colubroids might have originated in Africa. The presence of indeterminate scolecophidians and booids does not afford significant information. However, it should be noted that, contrary to what generally occurs worldwide in Eocene localities, booids represent only a small component of the snake assemblage.

In summary, the fauna from HGL50 includes West Gondwanan vicariants, possible African autochthons and likely immigrants.

\section{Palaeoenvironments}

The fauna includes an obligate aquatic, in freshwater, anuran (pipid) and a markedly terrestrial, fossorial snake (scolecophidian). In addition, the gymnophionan, amphisbaenian and Afrotortrix also were likely terrestrial. However, today some gymnophionan species live in freshwater, rare species of amphisbaenians do not avoid water, and anilioids may be found in water.

Ranoid frogs, other than Rocekophryne, may have been more or less strongly dependent on water and/or moisture, as is generally the case in this group. On the other hand, Rocekophryne is hyperossified, a skeletal characteristic that presumably results from arid or at least seasonally arid environment (Seibert et al., 1974; Trueb 1993). Such conflicting palaeoenvironmental inferences are also suggested by the 'agamid' and amphisbaenian, whose presence is generally consistent with aridity, whereas the gymnophionan and anilioid are indicative of vegetated, even forested areas. Unlike about half of Eocene localities in Africa, HGL50 lacks palaeophiid snakes. This absence may suggest that there was no nearby marine water.

Finally, the overall picture that emerges is confusing. The presence of permanent freshwater is demonstrated by the occurrence of pipid frogs and is confirmed by the charophytes and fishes recovered in the locality (Adaci et al., 2007; Mebrouk 2011). However, it is difficult to reconstruct the 
environments that were close to water. The gymnophionan, amphisbaenian, scolecophidian and anilioid require loose soils, which may occur in both arid and vegetated areas. However, it seems more possible that agamids and amphisbaenians lived in vegetated areas than gymnophionans and aniloids entered an arid zone; the occurrence of vegetated areas is supported by the presence of arboreal strepsirhine primates and anomaluroid rodents (Marivaux et al., 2011a, b). Taking into account only Rocekophryne, which is by far the most common taxon, leads also to puzzling inferences since this frog suggests both aquatic (or wet environment), but also at least temporary aridity. Most taxa suggest warm, perhaps even tropical temperatures.

Comparisons between HGL50 and other Palaeogene faunas in Africa

Apart from HGL50, only four Palaeogene localities produced diverse faunas of amphibians and/or squamates in Africa: Adrar Mgorn 1 (Late Palaeocene, Morocco), Silica North (? Middle Eocene, Namibia), Birket Qarun locality 2 (early Late Eocene, Egypt) and the Rukwa Basin (Songwe sub-basin, Late Oligocene, Tanzania).

Comparisons cannot be exhaustive and really reliable because all taxa were not studied in every locality. In addition, palaeoenvironmental and taphonomic biases affected the composition of faunas; for example, the proximity of marine water was likely not favourable to amphibians.

HGL50 is the earliest diverse assemblage of amphibians and squamates from the Eocene of Africa. Unfortunately, comparison with the Late Palaeocene fauna of Adrar Mgorn 1 , which is geographically close, is not clearly conclusive. The Thanetian beds of Adrar Mgorn 1 yielded a quite unbalanced fauna comprised of very rare anurans (only a pipid may be identified; Gardner \& Rage 2016) and diverse squamates (Augé $\&$ Rage 2006). Gheerbrant (1995) noted that the fauna is tilted to the side of small forms as a result of taphonomic size sorting. Moreover, fossils were deposited in marine water (Gheerbrant et al., 1993). Unlike HGL50, Adrar Mgorn 1 includes a madtsoiid (small sized), Coniophis (? anilioid) and Dunnophis (tropidophiid s.1.). The peculiar amphisbaenian Todrasaurus remains known only from Adrar Mgorn 1. Conversely, Adrar Mgorn 1 lacks ranoid frogs, gymnophionans and caudates, which occur at HGL50. A single taxon may be common to both localities: the scincomorphan 'genus and species indeterminate A' from HGL50 may belong to the same taxon as 'indeterminate lacertilian A' from Adrar Mgorn 1.

From a stratigraphical point of view, the absence of madtsoiids, Coniophis and Dunnophis at HGL50 is perhaps meaningless because these snakes may occur in localities younger than HGL50. Moreover, the absence of gymnophionans and caudates at Adrar Mgorn 1 cannot be taken into account because, as fossils, they are extremely rare worldwide (gymnophionans) or in Gondwanan continents (caudates). By contrast, the diversity of ranoids at HGL50 may be significant because their worldwide record suggests that their radiation did not take place before the Eocene; however, the role of marine influences at Adrar Mgorn 1 cannot be definitively discarded.

Silica North is younger (Bartonian after Pickford et al., 2014) than HGL50 and it is located in southern Africa (Namibia). However, it should be noted that the age of that locality was repeatedly questioned (Seiffert 2010; Coster et al., 2012; Marivaux et al., 2012, 2014a; Sallam \& Seiffert 2016).
Coster et al., (2012) and Sallam \& Seiffert (2016) suggested an Oligocene age, whereas Marivaux et al., (2014a) even advocated an Early Miocene age (the age of Silica South, the fauna of which is clearly less diverse, was questioned in the same way). Amphibian and squamate taxa from Silica North do not provide direct information on the geological age. However, it may be presumed that if the locality were Miocene, or even Oligocene in age, the assemblage of squamates would be more diverse (nevertheless, the possibility exists that the squamate record of Silica North is incomplete due to peculiar taphonomic conditions). The possibility that the Namibian deposits are 'multiphased' (Marivaux et al., 2012) deserves consideration. Silica North is characterized by the presence of permanent freshwater in a sub-humid to sub-arid general environment (Rage et al., 2013; Pickford et al., 2014). Silica North lacks several taxa that are present at HGL50: gymnophionans, caudates, acrodontans, gekkotans, varanoids, scolecophidians, anilioids, and booids. The composition of the anuran assemblage from both localities is similar at high taxonomic level. More specifically, ranoids are diverse (Rage et al., 2013). However, based on ilia, pipids and most ranoids from Silica North are different from those of HGL50. Only one ranoid may be common to both localities; the ilium from Silica North that is referred to as 'ranoid 1' is similar to the ilium assigned to Rocekophryne (Fig. 4I). However, these incomplete ilia do not permit to confirm the presence of Rocekophryne at Silica North. A colubroid vertebra is present in the two localities, but they are clearly different and they belong to distinct taxa. However, in any case, comparisons with Silica North cannot be conclusive as long as the question of the geological age of the locality remains unsettled.

The Late Eocene (Priabonian) of Birket Qarun locality 2 (hereafter BQ-2) corresponds to a freshwater, fluvial environment. No amphibians were reported from the locality; apparently, this does not result from an absence of study because Holmes et al., (2010a) did not report amphibians in the faunal list of the Birket Qarun Formation. This may result from the marine influences that affected the Late Eocene of the region. Lizards are scarce at BQ-2 and, among them, only a varanid was studied (Holmes et al., 2010a). As stated above, it is different from that of HGL50. Several snake taxa reported from BQ-2 by McCartney \& Seiffert (2016) are lacking from HGL50: a madtsoiid (Gigantophis garstini Andrews, 1901), a palaeophiid (Pterosphenus schweinfurthi (Andrews, 1901)), a tropidophiid s.s., and a russellophiid. Palaeophiid snakes were primarily marine (Rage et al., 2003) and the presence of Pterosphenus at BQ-2 is likely connected to the importance of marine influences in the area. The absence of scolecophidians at BQ-2 is probably not significant but the absence of an anilioid, as is the case at Silica North, may have a stratigraphical meaning: there is no anilioid snake in Africa after HGL50. Taxa common to BQ-2 and HGL50 are indeterminate booids and colubroids. Booids are frequent in the Eocene, worldwide, and their presence in both localities does not deserve peculiar comments. On the other hand, the presence of two colubroids (including russellophiids) at BQ-2 shows that this group of advanced snakes occurs in the three faunas of snakes known from the Eocene of Africa, i.e. HGL50, Silica North (if really Eocene) and BQ-2. Colubroids from BQ-2 differ from those of HGL50; there is no russellophiid at HGL50 and the colubroid of the latter locality is clearly distinct from Renenutet that occurs at BQ-2.

To sum up, differences between the three Eocene faunas of Africa appear as the result of possible stratigraphical, 
environmental and geographical factors. The environment seemingly played a critical role in generating differences.

An important step towards modernization occurs between the Eocene faunas and the only known Oligocene assemblage in Africa, i.e. the fauna from the Chattian of the Rukwa Basin (Tanzania). The latter fauna was incompletely studied but Blackburn et al. (2015) identified Ptychadenidae among anurans and McCartney et al. (2014) showed that the snake assemblage was dominated by colubroids. Ptychadenidae is an extant family of frogs and domination of colubroids did not begin before the Miocene in Europe and North America. Despite similarity between 'booid taxon A' from HGL50 and Rukwanyoka holmani from the Late Oligocene of the Rukwa Basin, the two faunas are clearly distinct from one another; the overall composition of the fauna from HGL50 is consistent with those of the Eocene, whatever the continent, while what is known from the Late Oligocene of Tanzania heralds modern, Neogene faunas.

\section{CONCLUSION}

The fauna from the latest Early-early Middle Eocene of HGL50 is one of the rare assemblages including amphibians and squamates from the period of geographic isolation of Africa. In addition, this is the richest and most diverse fauna of amphibians and squamates from the Palaeogene of Africa; it includes at least 17 taxa. The fauna comprises Gondwanan, and more specifically West Gondwanan vicariants (pipids and 'agamids'), likely autochthonous forms (ranoids and colubroids) and a Eurasian immigrant (likely a caudate). An anuran and a snake represent new taxa.

The locality produced the first gymnophionan from the Palaeogene of Africa. The caudate, assuming the identification is right, represents the only report of the group from the African Palaeogene; moreover, taking into account the fact that the single report of a caudate from the African Neogene is likely erroneous, the caudate of HGL50 would be the only record from the Tertiary of Africa. The presence of a caudate in the Eocene of Africa would represent an immigration from Eurasia; unfortunately, the identification cannot be definitively confirmed on the basis of the available material. Finally, the anilioid snake is the only confirmed representative of the group from Africa.

About the palaeoenvironment, it may be only stated that permanent freshwater was present at HGL50. Reconstruction of the environment of the zone close to water is rendered difficult because of the presence of both animals living in vegetated or arid areas. Temperature was likely warm, perhaps tropical.

The assemblage from HGL50 clearly differs from faunas of the few other Eocene localities in Africa. This certainly reflects distinct stratigraphic positions, but also differences in geographic locations and mainly in environments.

Acknowledgements: Jean-Claude Rage, who initiated and wrote most part of this monograph, sadly suddenly passed away after submission of our manuscript. RT and LM dedicates posthumously this paper to the honour and memory of JeanClaude. The Vice-Chancellor of the University of Tlemcen (Algeria) and the authorities of the Bechar and Tindouf districts facilitated field expeditions to the Gour Lazib area from 2004 to 2011; we are very grateful to many colleagues for their help during fieldtrips. We are also grateful to M. Augé, D. Nolf,
R.L. Nydam, O. Otero, and Z. Roček, who provided significant information. Photographs were taken by L. Cazes. We finally thank A. L. Charruault for her efficient technical assistance (acid etching of the fossiliferous limestone and extraction of the fossils). This research was supported by the French ANRERC PALASIAFRICA Program (ANR-08-JCJC-0017) and a grant from the Conseil Scientifique (CS) of the Université de Montpellier (UM). M. Venczel and an anonymous reviewer provided constructive comments.

\section{BIBLIOGRAPHY}

Adaci, M., Bensalah, M., Tabuce, R., Mebrouk, F., Marivaux, L., Otero, O., Zaoui, D., Benyoucef, M., Mahboubi, M., 2016. L'Éocène continental du Complexe de Gour Lazib (Sahara nord-occidental, Algérie). Mémoires du Service Géologique de l'Algérie, 19, 63-89.

Adaci, M., Tabuce, R., Mebrouk, F., Bensalah, M., Fabre, P.-H., Hautier, L., Jaeger, J.-J., Lazzari, V., Mahboubi, M., Marivaux, L., Otero, O., PeignÉ, S., Tong, H., 2007. Nouveaux sites à vertébrés paléogènes dans la région des Gour Lazib (Sahara nord-occidental, Algérie). Comptes Rendus Palevol, 6, 535544. https://doi.org/10.1016/j.crpv.2007.09.001

Agnolin, F., 2012. A new Calyptocephalellidae (Anura, Neobatrachia) from the Upper Cretaceous of Patagonia, Argentina, with comments on its systematic position. Studia Geologica Salmanticensia, 48, 129-178.

Andrews, C. W., 1901. Preliminary notes on some recently discovered extinct vertebrates from Egypt (Part II). Geological Magazine, 8, 434-444. https://doi.org/10.1017/S0016756800179750

Andrews, P., Meyer, G. E., Pilbeam, D. R., Van Couvering, J. A., Van Couvering, J. A. H., 1981. The Miocene fossil beds of Maboko Island, Kenya: geology, age, taphonomy and palaeontology. Journal of Human Evolution, 10, 35-48. https://doi.org/10.1016/S0047-2484(81)80024-3

Antunes, M. T., 1964. O Neocretácico e o Cenozóico do litoral de Angola. Junta de Investigações do Ultramar, Lisbon, 259 pp.

Apesteguía, S., Daza, J. D., Simões, T. R., Rage, J.-C., 2016. The first iguanian lizard from the Mesozoic of Africa. Royal Society Open Science, 3, e160462. https://doi.org/10.1098/ rsos. 160462

Archer, M., Arena, D. A., Bassarova, M., Beck, R. M. D., Black, K., Boles, W. E., Brewer, P., Cooke, B. N., Crosby, K., Gillespie, A., Godthelp, H., Hand, S. J., Kear, B. P., Louys, J., Morrell, A., Muirhead, J., Roberts, K. K., Scanlon, J. D., Travouillon, K. J., Wroe, S., 2006. Current status of specieslevel representation in faunas from selected fossil localities in the Riversleigh World Heritage Area, northwestern Queensland. Alcheringa Special Issue, 1, 1-17. https://doi. org/10.1080/03115510608619570

Armstrong-Ziegler, J. G., 1978. An aniliid snake and associated vertebrates from the Campanian of New Mexico. Journal of Paleontology, 52, 480-483.

Arnold, E. N., Poinar, G., 2008. A 100 million year old gecko with sophisticated adhesive toe pads, reserved in amber from Myanmar. Zootaxa, 1847, 62-68. https://doi.org/10.11646/ zootaxa.1847.1.5

Auffenberg, W., 1963. The fossil snakes of Florida. Tulane Studies in Zoology, 10, 131-216. https://doi.org/10.5962/bhl.part.4641

Augé, M., 2005. Évolution des lézards du Paléogène en Europe. Mémoires du Muséum national d'Histoire naturelle, 192, 5-369.

Augé, M., 2012. Amphisbaenians from the European Eocene: a biogeographical review. In: Lehmann, T. and Schaal, S. F. K. (Eds). Messel and the terrestrial Eocene - Proceedings of the $22^{\text {nd }}$ Senckenberg Conference. Palaeobiodiversity and Palaeoenvironments, 92, 425-443. https://doi.org/10.1007/ s12549-012-0104-6

Augé, M., Rage, J.-C., 2006. Herpetofaunas from the Upper Paleocene 
and Lower Eocene of Morocco. Annales de Paléontologie, 92, 235-253. https://doi.org/10.1016/j.annpal.2005.09.001

Averianov, A., Danilov, I., 1996. Agamid lizards (Reptilia, Sauria, Agamidae) from the Early Eocene of Kyrgyzstan. Neues Jahrbuch für Geologie und Paläontologie, Monatshefte, 12, 739-750. https://doi.org/10.1127/njgpm/1996/1996/739

Averianov, A., Martin, T., Skutchas, P. P., Rezvyi, A. S., Bakirov, A. A., 2008. Amphibians from the middle Jurassic Balabansai Svita in the Fergana Depression, Kyrgyzstan (Central Asia). Palaeontology, 51, 471-485. https://doi.org/10.1111/j.14754983.2007.00748.x

Báez, A. M., Harrison, T., 2005. A new pipine frog from an Eocene crater lake in North-Central Tanzania. Palaeontology, 48, 723737. https://doi.org/10.1111/j.1475-4983.2005.00477.x

Báez, A. M., Gómez, R., 2014. Is hyperossification concealing the phylogenetic signal of osteological traits in anurans? A testcase from the Upper Cretaceous of Brazil. In: Maxwell, E. and Miller-Camp, J. (Eds). 74th Meeting of Society of Vertebrate Paleontology, Abstract Book. Estrel, Berlin, p. 83.

Báez, A. M., Muzzopappa, P., Nicoli, L., 2007. Anurans from the Candeleros Formation (?Cenomanian-Turonian) of westcentral Argentina: new evidence for pipoid evolution. Cretaceous Research, 28, 1005-1016. https://doi.org/10.1016/j. cretres.2007.01.004

Báez, A. M., Moura, G. J. B., Gómez, R. O., 2009. Anurans from the Lower Cretaceous Crato Formation of northeastern Brazil: implications for the early divergence of neobatrachians. Cretaceous Research, 30, 829-846. https://doi.org/10.1016/j. cretres.2009.01.002

Bailon, S., 1988. Un Aniliidé (Reptilia, Serpentes) dans le Pliocène supérieur européen. Comptes Rendus de l'Académie des Sciences de Paris, 306 II, 1255-1258.

Bailon, S., Rage, J.-C., Stoetzel, E., 2011. First fossil representative of the salamander crown-group from a Gondwanan continent: Pleurodeles cf. waltl from the Quaternary of Morocco. Amphibia-Reptilia, 32, 245-252. https://doi. org/10.1163/017353711X565501

Blackburn, D. C., Roberts, E. M., Stevens, N. J., 2015. The earliest record of the endemic African frog family Ptychadenidae from the Oligocene Nsungwe Formation of Tanzania. Journal of Vertebrate Paleontology, 35, e907174. https://doi.org/10.108 $\underline{0 / 02724634.2014 .907174}$

Blain, H.-A., Canudo, J.-I., Cuenca-Bescós, G., López-Martínez, N., 2010. Amphibians and squamate reptiles from the latest Maastrichtian (Upper Cretaceous) of Blasi 2 (Huesca, Spain). Cretaceous Research, 31, 433-446. https://doi.org/10.1016/j. cretres.2010.06.001

Bogert, C. M., 1968. New genus and species of dwarf boa from Southern Mexico. American Museum Novitates, 2354, 24-35.

Böhme, M., 2010. Ectothermic vertebrates (Actinopterygii, Allocaudata, Urodela, Anura, Crocodylia, Squamata) from the Miocene of Sandelzhausen (Germany, Bavaria) and their implications for environment reconstruction and palaeoclimate. Palaeontologische Zeitschrift, 84, 3-41. https:// doi.org/10.1007/s12542-010-0050-4

Burbrink, F. T., Pyron, R. A., 2008. The taming of the skew: Estimating proper confidence intervals for divergence dates. Systematic Biology, 57, 317-328. https://doi. org/10.1080/10635150802040605

Burbrink, F. T., Crother, B. I., 2011. Evolution and taxonomy of snakes. In: Aldridge, R. D. and Sever, D. M. (Eds). Reproductive biology and phylogeny of snakes, 9. CRC Press, Boca Raton, 19-53. https://doi.org/10.1201/b10879-3

Caldwell, M. W., Lee, M. S. Y., 1997. A snake with legs from the marine Cretaceous of the Middle East. Nature, 386, 705-709. https://doi.org/10.1038/386705a0

Cavin, L., Tong, H., Boudad, L., Meister, C., Piuz, A., Tabouelle, J., Aarab, M., Amiot, R., Buffetaut, E., Dyke, G., Hua, S., Le Loeuff, J., 2010. Vertebrate assemblages from the early Late Cretaceous of southeastern Morocco: An overview. Journal of African Earth Sciences, 57, 391-412. https://doi.org/10.1016/j. jafrearsci.2009.12.007

Čerňanský, A., 2010. A revision of chamaeleonids from the Lower Miocene of the Czech Republic with description of a new species of Chamaeleo (Squamata, Chamaeleonidae). Geobios, 43, 605-603. https://doi.org/10.1016/j.geobios.2010.04.001

Chaimanee, Y., Chavasseau, O., Beard, K. C., Kyaw, A. A., Soe, A. N., Sein, C., Lazzari, V., Marivaux, L., Marandat, B., Swe, M., Rugbumrung, M., Lwin, T., Valentin, X., Thein, Z. M. M., Jaeger, J.-J., 2012. A new middle Eocene primate from Myanmar and the initial anthropoid colonization of Africa. Proceedings of the National Academy of Science, 109, 10293-10297. https://doi.org/10.1073/pnas.1200644109

Coiffait, P.-E., Coiffait, B., Jaeger, J.-J., Mahboubi, M., 1984. Un nouveau gisement à Mammifères fossiles d'âge Éocène supérieur sur le versant sud des Nementcha (Algérie orientale): découverte des plus anciens Rongeurs d'Afrique. Comptes Rendus de l'Académie des Sciences, Paris, 299 II, 893-898.

Conrad, J. L., 2006. Postcranial skeleton of Shinisaurus crocodilurus (Squamata: Anguimorpha). Journal of Morphology, 267, 759775. https://doi.org/10.1002/jmor.10291

Conrad, J. L., 2008. Phylogeny and systematics of Squamata (Reptilia) based on morphology. Bulletin of the American Museum of Natural History, 310, 1-182. https://doi.org/10.1206/310.1

Conrad, J. L., Ast, J. C., Montanari, S., Norell, M. A., 2011. A combined evidence phylogenetic analysis of Anguimorpha (Reptilia: Squamata). Cladistics, 27, 230-277. https://doi. org/10.1111/j.1096-0031.2010.00330.x

Coster, P., Benammi, M., Mahboubi, M., Tabuce, R., Adaci, M., Marivaux, L., Bensalah, M., Mahboubi, S., Mahboubi, A., Mebrouk, F., Maameri, C., Jaeger, J.-J., 2012. Chronology of the Eocene continental deposits of Africa: Magnetostratigraphy and biostratigraphy of the El Kohol and Glib Zegdou Formations, Algeria. Geological Society of America Bulletin, 124, 1590-1606. https://doi.org/10.1130/B30565.1

Cundall, D., Wallach, V., Rossman, D. A., 1993. The systematic relationships of the snake genus Anomochilus. Zoological Journal of the Linnean Society, 109, 275-299. https://doi. org/10.1111/j.1096-3642.1993.tb02536.x

Daza, J. D, Bauer, A. M., Snively, E. D., 2014. On the fossil record of the Gekkota. In: Daza, J. D. and Miller, S. C. (Eds). New advances in morphology and evolution of living and extinct Squamates. The Anatomical Record, 297, 433-462. https:// doi.org/10.1002/ar.22856

De Bast, E., Smith, T., 2013. Reassessment of the small 'arctocyonid' Prolatidens waudruae from the early Paleocene of Belgium, and its phylogenetic relationships with ungulate-like mammals. Journal of Vertebrate Paleontology, 33, 964-976. https://doi.org/10.1080/02724634.2013.747531

De Bast, E., Smith, T., 2017. The oldest Cenozoic mammal fauna of Europe: implication of the Hainin reference fauna for mammalian evolution and dispersals during the Palaeocene. Journal of Systematic Palaeontology, 15, 741-785. https://doi. org $/ 10.1080 / 14772019.2016 .1237582$

Dong, L. P., Evans, S. E., Wang, Y., 2016. Taxonomic revision of lizards from the Paleocene deposits of the Qianshan Basin, Anhui, China. Vertebrata PalAsiatica, 54, 243-268.

Eisawi, A. A. M., 2015. Palynological Evidence of a CampanianMaastrichtian Age of the Shendi Formation (Shendi Basin, Central Sudan). American Journal of Earth Sciences, 2, 206210.

Estes, R., Wake, M. H., 1972. The first fossil record of caecilian amphibians. Nature, 239, 228-231. https://doi. org/10.1038/239228b0

Estes, R., Queiroz, K. de, Gauthier, J., 1988. Phylogenetic relationships within Squamata. In: Estes, R. and Pregill, G. (Eds). Phylogenetic Relationships of the Lizard Families. Stanford University Press, Stanford, 119-281.

Evans, S. E., 2003. At the feet of the dinosaurs: the early history and radiation of lizards. Biological Review, 78, 513-551. https:// doi.org/10.1017/S1464793103006134

Evans, S. E., Milner, A. R., 1994. Middle Jurassic microvertebrate 
assemblages from the British Isles. In: Fraser, N. C. and Sues, H.-D. (Eds). In the Shadow of the Dinosaurs: Early Mesozoic Tetrapods. Cambridge University Press, Cambridge, 303-321.

Evans, S. E., Sigogneau-Russell, D., 2001. A stem-group caecilian (Lissamphibia: Gymnophiona) from the Lower Cretaceous of North Africa. Palaeontology, 44, 259-373. https://doi. org/10.1111/1475-4983.00179

Evans, S. E., Milner, A. R., Mussett, F., 1988. The earliest known salamanders (Amphibia, Caudata): a record from the middle Jurassic of England. Geobios, 21, 539-552. https://doi. org/10.1016/S0016-6995(88)80069-X

Evans, S. E., Milner, A.R., Werner, C., 1996. Sirenid Salamanders and a Gymnophionan amphibian from the Cretaceous of Sudan. Palaeontology, 39, 77-95.

Evans, S. E., Prasad, G. V. R., Manhas. B. K., 2002. Fossil lizards from the Jurassic Kota Formation of India. Journal of Vertebrate Paleontology, 22, 299-312. https://doi.org/10.1671/02724634(2002)022[0299:FLFTJK]2.0.CO;2

Evans, S. E., Jones, M. E. H., Krause, D. W., 2008. A giant frog with South American affinities from the Late Cretaceous of Madagascar. Proceedings of the National Academy of Sciences, 105, 2951-2956. https://doi.org/10.1073/ pnas. 0707599105

Evans, S. E., Groenke, J. R., Jones, M. E. H., Turner, A. H., Krause, D. W., 2014. New material of Beelzebufo, a hyperossified frog (Amphibia: Anura) from the Late Cretaceous of Madagascar. PLoS ONE, 9, e87236. https://doi.org/10.1371/journal. pone. 0087236

Fabrezi, M., 2006. Morphological evolution of Ceratophryinae (Anura, Neobatrachia). Journal of Zoological Systematics and Evolutionary Research, 44, 153-166. https://doi.org/10.1111/ j.1439-0469.2005.00349.x

Fabrezi, M., Barg, M., 2001. Patterns of carpal development among anuran amphibians. Journal of Morphology, 249, 210-220. https://doi.org/10.1002/jmor.1050

Feller, A. E., Hedges, S. B., 1998. Molecular evidence for the early history of living amphibians. Molecular Phylogenetics and Evolution, 9, 509-516. https://doi.org/10.1006/ mpev. 1998.0500

Folie, A., 2006. Evolution des amphibiens et squamates de la transition Crétacé-Paléogène en Europe: les faunes du Maastrichtien du Bassin de Hateg (Roumanie) et du Paléocène du Bassin de Mons (Belgique). Unpublished $\mathrm{PhD}$ thesis, Université libre de Bruxelles, 274 pp.

Folie, A., Smith, R., Smith, T., 2013. New amphisbaenian lizards from the Early Paleogene of Europe and their implications for the early evolution of modern amphisbaenians. Geologica Belgica, 16, 227-235.

Frost, D., Grant, T., Faivovich, J., Bain, R. H., Haas, A., Haddad, C. F. B., Sá, R. O. DE, Channing, A., Wilkinson, M., Donnellan, S. C., Raxworthy, C. J., Campbell, J. A., Blotto, B. L., Moler, P., Drewes, R. C., Nussbaum, R. A., Lynch, J. D., Green, D. M., Wheeler, W. C., 2006. The amphibian tree of life. Bulletin of the American Museum of Natural History, 297, 1-370. https://doi.org/10.1206/0003-0090(2006)297[0001:TATOL]2 $.0 . \mathrm{CO} ; 2$

Gao, K., Hou, L., 1995. Iguanians from the Upper Cretaceous Djadochta Formation, Gobi desert, China. Journal of Vertebrate Paleontology, 15, 57-78. https://doi.org/10.1080/0 2724634.1995.10011207

Gao, K., Fox, R. C., 1996. Taxonomy and evolution of late Cretaceous lizards (Reptilia: Squamata) from Western Canada. Bulletin of Carnegie Museum of Natural History, 33, 1-107.

Gardner, J. D., 2008. New information on frogs (Lissamphibia: Anura) from the Lance Fomation (Late Maastrichtian) and Bug Creek Anthills (Late Maastrichtian and Early Paleocene), Hell Creek Formation, USA. In: Sankey, J. T. and Baszio, S. (Eds). Vertebrate Microfossil Assemblages. Indiana University Press, Bloomington and Indianapolis, 219-249.

Gardner, J. D., Brinkman, D. B., 2015. A new frog (Lissamphibia, Anura) from the Late Cretaceous of Alberta, Canada. In:
Bininda-Emonds, O. R. P., Powell, G. L., Jamniczky, H. A., Bauer, A. M. and Theodor, J. (Eds). All Animals are Interesting. A Festschrift in Honour of Anthony P. Russell. BIS-Verlag der Carl von Ossietzky Universität, Oldenburg, 35-105.

Gardner, J. D., Rage, J. C., 2016. The fossil record of lissamphibians from Africa, Madagascar, and the Arabian Plate. In: Gardner, J. D. and Přikryl, T. (Eds). Contributions in Honour of Zbyněk Roček. Palaeobiodiversity and Palaeoenvironments, 96, 169220. https://doi.org/10.1007/s12549-015-0221-0

Gauthier, J. A., Kearney, M., Maisano, J. A., Rieppel, O., Behlke, A. D. B., 2012. Assembling the squamate tree of life: Perspectives from the phenotype and the fossil record. Bulletin of the Peabody Museum of Natural History, 53, 3-308. https://doi. org/10.3374/014.053.0101

Gheerbrant, E., 1995. Les mammifères paléocènes du Bassin d'Ouarzazate (Maroc). III. Adapisoriculidae et autres mammifères (Carnivora, ?Creodonta, Condylarthra, ?Ungulata et incertae sedis). Palaeontographica A, 237, 39-132.

Gheerbrant, E., Rage, J. C. 2006. Paleobiogeography of Africa: How distinct from Gondwana and Laurasia? Palaeogeography, Palaeoclimatology, Palaeoecology, 241, 224-246. https://doi. org/10.1016/j.palaeo.2006.03.016

Gheerbrant, E., Cappetta, H., Feist, M., Jaeger, J.-J., Sudre, J., Vianey-Liaud, M., Sigé, B., 1993. La succession des faunes de vertébrés d'âge paléocène supérieur et éocènes inférieur dans le bassin d'Ouarzazate, Maroc. Contexte géologique, portée biostratigraphique et paléogéographique. Newsletters on Stratigraphy, 28, 33-58. https://doi.org/10.1127/ nos/28/1993/33

Gómez, R. O., BÁez, A. M., Rougier, G. W., 2008. An anilioid snake from the Upper Cretaceous of northern Patagonia. Cretaceous Research, 29, 481-488. https://doi.org/10.1016/j. cretres.2008.01.002

Haddoumi, H., Allain, R., Meslouh, S., Métais, G., Monbaron, M., Pons, D., Rage, J.-C., Vullo, R., Zouhri, S., Gheerbrant, E., 2016. Guelb el Ahmar (Bathonian, Anoual Syncline, eastern Morocco): First continental flora and fauna including mammals from the Middle Jurassic of Africa. Gondwana Research, 29, 290-319. https://doi.org/10.1016/j.gr.2014.12.004

Head, J. J., Holroyd, P. A., Hutchison, J. H., Ciochon, R. L., 2005. First report of snakes (Serpentes) from the Late Middle Eocene Pondaung Formation, Myanmar. Journal of Vertebrate Paleontology, 25, 246-250. https://doi.org/10.1671/02724634(2005)025[0246:FROSSF]2.0.CO;2

Hecht, M. K., 1959. Amphibians and Reptiles. In: McGrew, P. O. (Ed). The geology and paleontology of the Elk Mountain and Tabernacle Butte area, Wyoming. Bulletin of the American Museum of Natural History, 117, 130-146.

Hoffstetter, R., 1961. Nouvelles récoltes de serpents fossiles dans l'Eocène supérieur du désert libyque. Bulletin du Muséum National d'Histoire Naturelle, 33, 326-331.

Hoffstetter, R., Rage, J. C., 1977. Le gisement de vertébrés miocènes de La Venta (Colombie) et sa faune de serpents. Annales de Paléontologie, 63, 161-190.

Holman, J. A., 2000. Fossil snakes of North America. Indiana University Press, Bloomington and Indianapolis, $357 \mathrm{pp}$.

Holman, J. A., Harrison, D. L., 2002. A new Thaumastosaurus (Anura: Familia incertae sedis) from the Late Eocene of England, with remarks on the taxonomic and zoogeographic relationships of the genus. Journal of Herpetology, 36, 621-626. https://doi. org/10.1670/0022-1511(2002)036[0621:ANTAFI]2.0.CO;2

Holman, J. A., Harrison, D. L., 2003. A new helmeted frog of the genus Thaumastosaurus from the Eocene of England. Acta Palaeontologica Polonica, 48, 157-160.

Holmes, R. B., Murray, A. M., Attia, Y. S., Simons, E. L., Chatrath, P., 2010a. Oldest known Varanus (Squamata: Varanidae) from the upper Eocene and lower Oligocene of Egypt: support for an African origin of the genus. Palaeontology, 53, 1099-1110. https://doi.org/10.1111/j.1475-4983.2010.00994.x

Holmes, R. B., Murray, A. M., Chatrath, P., Attia, Y. S., Simons, E. L., 
2010b. Agamid lizard (Agamidae: Uromastycinae) from the lower Oligocene of Egypt. Historical Biology, 22, 215-223. https://doi.org/10.1080/08912960903302128

Hossini, S., Rage, J. C., 2000. Palaeobatrachid frogs from the earliest Miocene (Agenian) of France, with description of a new species. Geobios, 33, 223-231. https://doi.org/10.1016/S00166995(00)80019-4

Houssaye, A., Rage, J.-C., Bardet, N., Vincent, P., Amaghzaz, M., Meslouh, S., 2013. New highlights about the enigmatic marine snake Palaeophis maghrebianus (Palaeophiidae; Palaeophiinae) from the Ypresian (Lower Eocene) Phosphates of Morocco. Palaeontology, 56, 647-661. https://doi. org $/ 10.1111 /$ pala. 12008

Hsiou, A. S., Albino, A. M., Ferigolo, J., 2010. Reappraisal of the South American Miocene snakes of the genus Colombophis, with description of a new species. Acta Palaeontologica Polonica, 55, 365-379. https://doi.org/10.4202/app.2009.1111

Ikeda, T., 2007. A comparative morphological study of the vertebrae of snakes occurring in Japan and adjacent regions. Current Herpetology, 26, 13-34. https://doi.org/10.3105/13455834(2007)26[13:ACMSOT]2.0.CO;2

Jenkins, F. A., Walsh, D. M., 1993. An Early Jurassic caecilian with limbs. Nature, 365, 246-249. https://doi.org/10.1038/365246a0

Jones, M. E., Anderson, C. L., Hipsley, C. A., Müller, J., Evans, S. E., Schoch, R. R., 2013. Integration of molecules and new fossils supports a Triassic origin for Lepidosauria (lizards, snakes, and tuatara). BMC Evolutionary Biology, 13, 208. https://doi. org/10.1186/1471-2148-13-208

Kearney, M., 2003. Systematics of the Amphisbaenia (Lepidosauria: Squamata) based on morphological evidence from recent and fossil forms. Herpetological Monographs, 17, 1-74. https:// doi.org/10.1655/0733-1347(2003)017[0001:SOTALB]2.0. $\mathrm{CO} ; 2$

Klein, N., Bussert, R., Evans, D., Salih, K. A. O., Eisawi, A. A. M., Nafi, M., Müller, J., 2016. Turtle remains from the Wadi Milk Formation (Upper Cretaceous) of Northern Sudan. Palaeobiodiversity and Palaeoenvironments, 96, 281-303. https://doi.org/10.1007/s12549-015-0225-9

Kosma, R., 2004. The dentitions of recent and fossil scinmorphan lizards (Lacertilia, Squamata). Systematics, functional morphology, Palecology. Unpublished $\mathrm{PhD}$ thesis, Universität Hannover, 187 pp.

LaDuke, T. C., 1991. The fossil snakes of Pit 91, Rancho La Brea, California. Contributions in Science, Natural History Museum of Los Angeles County, 424, 2-28.

Laloy, F., Rage, J. C., Evans, S. E., Boistel, R., Lenoir, N., Laurin, M., 2013. A re-Interpretation of the Eocene anuran Thaumastosaurus based on microCT examination of a 'mummified' specimen. PLoS ONE, 8, e74874. https://doi. org/10.1371/journal.pone.0074874

Lartet, E., 1851. Notice sur la colline de Sansan. J.A. Portes, Auch, $45 \mathrm{pp}$

Lee, M. S. Y., Scanlon, J. D., 2002. Snake phylogeny based on osteology, soft anatomy and ecology. Biological Review, 77, 333-401. https://doi.org/10.1017/S1464793102005924

Lehr, E., Trueb, L., 2007. Diversity among New World microhylid frogs (Anura: Microhylidae): morphological and osteological comparisons between Nelsonophryne (Günther 1901) and a new genus from Peru. Zoological Journal of the Linnean Society, 149, 583-609. https://doi.org/10.1111/j.10963642.2007.00270.x

Longrich, N. R., Bhullar, B.-A. S., Gauthier, J. A., 2012. A transitional snake from the Late Cretaceous period of North America. Nature, 488, 205-208.

Longrich, N. R., Vinther, J., Pyron, R. A., Pisani, D., Gauthier, J. A., 2015. Biogeography of worm lizards (Amphisbaenia) driven by end-Cretaceous mass extinction. Proceedings of the Royal Society B, 282, 20143034. https://doi.org/10.1098/ rspb.2014.3034

Macey, J. R., Shulte, J. A. II, Larson, A., Ananjeva, N. B., Wang, Y., Pethiyagoda, R., Rastegar-Pouyani, N., Papenfuss, T. J., 2000.
Evaluating trans-Tethys migration: an example using acrodont lizard phylogenetics. Systematic Biology, 49, 233-256. https:// doi.org/10.1093/sysbio/49.2.233

Mahboubi, M., 1995. Etude géologique et paléontologique des formations continentales paléocènes et éocènes d'Algérie. Unpublished $\mathrm{PhD}$ thesis, Université d'Oran, $169 \mathrm{pp}$.

Mahboubi, M., Ameur, R., Crochet, J.-Y., Jaeger, J.-J., 1986. El Kohol (Saharan Atlas, Algeria): A new Eocene mammal locality in North Western Africa. Palaeontographica A, 192, 15-49.

Marivaux, L., Lihoreau, F., Manthi, F. K., Ducrocq, S., 2012. A new basal phiomorph (Rodentia, Hystricognathi) from the late Oligocene of Lokone (Turkana Basin, Kenya). Journal of Vertebrate Paleontology, 32, 646-657. https://doi.org/10.1080 /02724634.2012.657318

Marivaux, L., Adnet, S., Benammi, M., Tabuce, R., Benammi, M., 2017. Anomaluroid rodents from the earliest Oligocene of Dakhla, Morocco, reveal the long-lived and morphologically conservative pattern of the Anomaluridae and Nonanomaluridae during the Tertiary in Africa. Journal of Systematic Palaeontology, 15, 539-569. https://doi.org/10.108 0/14772019.2016.1206977

Marivaux, L., Tabuce, R., Lebrun, R., Ravel, A., Adaci, M., Mahboubi, M., Bensalah, M., 2011a. Talar morphology of azibiids, strepsirhine-related primates from the Eocene of Algeria: phylogenetic affinities and locomotor adaptation. Journal of Human Evolution, 61, 447-457. https://doi.org/10.1016/j. ihevol.2011.05.013

Marivaux, L., Adaci, M., Bensalah, M., Gomes Rodrigues, H., Hautier, L., Mahboubi, M., Mebrouk, F., Tabuce, R., VianeyLiaud, M., 2011b. Zegdoumyidae (Rodentia, Mammalia), stem anomaluroid rodents from the Early to Middle Eocene of Algeria (Gour Lazib, Western Sahara): new dental evidence. Journal of Systematic Palaeontology, 9, 563-588. https://doi. org $/ 10.1080 / 14772019.2011 .562555$

Marivaux, L., Essid, E. M., Marzougui, W., Khayati Ammar, H., Adnet, S., Marandat, B., Merzeraud, G., Tabuce, R., Vianey-Liaud, M., 2014a. A new and primitive species of Protophiomys (Rodentia, Hystricognathi) from the late middle Eocene of Djebel el Kébar, Central Tunisia. Palaeovertebrata, 38, 1-17. https://doi.org/10.18563/pv.38.1.e2

Marivaux, L., Ramdarshan, A., Essid, E. M., Marzougui, W., Khayati Ammar, H., Lebrun, R., Marandat, B., Merzeraud, G., Tabuce, R., Vianey-Liaud, M., 2013. Djebelemur, a tiny pre-toothcombed primate from the Eocene of Tunisia: a glimpse into the origin of crown strepsirhines. PLoS ONE, 8, 1-21. https:// doi.org/10.1371/journal.pone.0080778

Marivaux, L.,Essid, E. M., Marzougui, W., Khayati Ammar, H., Adnet, S., Marandat, B., Merzeraud, G., Ramdarshan, A., Tabuce, R., Vianey-Liaud, M., Yans, Y., 2014b. A morphological intermediate between eosimiiform and simiiform primates from the late middle Eocene of Tunisia: macroevolutionary and paleobiogeographic implications of early anthropoids. American Journal of Physical Anthropology, 154, 387-401. https://doi.org/10.1002/ajpa.22523

McCartney, J. A., Seiffert, E. R., 2016. A late Eocene snake fauna from the Fayum Depression, Egypt. Journal of Vertebrate Paleontology, 36, e1029580. https://doi.org/10.1080/027246 $\underline{34.2015 .1029580}$

McCartney, J. A., Stevens, N. J., O'Connor, P. M., 2014. The earliest colubroid-dominated snake fauna from Africa: Perspectives from the Late Oligocene Nsungwe Formation of Southwestern Tanzania. PLoS ONE, 9, e90415. https://doi.org/10.1371/ journal.pone.0090415

Mead, J. I., 2013. Scolecophidia (Serpentes) of the Late Oligocene and Early Miocene, North America, and a fossil history overview. Geobios, 46, 225-231. https://doi.org/10.1016/j. geobios.2012.10.016

Mebrouk, F., 2011. Les charophytes du Maghreb, systématique, biostratigraphie et environnements Crétacés-Paléogènes. Unpublished $\mathrm{PhD}$ thesis, Université d'Oran, $173 \mathrm{pp}$.

Mebrouk, F., Feist, M., 1999. Nouvelles charophytes de l'Eocène 
continental de l'Algérie. Géologie Méditerranéenne, 26, 2945. https://doi.org/10.3406/geolm.1999.1644

Mebrouk, F., Mahboubi, M., Bessedik, M., Feist, M., 1997. L'apport des charophytes à la stratigraphie des formations continentales paléogènes de l'Algérie. Geobios, 30, 171-177. https://doi. org/10.1016/S0016-6995(97)80221-5

Mourer-Chauviré, C., Tabuce, R., Mahboubi, M., Adaci, M., Bensalah, M., 2011. A phororhacoid bird from the Eocene of Africa. Naturewissenschaften, 98, 815-823. https://doi.org/10.1007/ s00114-011-0829-5

Muzzopappa, P., Báez, A. M., 2009. Systematic status of the midTertiary neobatrachian frog Calyptocephalella canqueli from Patagonia (Argentina), with comments on the evolution of the genus. Ameghiniana, 46, 113-125.

Nydam, R. L., Cifelli, R. L., 2002. Lizards from the Lower Cretaceous (Aptian-Albian) Antlers and Cloverly Formations. Journal of Vertebrate Paleontology, 22, 286-298. https://doi. org/10.1671/0272-4634(2002)022[0286:LFTLCA]2.0.CO;2

Nydam, R. L., Voci, G. E., 2007. Teiid-like sincomorphan lizards from the late Cretaceous (Campanian) of Southern Utah. Journal of Herpetology, 41, 211-219. https://doi.org/10.1670/00221511(2007)41[211:TSLFTL]2.0.CO;2

Nydam, R. L., Fitzpatrick, B. M., 2009. The occurrence of Contogenys-like lizards in the Late Cretaceous and Early Tertiary of the Western Interior of the U.S.A. Journal of Vertebrate Paleontology, 29, 677-701. https://doi. org/10.1671/039.029.0331

Nydam, R. L., Caldwell, M. W., Palci, A., 2014. Reassessement of cranial elements assigned to the fossil snake Coniophis precedens, late Cretaceous, North America. In: Maxwell, E. and Miller-Camp, J. (Eds). 74th Meeting of Society of Vertebrate Paleontology, Abstract Book. Estrel, Berlin, p. 196.

Palci, A., Caldwell, M. W., Albino, A. M., 2013. Emended diagnosis and phylogenetic relationships of the Upper Cretaceous fossil snake Najash rionegrina Apesteguía and Zaher, 2006. Journal of Vertebrate Paleontology, 33, 131-140. https://doi.org/10.10 $\underline{80 / 02724634.2012 .713415}$

Parmley, D., Holman, J. A., 2003. Nebraskophis Holman from the Late Eocene of Georgia (USA), the oldest known North American colubrid snake. Acta Zoologica Cracoviensia, 46, 1-8.

Pickford, M., Senut, B., Morales, J., Mein, P., Sanchez, I. M., 2008. Mammalia from the Lutetian of Namibia. In: Pickford, M. and Senut, B. (Eds). Geology and Palaeobiology of the Northern Sperrgebeit. Namibia. Memoir of the Geological Survey of Namibia, 20, 465-514.

Pickford, M., Senut, B., Mocke, H., Mourer-Chauviré, C., Rage, J.-C., Mein, P., 2014. Eocene aridity in southwestern Africa: timing of onset and biological consequences. Transactions of the Royal Society of South Africa, 69, 139-144. https://doi.org/10 $.1080 / 0035919$ X.2014.933452

Pregill, G. K., Gauthier, J. A., Greene, H. W., 1986. The evolution of helodermatid squamates, with description of a new taxon and an overview of Varanoidea. Transactions of the San Diego Society of Natural History, 21, 167-202.

Pyron, R. A., Burbrink, F. T., Wiens, J. J., 2013. A phylogeny and revised classification of Squamata, including 4161 species of lizards and snakes. BMC Evolutionary Biology, 13, 93. https://doi.org/10.1186/1471-2148-13-93

Rage, J.-C., 1983. Palaeophis colossaeus nov. sp. (le plus grand serpent connu?) de l'Eocène du Mali et le problème du genre chez les Palaeopheidae. Comptes Rendus de l'Académie des Sciences de Paris, 296 II, 1741-1744.

Rage, J.-C., 1984. Serpentes. In: Wellnhofer, P. (Ed). Handbuch der Paläoherpetologie, 11. G. Fischer, Stuttgart, 1-80.

Rage, J.-C., 1987. Fossil History. In: Seigel, R. A., Collins, J. T. and Novak, S. S. (Eds). Snakes: Ecology and Evolutionary Biology. McMillan, New York, 51-76.

Rage, J.-C., 1998. Fossil snakes from the Palaeocene of São José de Itaboraí, Brazil. Part I. Madtsoiidae, Aniliidae. Palaeovertebrata, 27, 109-144.

Rage, J.-C., 1999. Squamates (Reptilia) from the Upper Cretaceous of Laño (Basque Country, Spain). Estudios del Museo de Ciencias Naturales de Alava, 14 (núm. esp. 1), 121-133.

Rage, J.-C., 2006. The lower vertebrates from the Eocene and Oligocene of the Phosphorites du Quercy (France): An overview. Strata, 13, 161-173.

Rage, J.-C., 2008. Fossil snakes from the Palaeocene of São José de Itaboraí, Brazil. Part III. Ungaliophiinae, booids incertae sedis, and Caenophidia. Summary, update, and discussion of the snake fauna from the locality. Palaeovertebrata, 36, 37-73. https://doi.org/10.18563/pv.36.1-4.37-73

Rage, J.-C., 2013. Mesozoic and Cenozoic squamates of Europe. In: Gardner, J. D. and Nydam, R. L. (Eds). Mesozoic and Cenozoic lissamphibian and squamate assemblages of Laurasia. Palaeobiodiversity and Palaeoenvironments, 93, 517-534. https://doi.org/10.1007/s12549-013-0124-x

Rage, J.-C., Vergnaud-Grazzini, C., 1995. Ostéologie des Amphibiens. In : Grassé, P. P. (Ed). Traité de Zoologie, XIV(I-A). Masson, Paris, 99-168.

Rage, J.-C., Werner, C., 1999. Mid-Cretaceous (Cenomanian) snakes from Wadi Abu Hashim, Sudan: the earliest snake assemblage. Palaeontologia Africana, 35, 85-110.

Rage, J.-C., Hossini, S., 2000. Les Amphibiens du Miocène moyen de Sansan. Mémoires du Muséum national d'Histoire natutrelle, 183, 177-217.

Rage, J.-C., Roček, Z., 2007. A new species of Thaumastosaurus (Amphibia: Anura) from the Eocene of Europe. Journal of Vertebrate Paleontology, 27, 329-336. https://doi. org/10.1671/0272-4634(2007)27[329:ANSOTA]2.0.CO;2

Rage, J.-C., Dutheil, D. B., 2008. Amphibians and squamates from the Cretaceous (Cenomanian) of Morocco. A preliminary study, with description of a new genus of pipid frog. Palaeontographica A, 285, 1-22. https://doi.org/10.1127/ pala/285/2008/1

Rage, J.-C., Augé, M., 2010. Squamate reptiles from the middle Eocene of Lissieu (France). A landmark in the middle Eocene of Europe. Geobios, 43, 243-268. https://doi.org/10.1016/j. geobios.2009.08.002

Rage, J.-C., Pickford, M., 2011. Discovery of a Gymnophionan skull (?Caeciliidae, Amphibia) in the Early Miocene of Uganda. Geo-Pal Uganda, 4, 1-9.

Rage, J.-C., Marshall, L. G., Gayet, M., 1993. Enigmatic Caudata (Amphibia) from the Upper Cretaceous of Gondwana. Geobios, 26, 515-519. https://doi.org/10.1016/S00166995(06)80234-2

Rage, J.-C., Prasad, G. V. R., Bajpai, S., 2004. Additional snakes from the uppermost Cretaceous (Maastrichtian) of India. Cretaceous Research, 25, 425-434. https://doi.org/10.1016/j. cretres.2004.02.003

Rage, J.-C., Pickford, M., Senut, B., 2013. Amphibians and squamates from the middle Eocene of Namibia, with comments on preMiocene anurans from Africa. Annales de Paléontologie, 99, 217-242. https://doi.org/10.1016/j.annpal.2013.04.001

Rage, J.-C., Bajpai, S., Thewissen, J. G. M., Tiwari, B. N., 2003. Early Eocene snakes from Kutch, Western India, with a review of the Palaeophiidae. Geodiversitas, 25, 695-716.

Rage, J.-C., Folie, A., Rana, R. S., Singh, H., Rose, K. D., Smith T., 2008. A diverse snake fauna from the early Eocene of Vastan Lignite Mine, Gujarat, India. Acta Palaeontologica Polonica, 53, 391-403. https://doi.org/10.4202/app.2008.0303

Rage, J.-C., Buffetaut, E., Buffetaut-Tong, H., Chaimanee, Y., Ducrocq, S., Jaeger, J.-J., Suteethorn, V., 1992. A colubrid snake in the late Eocene of Thailand: The oldest known Colubridae (Reptilia, Serpentes). Comptes Rendus des séances de l'Académie des Sciences, 314 II, 1085-1089.

Ravel, A., Adaci, M., Bensalah, M., Mahboubi, M., Mebrouk, F., Essid, M., Marzougui, W., Khayati Ammar, H., Charruault, A. L., Lebrun, R., Tabuce, R., Vianey-Liaud, M., Marivaux, L., 2015. New philisids (Mammalia, Chiroptera) from the Early-Middle Eocene of Algeria and Tunisia: new insight into the phylogeny, palaeobiogeography and palaeoecology of the Philisidae. Journal of Systematic Palaeontology, 13, 691-709. 
https://doi.org/10.1080/14772019.2014.941422

Ravel, A., Adaci, M., Bensalah, M., Charruault, A.-L., Essid, E. M., Khayati Ammar, H., Marzougui, W., Mahboubi, M., Mebrouk, F., Merzeraud, G., Vianey-Liaud, M., Tabuce, R., Marivaux, L., 2016. Origine et radiation initiale des chauves-souris modernes : nouvelles découvertes dans l'Éocène d'Afrique du Nord. Geodiversitas, 38, 355-434. https://doi.org/10.5252/ g2016n3a3

Reeder, T. W., Townsend, T. M., Mulcahy, D. G., Noonan, B. P., Wood, P. L. Jr, Sites, J. W. Jr, Wiens, J. J., 2015. Integrated analyses resolve conflicts over squamate reptile phylogeny and reveal unexpected placements for fossil taxa. PLoS ONE, 10, e0118199. https://doi.org/10.1371/journal.pone.0118199

Roček, Z., 1980. A contribution to the systematics of European ranid frogs (Amphibia, Ranidae) on the basis of the incrassatio frontoparietalis. Věstník Československé Společnosti Zoologické, 44, 219-229.

Roček, Z., 1981. Cranial anatomy of frogs of the family Pelobatidae Stannius, 1856, with outlines of their phylogeny and systematics. Acta Universitatis Carolinae-Biologica, 1-2, $1-164$.

Roček, Z., 1994. Taxonomy and distribution of Tertiary discoglossids (Anura) of the genus Latonia v. Meyer, 1843. Geobios, 27 , 717-751. https://doi.org/10.1016/S0016-6995(94)80058-8

Roček, Z., 2005. Late Miocene Amphibia from Rudabánya. Palaeontographica Italica, 90, 11-29.

Roček, Z., Lamaud, P., 1995. Thaumastosaurus bottii de Stefano, 1903, an anuran with Gondwanan affinities from the Eocene of Europe. Journal of Vertebrate Paleontology, 15, 506-515. https://doi.org/10.1080/02724634.1995.10011244

Roček, Z., Rage, J.-C., 2000. Tertiary Anura of Europe, Africa, Asia, and North America. In: Heatwole, H. and Carroll, R. L. (Eds). Amphibian Biology, 4, Palaeontology. Surrey Beatty and sons, Chipping Norton, 1332-1387.

Roček, Z., Boistel, R., Lenoir, N., Mazurier, A., Pierce, S. E., Rage, J.-C., Smirnov, S. V., Schwermann, A. H., Valentin, X., Venczel, M., Wuttke, M., Zikmund, T., 2015. Frontoparietal bone in extinct Palaeobatrachidae (Anura): its variation and taxonomic value. The Anatomical Record, 298, 1848-1863. https://doi.org/10.1002/ar.23203

Sá, R. O. de, Trueb, L., 1991. Osteology, skeletal development, and chondrocranial structure of Hamptophryne boliviana (Anura: Microhylidae). Journal of Morphology, 209, 311-330. https:// doi.org/10.1002/jmor.1052090307

Sallam, H. M., Seiffert, E. R., 2016. New phiomorph rodents from the latest Eocene of Egypt, and the impact of Bayesian 'clock'-based phylogenetic methods on estimates of basal hystricognath relationships and biochronology. PeerJ, 4, e1717. https://doi.org/10.7717/peerj.1717

Sanchiz, B., 1998. Salientia. In: Wellnhofer, P. (Ed). Encyclopedia of Paleoherpetology, 4. Friedrich Pfeil, Munich, 1-275.

Savage, J. M., 1973. The geographic distribution of frogs: patterns and predictions. In: Vial, J. L. (Ed). Evolutionary biology of the anurans. University of Missouri Press, Columbia, 351-445.

Seibert, E. A., Lillywhite, H. B., Wassersug, R. J., 1974. Cranial coossification in frogs: relationships to evaporative water loss. Physiological Zoology, 47, 261-265. https://doi.org/10.1086/ physzool.47.4.30152529

Seiffert, E. R., 2010. Chronology of Paleogene mammal localities. In: Werdelin, L. and Sanders, W. J. (Eds). Cenozoic Mammals of Africa. University of California Press, Berkeley, 19-26. https://doi.org/10.1525/california/9780520257214.003.0002

Simões, T. R., Caldwell, M. W., Palci, A., Nydam, R. L., 2017. Giant taxon-character matrices: Quality of character constructions remains critical regardless of size. Cladistics, 33, 198-219. https://doi.org/10.1111/cla.12163

Simões, T. R., Wilner, E., Caldwell, M. W., Weinschutz, L. C., Kellner, A. W. A., 2015. A stem acrodontan lizard in the Cretaceous of Brazil revises early lizard evolution in Gondwana. Nature Communication, 6, 9149. https://doi.org/10.1038/ ncomms 9149
Skutschas, P. P., 2006. Mesozoic amphibians from Siberia, Russia. In: Barrett, P. M. and Evans, S. E. (Eds). Ninth International Symposium on Mesozoic Terrestrial Ecosystems and Biota. Natural History Museum Publications, London, 123-126.

Skutschas, P. P., 2013. Mesozoic salamanders and albanerpetontids of Middle Asia, Kazakhstan, and Siberia. In: Gardner, J. D. and Nydam, R. L. (Eds). Mesozoic and Cenozoic lissamphibian and squamate assemblages of Laurasia. Palaeobiodiversity and Palaeoenvironments, 93, 441-457. https://doi.org/10.1007/ s12549-013-0126-8

Skutschas, P. P., 2016. A new crown-group salamander from the Middle Jurassic of Western Siberia, Russia. Palaeobiodiversity and Palaeoenvironments, 96, 41-48. https://doi.org/10.1007/ s12549-015-0216-X

Skutschas, P. P., Krasnolutskii, S. A., 2011. A new genus and species of basal salamanders from the Middle Jurassic of western Siberia, Russia. Proceedings of the Zoological Institute of the Russian Academy of Sciences, 315, 167-175.

Smith, K. T., 2009. Eocene lizards of the clade Geiseltaliellus from Messel and Geiseltal, Germany, and the early radiation of Iguanidae (Reptilia: Squamata). Bulletin of the Peabody Museum of Natural History, 50, 219-306. https://doi. org/10.3374/014.050.0201

Smith, K. T., 2011. The Evolution of mid-latitude faunas during the Eocene: Late Eocene lizards of the Medicine Pole Hills reconsidered. Bulletin of the Peabody Museum of Natural History, 52, 3-105. https://doi.org/10.3374/014.052.0101

Smith, K. T., 2013. New constraints on the evolution of the snake clades Ungaliophiinae, Loxocemidae and Colubridae (Serpentes), with comments on the fossil history of erycine boids in North America. Zoologischer Anzeiger, 252, 157182. https://doi.org/10.1016/j.jcz.2012.05.006

Smith, K. T., Bhullar, B.-A. S., Holroyd, P. A., 2008. Earliest African record of the Varanus stem-clade (Squamata: Varanidae) from the early Oligocene of Egypt. Journal of Vertebrate Paleontology, 28, 909-913. https://doi.org/10.1671/02724634(2008)28[909:EAROTV]2.0.CO;2

Solé, F., Lhuillier, J., Adaci, M., Bensalah, M., Mahboubi, M., Tabuce, R., 2014. The hyaenodontidans from the Gour Lazib area (?Early Eocene, Algeria): implications concerning the systematics and the origin of the Hyainailourinae and Teratodontinae. Journal of Systematic Palaeontology, 12, 303322. https://doi.org/10.1080/14772019.2013.795196

Stefano, G. de, 1903. I Sauri del Quercy appartenenti alla collezione Rossignol. Atti della Societa Italiana di Scienze Naturali, 42, 382-418.

Sullivan, R. M., Lucas, S. G., 1986. Annotated list of lower Vertebrates from the Paleocene Nacimiento Formation (Puercan-Torrejonian), San Juan Basin, New Mexico. Journal of Herpetology, 20, 202-209. https://doi.org/10.2307/1563945

Sullivan, R. M., Lucas, S. G., 2015. Cretaceous Vertebrates of New Mexico. In: Lucas, S. G. and Sullivan, R. M. (Eds). Fossil Vertebrates in New Mexico. New Mexico Museum of Natural History and Science Bulletin, 68, 105-129.

Szyndlar, Z., 1994. Oligocene snakes of Southern Germany. Journal of Vertebrate Paleontology, 14, 24-37. https://doi.org/10.1080 /02724634.1994.10011536

Szyndlar, Z., Rage, J.-C., 2003. Non-erycine Booidea from the Oligocene and Miocene of Europe. Institute of Systematics and Evolution of Animals, Polish Academy of Sciences, Cracow, $109 \mathrm{pp}$.

Szyndlar, Z., Smith, R., Rage, J.-C., 2008. A new dwarf boa (Serpentes, Booidea, 'Tropidophiidae') from the Early Oligocene of Belgium: a case of the isolation of Western European snake faunas. Zoological Journal of the Linnean Society, 152, 393406. https://doi.org/10.1111/j.1096-3642.2007.00357.x

Tabuce, R., Marivaux, L., Adaci, M., Bensalah, M., Hartenberger, J.L., Mahboubi, M., Mebrouk, F., Tafforeau, P., Jaeger, J.-J., 2007. Early Tertiary mammals from North Africa reinforce the molecular Afrotheria clade. Proceeding of the Royal Society B, 274, 1159-1166. https://doi.org/10.1098/rspb.2006.0229 
Tabuce, R., Marivaux, L., Lebrun, R., Adaci, M., Bensalah, M., Fabre, P.-H., Fara, E., Gomes Rodriguez, H., Hautier, L., Jaeger, J.-J., Lazzari, V., Mebrouk, F., PeignÉ, S., Sudre, J., Tafforeau, P., Valentin, X., Mahboubi, M., 2009. Anthropoid versus strepsirhine status of the African Eocene primates Algeripithecus and Azibius: craniodental evidence. Proceeding of the Royal Society B, 276, 4087-4094. https:// doi.org/10.1098/rspb.2009.1339

Tałanda, M., 2016. Cretaceous roots of the amphisbaenian lizards. Zoologica Scripta, 45, 1-8. https://doi.org/10.1111/zsc.12138

Thomas, H., Roger, J., Sen, S., Dejax, J., Schuler, M., Al-Sulaimani, Z., Bourdillon de Grissac, C., Breton, G., Broin, F. de, Camoin, G., Cappetta, H., Carriol, R. P., Cavelier, C., Chaix, C., Crochet, J.-Y., Farjanel, G., Gayet, M., Gheerbrant, E., Lauriat-Rage, A., Noël, D., Pickford, M., Poignant, A.-F., Rage, J.-C., Roman, J., Rouchy, J.-M., Secrétan, S., Sigé, B., Tassy, P., Wenz, S., 1991. Essai de reconstitution des milieux de sédimentation et de vie des primates anthropoïdes de l'Oligocène de Taqah (Dhofar, Sultanat d'Oman). Bulletin de la Société Géologique de France, 162, 713-724. https://doi. org/10.2113/gssgfbull.162.4.713

Tihen, J. A., 1962. A review of New World fossil Bufonids. American Midland Naturalist, 68, 1-50. https://doi.org/10.2307/2422634

Trueb, L., 1993. Patterns of cranial diversity among the Lissamphia. In: Hanken, J. and Hall, B. K. (Eds). The skull, 2. Patterns of structural and systematic diversity. University of Chicago Press, Chicago, 255-343.

Underwood, G., 1967. A contribution to the classification of snakes. Publication 653, British Museum (N.H.), London, 179 pp.

Van Dijk, D. E., 2001. Osteology of the ranoid burrowing African anurans Breviceps and Hemisus. African Zoology, 36, 137141. https://doi.org/10.1080/15627020.2001.11657131

Venczel, M., 2004. Middle Miocene anurans from the Carpathian Basin. Palaeontographica A, 271, 151-174.

Venczel, M., Codrea, V., Fărcaş, C., 2013. A new palaeobatrachid frog from the early Oligocene of Suceag, Romania. Journal of Systematic Palaeontology, 11, 179-189. https://doi.org/10.108 $0 / 14772019.2012 .671790$

Vidal, N., Hedges, S. B., 2004. Molecular evidence for a terrestrial origin of snakes. Proceedings of the Royal Society B: Biological Sciences, 271 (suppl.), S226-S229. https://doi. org/10.1098/rsbl.2003.0151
Vidal, N., Hedges, S. B., 2009. The molecular evolutionary tree of lizards, snakes, and amphisbaenians. Comptes Rendus Biologies, 332, 129-139. https://doi.org/10.1016/j. crvi.2008.07.010

Villa, A., Roček, Z., Tschopp, E., Hoek Ostende, L. W. van den, Delfino, M., 2016. Palaeobatrachus eurydices, sp. nov. (Amphibia, Anura), the last western European palaeobatrachid. Journal of Vertebrate Paleontology, 36, e1211664. https://doi.org/10.108 $0 / 02724634.2016 .1211664$

Wild, E. R., 1997. Description of the adult skeleton and developmental osteology of the hyperossified horned frog, Ceratophrys cornuta (Anura: Leptodactylidae). Journal of Morphology, 232, 169-206. https://doi.org/10.1002/(SICI)10974687(199705)232:2<169::AID-JMOR4>3.0.CO;2-5

Worthy, T. H., 1987. Osteology of Leiopelma (Amphibia: Leiopelmatidae) and descriptions of three new subfossil Leiopelma species. Journal of the Royal Society of New Zealand, 17, 201-251. https://doi.org/10.1080/03036758.198 7.10418160

Wuttke, M., Přikryl, T., Ratnikov, V. Yu., Dvořák, Z., Roček, Z., 2012. Generic diversity and distributional dynamics of the Palaeobatrachidae (Amphibia: Anura). Palaeobiodiversity and Palaeoenvironments, 92, 367-395. https://doi.org/10.1007/ s12549-012-0071-y

Zaher, H., Gobbi Grazziotin, F., Cadle, J. E., Murphy, R. W., MouraLeite, J. C. de, Bonatto, S. L., 2009. Molecular phylogeny of advanced snakes (Serpentes, Caenophidia) with an emphasis on South American Xenodontines: a revised classification and descriptions of new taxa. Papéis Avulsos de Zoologia, 49, 115-153. https://doi.org/10.1590/S0031-10492009001100001

Zheng, Y., Wiens J. J., 2016. Combining phylogenomic and supermatrix approaches, and a time-calibrated phylogeny for squamate reptiles (lizards and snakes) based on 52 genes and 4162 species. Molecular Phylogenetics and Evolution, 94, 537-547. https://doi.org/10.1016/j.ympev.2015.10.009

\section{A note from the Editor:}

The senior author of this paper, Jean-Claude Rage (1943-2018), passed away before its publication. He was a leading authority on Mesozoic and Cenozoic amphibians and squamates and was influential in demonstrating to the palaeontological community as a whole how important these sometimes forgotten groups were for a proper understanding of past ecosystems, in particular from a palaeobiogeographical point of view. This paper about the herpetofauna from the Glib Zegdou locality of Algeria, in which he describes the most important assemblage hitherto recorded from the Paleogene of Africa, not only exemplifies his outstanding knowledge of these groups. It will also stand as a posthumous memorial to a researcher who was unanimously respected and appreciated by his colleagues and friends. 